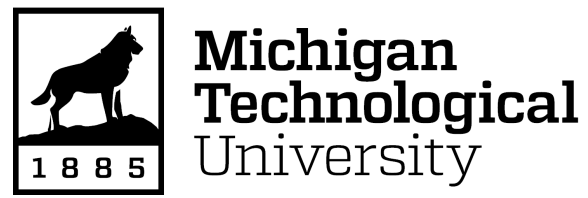

Michigan Technological University Digital Commons @ Michigan Tech

Dissertations, Master's Theses and Master's Reports

2021

\title{
An Overview of Converting Kabul's Traffic Circles and Rotaries to Modern Roundabouts
}

Mohammad Anas Taeb

Michigan Technological University, mtaeb@mtu.edu

Copyright 2021 Mohammad Anas Taeb

\section{Recommended Citation}

Taeb, Mohammad Anas, "An Overview of Converting Kabul's Traffic Circles and Rotaries to Modern Roundabouts", Open Access Master's Report, Michigan Technological University, 2021.

https://doi.org/10.37099/mtu.dc.etdr/1239

Follow this and additional works at: https://digitalcommons.mtu.edu/etdr

Part of the Transportation Engineering Commons 


\title{
AN OVERVIEW OF CONVERTING KABUL'S TRAFFIC CIRCLES AND ROTARIES TO MODERN ROUNDABOUTS
}

\author{
By \\ Mohammad Anas Taeb

\begin{abstract}
A REPORT
Submitted in partial fulfillment of the requirements for the degree of

MASTER OF SCIENCE

in Civil Engineering
\end{abstract}

MICHIGAN TECHNOLOGICAL UNIVERSITY

2021

(C) 2021 Mohammad Anas Taeb 
This report has been approved in partial fulfillment of the requirements for the Degree of MASTER OF SCIENCE in Civil Engineering.

Department of Civil, Environmental, and Geospatial Engineering Report Advisor: Dr. Pasi Lautala

Committee Member: Dr. William J. Sproule

Committee Member: Dr. Timothy Colling

Department Chair: $\quad$ Dr. Audra N. Morse 


\section{Table of Contents}

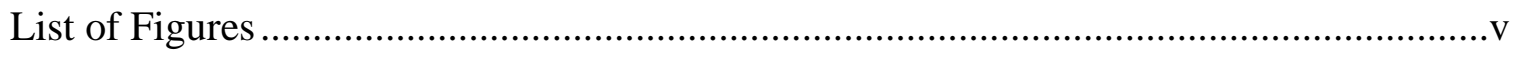

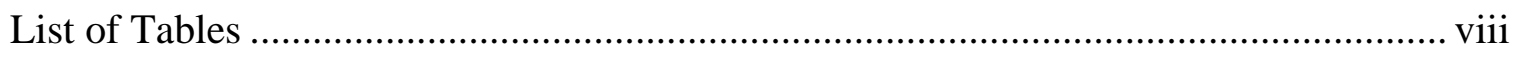

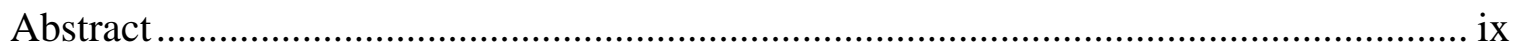

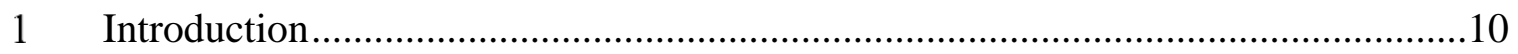

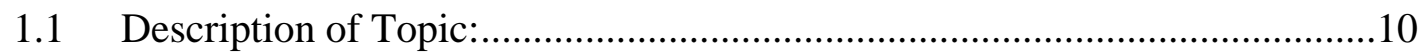

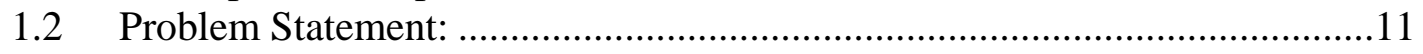

1.3 Research Objective:.............................................................................11

2 Literature Review.....................................................................................13

2.1 History of Circular Intersections .............................................................13

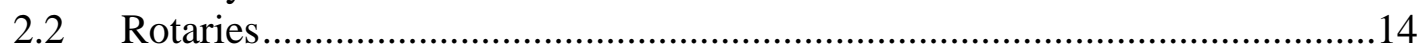

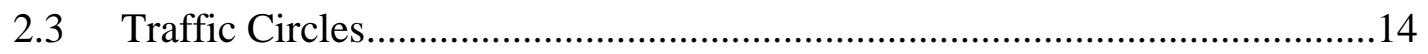

2.4 Modern Roundabouts ................................................................................ 15

2.5 Difference between Modern Roundabouts and other Circular Intersections

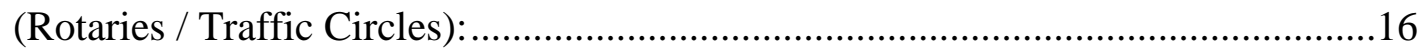

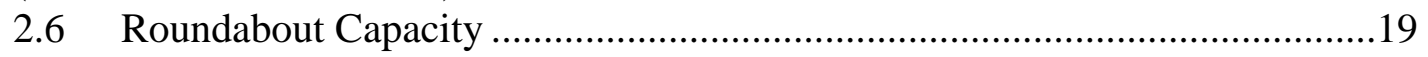

2.6.1 Capacity Analysis Methods .............................................................19

2.6.1.1 Analytical or Gap-Acceptance Method: ..........................20

2.6.1.2 Empirical Method ..........................................................21

2.7 Modern Roundabout Analysis with Microsimulation Tools ..........................23

2.8 Modern Roundabout versus Signalized Intersection Capacity........................23

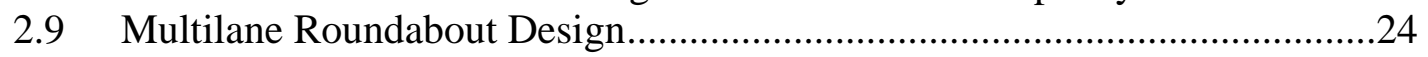

2.9.1 Design Features.............................................................................25

2.9.2 Performance Checks: ....................................................................22

2.10 Upgrading traffic circles to modern roundabouts to improve safety and efficiency - Case studies from Italy ......................................................................2

2.11 Other Traffic Circle Conversion Examples.................................................29

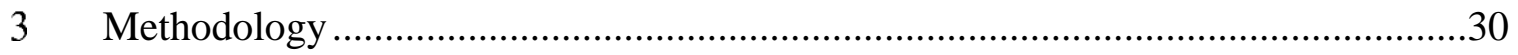

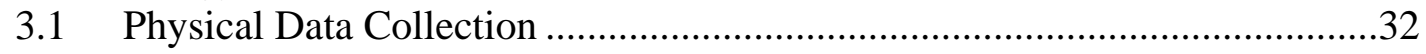

3.1.1 Google Earth Pro................................................................................ 32

3.1.2 ArcGIS Map \& World Imagery Wayback ..........................................32

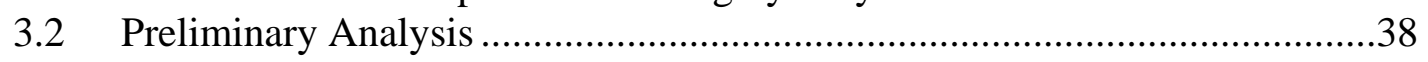

3.2.1 Road Network Score ...................................................................

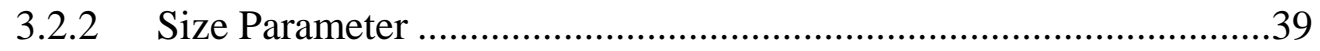

3.2.3 Shape Parameter: ...................................................................... 40

3.2.4 Total Suitability Score ………………………...............................4

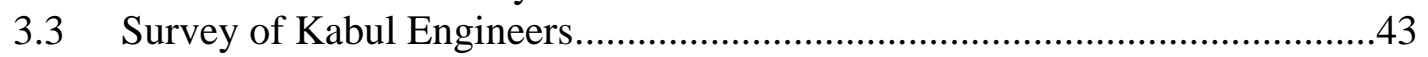




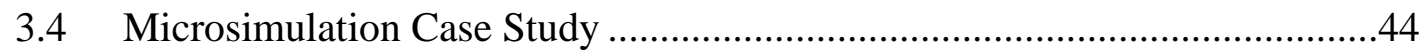

3.4.1 Geometric Design of the Modern roundabout....................................45

3.4.2 Modelling in VISSIM .................................................................

3.4.3 Entry Flow Rate, Relative Turning Movement, and Lane

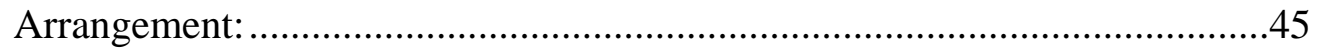

3.4.4 Priority Rule \& Minimum Gap: ........................................................45

3.4.5 Reduced Speed..............................................................................45

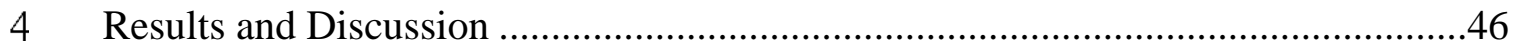

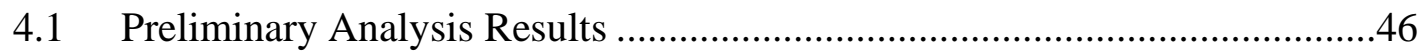

4.2 Kabul Engineers Survey Findings ...............................................................49

4.2.1 Rules for Current Traffic Circles/Rotaries........................................49

4.2.2 Driver's Behavior at Current Traffic Circles/Rotaries.......................50

4.2.3 View on Modern Roundabout Application.........................................51

4.2.4 Latest Changes to Kabul Traffic Circles/Rotaries ...............................53

4.3 Follow-up Interview …………….............................................................56

4.4 Summary of Survey/Follow-Up Interview Findings .......................................57

4.5 Abdul Haq Square Case Study …………………………………………....57

4.5.1 Design and Modelling Abdul Haq Modern Roundabout....................58

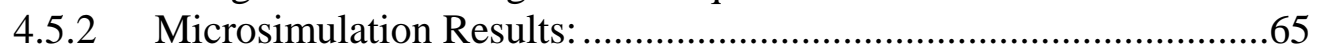

4.5.2.1 Vehicle Throughput ........................................................65

4.5.2.2 Average Queue Delay Results.........................................69

4.5.2.3 Average Queue Length Results. ......................................71

4.5.2.4 Maximum Queue Length: ................................................75

5 Conclusions and Recommendation for Future Work.................................................78

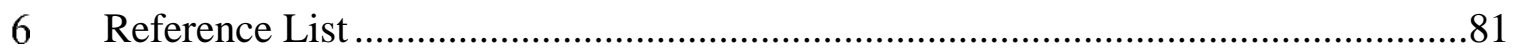

Appendix A: Survey Questions: ................................................................................ 82

Appendix B: Concept Roundabout Design Radiuses ......................................................90

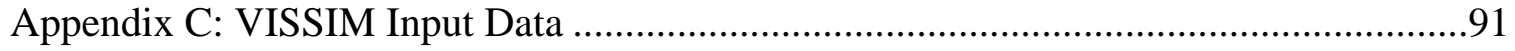




\section{List of Figures}

Figure 2.1: A typical rotary intersection [6] ..........................................................14

Figure 2.2: A typical traffic circle intersection [6] ...................................................15

Figure 2.3: Intersection/Roundabout Vehicle Conflict Point Comparison for Single-Lane Approaches [1] ........................................................................................16

Figure 2.4: (a) On the left, Medan Arghande Rotary in Kabul, Afghanistan, ( $b$ On the right, Abdul Haq Traffic Circle in Kabul, Afghanistan.........................................18

Figure 2.5: (a) on the left, Critical Gap. (b) on the right, Follow-up Gap [9] ...................21

Figure 2.6: U.K. Model Geometric Parameters [8] .....................................................22

Figure 2.7: Approach Alignment Offset Conditions [1] ...............................................25

Figure 2.8: Path Overlap Problem at Roundabout Entry [1] ...........................................26

Figure 2.9: Fastest path through multilane roundabout.[1]............................................27

Figure 2.10: (a) On the right, initial design of traffic circle (Design A). (b) On the left, proposed modern roundabout with bypass lanes (Design D).[4].........................28

Figure 2.11: On the left (a), initial large traffic circle in Luca. On the right (b), modern roundabout after improvement in Luca. [4] ....................................................29

Figure 3.1: Study Methodology Flowchart.................................................................

Figure 3.2: 33 Kabul rotaries/traffic circles (Image by Google Earth Pro, Image Captured:

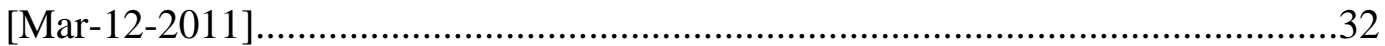

Figure 3.3: Most Recent Image Identifying Current State of Kabul Traffic Circles/Rotaries, By: ES RI, World Imagery Wayback. Captured on [Oct-12-

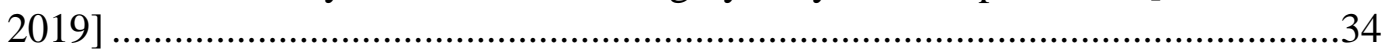

Figure 3.4: Distance of nearby intersection from Abdul-Haq Traffic Circle. ....................39

Figure 3.5: Distance of nearby intersection from Education University Traffic Circle. ...39

Figure 3.6: Inscribed circle size of Abdul Haq traffic circle. ..............................................40

Figure 3.7: Gul Surkh Traffic Circle, with shape score of (1) ..........................................42

Figure 3.8: Dahmazang Traffic Circle, with shape score of (2) ......................................42

Figure 3.9: Minar Nejat Traffic Circle, with shape score of (2) .......................................42

Figure 3.10: Abdul Haq Traffic Circle, with shape score (4)............................................43

Figure 4.1: Survey result for presence of aggressive drivers in traffic circles/rotaries. ....50 
Figure 4.2: Survey results for whether Kabul drivers will abide by the rules in modern roundabout.

Figure 4.3: Kabul drivers' responses on whether modern roundabout can be a good fit. .52 Figure 4.4: Average rating of Hurdles in Modern Roundabout Application in Kabul $(1=$

Least important, $4=$ Very important). .52

Figure 4.5: Average rating of Benefits of Modern Roundabouts in Kabul ( $1=$ Least important, $4=$ Very important $)$. .53

Figure 4.6: Number of Kabul Engineers' Views on Traffic Circle/Signalized Intersection Conversions.

Figure 4.7: Kabul Engineers' Thoughts on Recent Improvements of Traffic

Circle/Rotaries to Signalized Intersections. .54

Figure 4.8: Kabul Engineers' Opinions on Converting the Traffic Circles to Modern Roundabouts .56

Figure 4.9: Abdul-Haq Traffic Circle .58

Figure 4.10: Concept Modern Roundabout at Abdul-Haq Traffic Circle.........................60

Figure 4.11: Modelled roundabout within existing traffic circle footprint ......................63

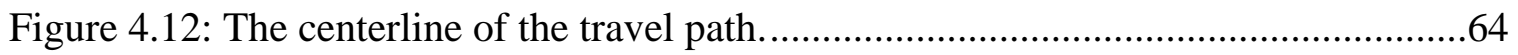

Figure 4.13: Average Throughput Result for Scenario (1) ..........................................65

Figure 4.14: Average Throughput Result for Scenario (2) .........................................66

Figure 4.15: Average Throughput Result for Scenario (3) .........................................66

Figure 4.16: Average Throughput Result for Scenario (4) ............................................67

Figure 4.17: Average Throughput Result for Scenario (5) .........................................67

Figure 4.18: Average Queue Delay for Scenario (1) ...................................................69

Figure 4.19: Average Queue Delay for Scenario (2) ....................................................69

Figure 4.20: Average Queue Delay for Scenario (3) .................................................... 70

Figure 4.21: Average Queue Delay for Scenario (4) .................................................. 70

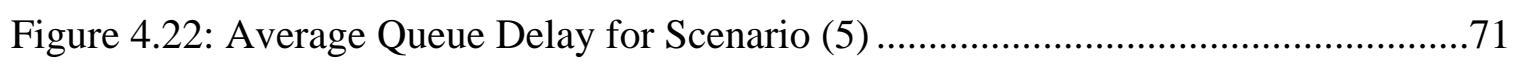

Figure 4.23: Average Queue Length for Scenario (1) .................................................72

Figure 4.24: Average Queue Length for Scenario (2) ............................................... 72

Figure 4.25: Average Queue Length for Scenario (3) ................................................73

Figure 4.26: Average Queue Length for Scenario (4) ..................................................73

Figure 4.27: Average Queue Length for Scenario (5) ............................................. 74

Figure 4.28: Maximum Queue Length for Scenario (1) ..............................................75 
Figure 4.29: Maximum Queue Length for Scenario (2) ............................................75

Figure 4.30: Maximum Queue Length for Scenario (3) ..............................................76

Figure 4.31: Maximum Queue Length for Scenario (4) ...............................................

Figure 4.32: Maximum Queue Length for Scenario (5) .........................................76

Fig. B. 1. Concept modern roundabout radiuses....................................................90

Fig. B. 2. Reference to radiuses in a Modern Roundabout. ..........................................90

Fig. C. 1. Abdul-Haq Modern Roundabout Model in VISSIM .....................................91

Fig. C. 2. Straight Portions of Approaches as Links/Lanes .........................................91

Fig. C. 3. Turning Portions of Approaches in Roundabout as Links/Lanes .....................92

Fig. C. 4. Reduced Speed Area at Roundabout Entry ...............................................92

Fig. C. 5. Priority Rules at Roundabout Entry.........................................................93

Fig. C. 6. Vehicle Routing Decisions (Turning Movements with Relative Flow) ............93

Fig. C. 7. Vehicle Travel Time Measurements..............................................................94

Fig. C. 8. Data Collection Points. ..........................................................................94

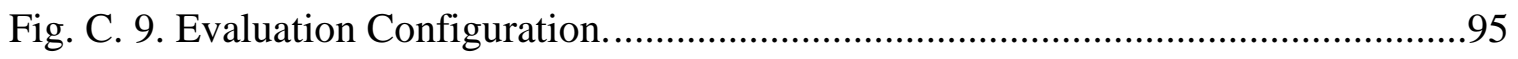

Fig. C. 10. Simulation Parameters …....................................................................... 96 


\section{List of Tables}

Table 2.1: Rotary vs Traffic Circle vs Modern Roundabout. [6]....................................17

Table 2.2: Summary of analytical and empirical Methods...........................................20

Table 3.1: List of Kabul Traffic Circles \& Rotaries .........................................................35

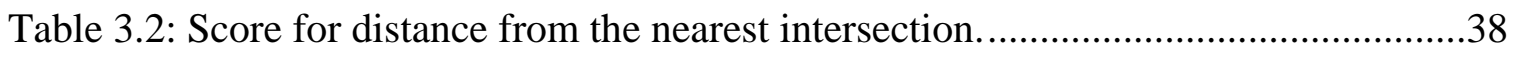

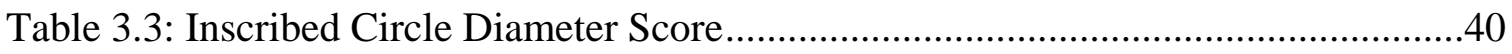

Table 3.4: Traffic Circles/Rotaries categories based on shapes ...................................41

Table 4.1: Traffic Circles/Rotaries Total Score for Conversion Appropriateness.............47

Table 4.2: Survey result for "Priority rule" in traffic circle/rotaries in Kabul..................49

Table 4.3: Survey result for ranked causes of congestion in Traffic circles and Rotaries.50

Table 4.4: Average Ranking for Improvement Options. .............................................55

Table 4.5: Design criteria and values for Abdul Haq simulation ..................................59

Table 4.6: Scenarios for Simulations Based on Entry Flow Rate, Relative Turning Movement 


\section{Abstract}

Circular intersections, in the form of traffic circles and rotaries, were built around the world in the first half of the twentieth century. However, with the rise in traffic flow, regular traffic congestion and accidents forced authorities to look for alternative solutions and, in many cases, signalized intersections became the preferred alternative. In the 1960s, the UK introduced concept of modern roundabouts and a new set of priority rules for the circulating traffic. Since the inception of modern roundabouts, they have enhanced both operational and safety aspects at these locations, even when used to replace large traffic circles/rotaries, proving that circular intersections can still exist in urban transportation networks.

Kabul City, the capital of Afghanistan, had more than 30 traffic circles and rotaries where regular congestion is present. Ten of them are recently changed to signalized intersection while the rest remains as either traffic circle or rotary. This report focused on investigating if the option of modern roundabout is a suitable, or even preferred alternative to some of the existing traffic circles and rotaries in Kabul City.

The research started with collecting geometric data for existing traffic circles/rotaries, followed by a preliminary analysis where they were scored for modern roundabout conversion suitability, based on initial geometric data of size, location, and shape. An online survey and one follow-up interview were conducted with Kabul engineers to characterize existing traffic circles/rotaries and their views on potential conversions to modern roundabouts. Finally, one of the current traffic circles was selected for a more detailed operational analysis via microsimulation, using the tool called PTV VISSIM.

Supported by literature, it seems that large traffic circles/rotaries can become a more desired location for modern roundabout conversion and as result as scored higher in terms of suitability in preliminary analysis. In the meantime, the survey conducted with Kabul's engineer showed either traffic is regulated by a traffic officer or no priority rules are applied in existing traffic circles. It also showed that aggressive driver's behavior is often noticed due to the lack of strict rules and planning from the authorities. Moreover, the survey showed the skepticism amongst responders in regard to the recent improvements with signalized intersection at traffic circles. Regarding the modern roundabout Kabul engineers were open to the option based on a more detailed data analysis. The Sensitivity analysis with microsimulation tool VISSIM showed that the additional bypass lane further enhances the operation. The results also showed that after certain flow rate thresholds there is dramatic increase in delays and queues. Moreover, when traffic includes higher portion of left turns a modern roundabout becomes more a desirable option.

The findings from geometric data, survey, and sensitivity analysis have provided evidence that modern roundabouts should be considered as a potential alternative in Kabul City. However, prior to any implementation, significant data gaps should be closed, so a more detailed analysis can be concluded on their suitability. 


\section{Introduction}

\subsection{Description of Topic:}

A roundabout is a form of circular intersection in which traffic travels counterclockwise (in right-hand traffic countries) around a central island and the entering traffic must yield to circulating traffic. The modern roundabout was initially developed in the United Kingdom in 1966. Since then the popularity has grown throughout the world to rectify the safety aspect of intersections. Roundabouts have significantly reduced severe crashes in the US and around the globe, and since their invention, many countries have adopted modern roundabouts to improve both operations and safety of intersections [1].

Research has also shown that when roundabouts are operating within their capacity, they operate with lower vehicle delays compared to other intersection types. When there is no conflicting flow or there is an adequate gap available for entering vehicles to merge into the roundabout, vehicles do not need to stop at the entry line, unlike in other intersections or control types where a full stop due to the signs and signals is mandatory. During offpeak hours, modern roundabouts perform at low average delays when compared to signalized or stop signed intersections. Unlike most traffic circles, modern roundabouts give priority to circulating flow and requiring entering flow to yield. This allows reduction in conflicting flow, which causes congestion or underperformance [1].Since the second half of the previous century, most countries have been looking to develop new modern roundabouts, and some are converting their traffic circles and rotaries, which existed in the form of large circular intersections.

Kabul City is the capital of Afghanistan with a population of over four millions cars. In the current transportation system, Kabul has right-hand traffic and possesses 150 major intersections where congestion is present every business day and crashes occur frequently. Out of these 150 intersections, 18 are signalized, 33 are traffic circles/rotaries, and the rest are uncontrolled intersections. Due to the ongoing war conflict, the idea of converting traffic circles' and rotaries' geometry, where appropriate, has not come to fruition and most Kabul intersections are directed by a traffic officer instead of traffic signals or signs [2].

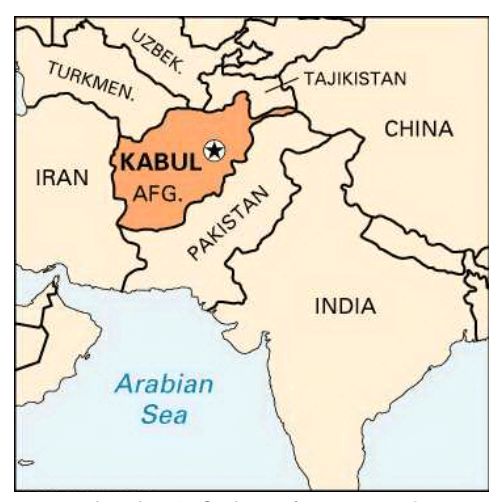

Kabul, Afghanistan. [3] 


\subsection{Problem Statement:}

The older traffic circles and rotary intersections are widely regarded as some of the main locations for bottlenecks in Kabul. Excessive delay and long queue lengths are regularly noticed during peak hours. This has put a burden on transportation authorities to find an alternative solution to Kabul's traffic circles and rotaries.

Recently, Kabul municipality proposed to remove the central island of 33 traffic circles and change them to traditional signalized intersections installed with "Actuated Traffic Signals." According to a source working in the municipality: "The decision made by the municipality is purely based on engineering judgement, and no actual data has been collected or analyzed prior to determining the best solution to ongoing congestion problems. It was assumed that these circular intersections are efficient only in low traffic volume and are required a conversion to signalized intersections when there is high traffic flow. The central islands of 10 traffic circles have recently been removed in the process of converting them to signalized intersection".

Other countries have considered modern roundabouts as the safer option for signalized intersections, improving not only the road safety but the overall traffic efficiency in terms of delays and queues. Case studies in Italy have shown that older, large traffic circles can be upgraded to modern roundabouts by the addition of greater entry deflection, yield signs, and yield lines in a cost-effective way [4]. The question of whether a modern roundabout can be a viable solution in the case of Kabul City needs to start with understanding how the current traffic circles or rotaries operate and in which situations roundabout is a suitable solution. It requires investigation of main causes for traffic congestion at intersections and the thresholds for traffic flow that a modern roundabout can handle in Kabul City at the desired level of service. In addition, we also need to understand if modern roundabout can bring potential benefits or challenges to traffic operations.

\subsection{Research Objective:}

This report focuses on using literature and case studies to discuss the suitability of modern roundabout application in Kabul. The current traffic circles and rotaries were first characterized by listing them according to their basic geometries. Furthermore, I wanted to understand how traffic operates and the reasons behind the congestion in these intersections. I was also interested in knowing certain factors that can be threats or opportunities while converting existing traffic circles to modern roundabouts. Finally, I looked into when a modern roundabout can suit as an option to alleviate traffic issues by figuring out the threshold of its capacity under different traffic conditions.

I quickly recognized that in the case of Kabul City, a complete analysis cannot be done to justify upgrading old traffic circles/rotaries to modern roundabouts due to lack of 
accurate traffic data. However, by studying the geometrics, the operational behavior, and by creating scenarios with a microsimulation tool to analogies with input data, I could develop engineered judgements on the potential suitability of modern roundabouts that then can be used as a foundation for further analysis, once the necessary data is available.

The study tasks included the following:

- To synthesize literature on modern roundabouts, including background, operational analysis, perceived benefits, and main criteria considered when determining their application.

- To physically characterize current traffic circles and rotaries in Kabul, including any data available on shapes and sizes using aerial images. Data collected such as inscribed circle sizes, number of lanes leading to traffic circles/rotaries, and central island sizes will help us in determining the suitability of modern roundabout with its available space and intersection shape. Based on these data and literature review, I evaluated each traffic circle/rotary for their geometric suitability to conversion.

- To conduct a survey with Kabul engineers to further understand the current operations at traffic circles in Kabul and to obtain their perception on the main challenges and on the possibility of using roundabouts as a solution.

- To interview one of the responding engineers with follow up questions in detail.

- To create a microsimulation case study converting one traffic circle in Kabul City into a roundabout and investigate its performance through sensitivity analysis. The microsimulation tool PTV VISSIM was used for the analysis. 


\section{Literature Review}

Circular intersections in the form of traffic circles and rotaries have existed since the start of the 20th century. This chapter will start with explaining a brief history of circular intersections and how they evolved into modern roundabouts, followed by describing key differences between rotaries, traffic circles, and modern roundabouts. It will outline the modern roundabout's operational capacity and known methods for analyzing capacities. In addition, it will discuss some basic design features of a modern roundabout. Lastly, the chapter will review some case studies where older traffic circles have been converted to modern roundabouts and consider how they have enhanced operational performance.

\subsection{History of Circular Intersections}

In 1903, the United States' first rotary system was proposed for Columbus Circle in New York City by William Phelps Eno. Prior to 1903, circular places did exist; however, they were primarily built as architectural features permitting two-way circulation around a central island. The Columbus circle in November 1904 was the first with a one-way circulation rule.

In 1906, Eugene Henard, the Architect for the City of Paris, proposed a gyratory traffic scheme (one-way circulation around a central island) for some major intersections in Paris. In 1907, the Place de l'Etoile became the first French gyratory, followed by several others built in 1910. Because of low traffic volume, the right of way rule didn't exist until 1913, when Wisconsin adopted the yield-to-right rule, meaning the entering vehicle had the right of way.

In 1929, Eno pointed out that yield-to-right has the drawback of locking up the traffic at higher volumes and recommended the yield-to-left rule. However, the traffic engineering community was not convinced of Enos's point, and instead focused on constructing larger traffic circles with the ability to weave traffic at higher speeds and larger distances. The right of way was still kept from yield-to-right to avoid rear-end collisions at the entrance.

With developing automobile technology, traffic volumes increased, and as a result, more traffic circle congestion was observed. In the 1950s, traffic circles fell out of favor in the United States largely because of the congestion problem. In many cases, they were either replaced with signalized intersections, or signals were added to traffic circles.

Between 1950 and 1977, in the United States, laws were passed that gave priority to circulating traffic. In the meantime, in France, the large sizes of traffic circles, together with the desire to maintain relatively high speeds and giving priority to the entering traffic became major impediments to safety and high capacity [5]. 


\subsection{Rotaries}

Rotaries are old circular intersections characterized by a large diameter often greater than $100 \mathrm{~m}(300 \mathrm{ft})$. The section between two legs is used for weaving traffic and changing lanes (Figure 2.1). For some movements, lane changing should happen inside the rotary. Weaving should happen at a higher speed, and in most cases, the circulating traffic must yield to entering traffic. The high-speed characteristic has allowed rotaries to exist with large diameters. These old circular intersection works well at low traffic flow, but at higher traffic flow, they perform poorly [1].

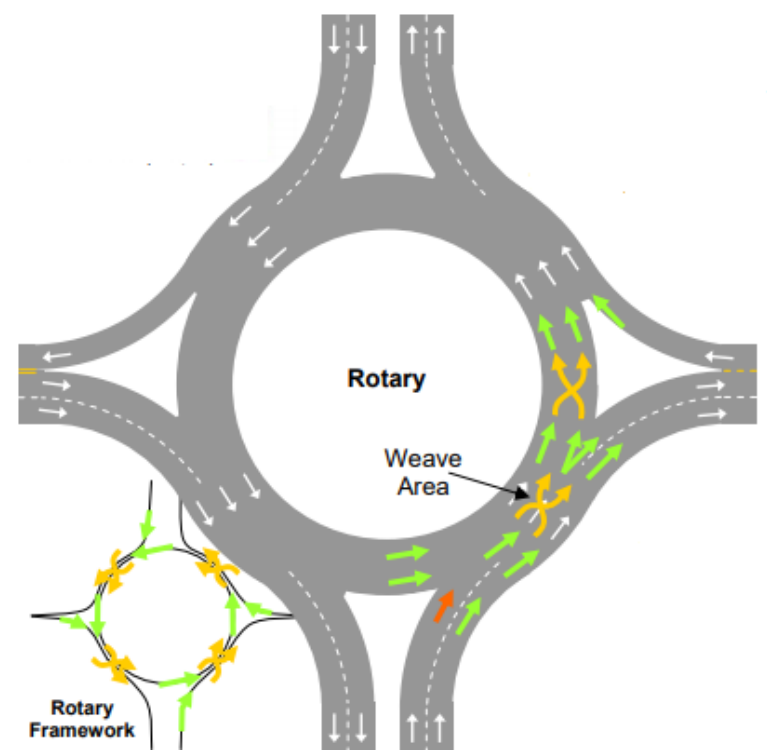

Figure 2.1: A typical rotary intersection [6].

\subsection{Traffic Circles}

Another type of older circular intersections, traffic circles, are controlled by signals or stop signs on one or more entries with a large central island (Figure 2.2). These intersections also operate at higher speeds for traffic weaving inside the circulatory roadway. They may also have pedestrian signals.

There are also neighborhood traffic circles, typically small in size and built at the intersection of local streets for traffic calming and/or aesthetic purposes. Unlike larger traffic circles, they do not normally have raised channelization for vehicle guidance [1]. 


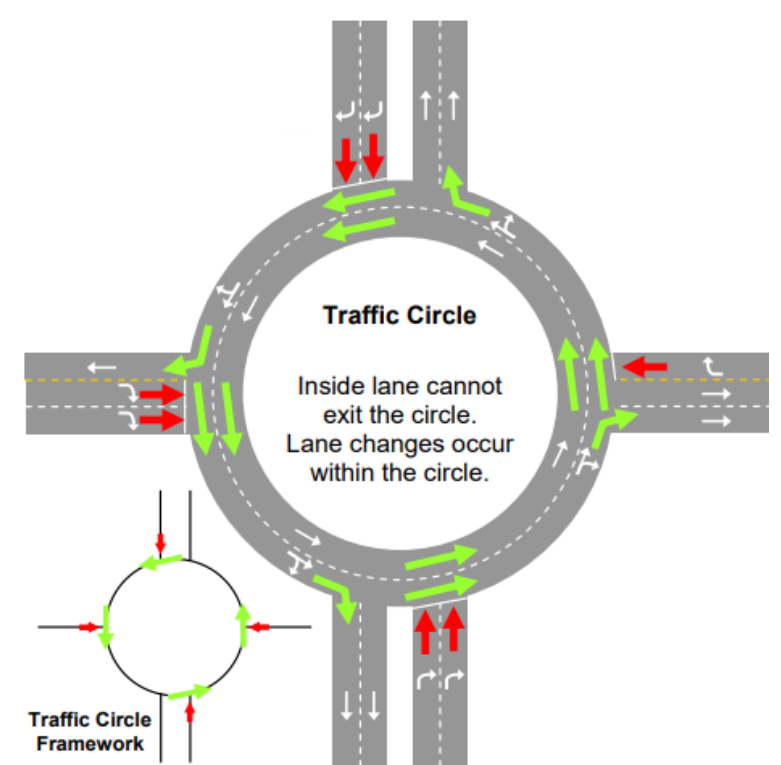

Figure 2.2: A typical traffic circle intersection [6].

\subsection{Modern Roundabouts}

Modern roundabout is a form of circular intersection in which traffic travels counterclockwise (in right-hand traffic countries) around a central island and the entering traffic must yield to circulating traffic.

One of the main reasons for countries in Europe, North America, and the Australian continent for upgrading their traditional signalized intersections or traffic circles to modern roundabouts is their safety aspect. The FHWA Office of Safety identified roundabouts as a "Proven Safety Countermeasure" because of their ability to substantially reduce the types of crashes that result in injury or loss of life. Roundabouts are designed to improve safety for all users, including pedestrians and bicyclists. Most significantly, roundabouts reduce the types of crashes where people are seriously hurt or killed by $78-82 \%$ when compared to conventional stop-controlled and signalized intersections [1].

Main factors improving the safety performance include reducing the number of conflict points and the speeds of vehicles moving through the intersection. For instance, comparison of a four-legged single lane intersection with an equivalent roundabout shows that there are 32 conflict points in a conventional intersection, while the modern roundabout has 8 total conflict points (Fig 2.3). More significantly, the crashes in roundabouts happen for the vehicles travel in the same direction, thus making them less severe or fatal. 


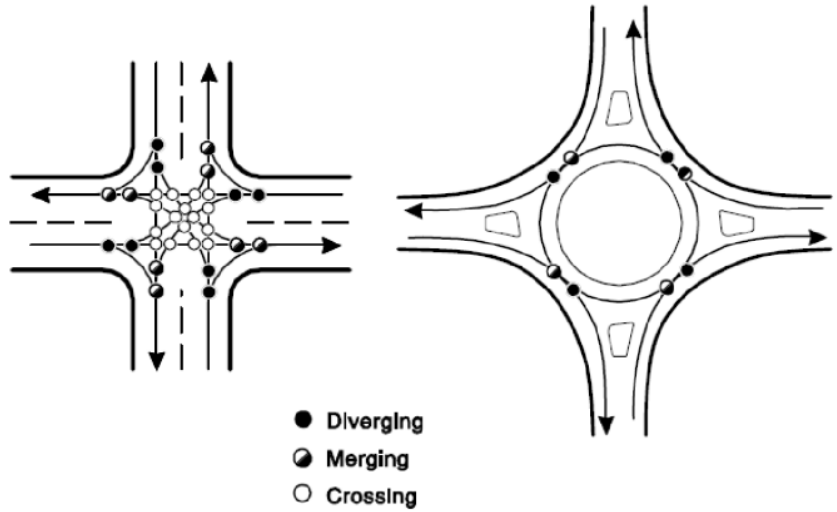

Figure 2.3: Intersection/Roundabout Vehicle Conflict Point Comparison for Single-Lane Approaches [1].

Research has also shown that when roundabouts are operating within their capacity, they operate with lower vehicle delays compared to other intersection types. When there is no conflicting flow, or there is an adequate gap available for entering vehicles to merge into the roundabout, the vehicles do not need to stop at the entry line, unlike with other intersection control types where a full stop due to the signs and signals is mandatory. During off-peak hours, modern roundabouts perform at low average delays when compared to signalized or stop signed intersections. Unlike most traffic circles, modern roundabouts give priority to circulating flow and require entering flow to yield. This allows reduction in conflicting flow, which causes congestion or underperformance.

\subsection{Difference between Modern Roundabouts and other Circular Intersections (Rotaries / Traffic Circles):}

Table 2.1 outlines the key differences between rotaries, traffic circles, and modern roundabouts. 
Table 2.1: Rotary vs Traffic Circle vs Modern Roundabout. [6]

\begin{tabular}{|c|c|c|c|}
\hline & Rotary & Traffic Circle & Modern Roundabout \\
\hline $\begin{array}{l}\text { Entering } \\
\text { Traffic }\end{array}$ & $\begin{array}{l}\text { Can enter alongside circulating } \\
\text { traffic } \\
\text { Can be controlled by stop sign, } \\
\text { signal, or no sign (uncontrolled). }\end{array}$ & $\begin{array}{l}\text { Can have priority right over circulating } \\
\text { traffic. } \\
\text { Can be controlled by stop sign, signals } \\
\text { or no sign. }\end{array}$ & $\begin{array}{l}\text { Must always yield to circulating } \\
\text { traffic. }\end{array}$ \\
\hline Size & $\begin{array}{l}\text { Typical diameter greater than } \\
100 \mathrm{~m}(300 \mathrm{ft})\end{array}$ & $\begin{array}{l}\text { Ranges from small neighborhood } \\
\text { "traffic calming" to larger traffic } \\
\text { circles (May be larger than a typical } \\
\text { modern roundabout or even smaller } \\
\text { than modern roundabout in form of } \\
\text { neighborhood traffic circle). }\end{array}$ & $\begin{array}{l}\text { Minimum inscribed circle of } 46 \mathrm{~m} \\
(150 \mathrm{feet}) \text {, and not greater than } 90 \\
\mathrm{~m}(300 \mathrm{ft}) \text { for Multilane } \\
\text { Roundabout. }\end{array}$ \\
\hline Speed & $\begin{array}{l}\text { Entering speed } 40 \mathrm{mph} \text { or higher } \\
\text { for weaving into traffic flow }\end{array}$ & $\begin{array}{l}\text { Lower entry speed but higher } \\
\text { circulating speed due to its size }\end{array}$ & $\begin{array}{l}\text { Entering and circulating speed are } \\
\text { roughly equal and rarely over } 25 \\
\text { mph. }\end{array}$ \\
\hline Lane changing & Allowed & Allowed & Not allowed \\
\hline Central Island & $\begin{array}{l}\text { May be used for parking or } \\
\text { businesses or used by } \\
\text { pedestrians. }\end{array}$ & $\begin{array}{l}\text { May be used for parking or businesses } \\
\text { or used by pedestrians. }\end{array}$ & $\begin{array}{l}\text { Mainly for slowing traffic and } \\
\text { aesthetics (not used for parking or } \\
\text { other businesses) }\end{array}$ \\
\hline Parking & $\begin{array}{l}\text { May be allowed on entry or } \\
\text { circulatory road. }\end{array}$ & $\begin{array}{l}\text { May be allowed on entry or circulatory } \\
\text { road. }\end{array}$ & Not allowed. \\
\hline
\end{tabular}


Entering traffic must always yield to circulating traffic in modern roundabouts, while in traffic circles and rotaries, it is possible that circulating traffic yields to entering traffic or traffic is controlled by a stop sign or signals. It is typical to enter a rotary alongside traffic that is circulating in the inside lane.

Modern roundabouts are typically smaller in diameter than traffic circles and rotaries. This makes vehicles travel at lower speeds and under safer conditions. Normal speeds in traffic circles and rotaries may vary from $30 \mathrm{mph}$ to $45 \mathrm{mph}$, while the geometry of a roundabout forces the vehicle to travel at 25-30 $\mathrm{mph}$.

The drivers must choose the appropriate lane based on their destination before entering a modern roundabout, and they must stay in that lane when entering and traversing the roundabout; this minimizes weaving of vehicles. However, large traffic circles and rotaries are designed to allow vehicles to weave or change lanes for some movements inside the circular intersection.

Parking is not allowed in a modern roundabout, whereas traffic circles and rotaries may still have space for parking vehicles. This increases the number of conflicts and decreases the safety and capacity of a circular intersection.

Modern roundabouts allow no pedestrian activity on the central island, while some rotaries and traffic circle may allow pedestrian crossing to and from central islands.

The splitter island (a raised or painted area used for separating entering and exiting traffic, which deflects and slows entering traffic) is a requirement in modern roundabouts. However, at traffic circles and rotaries, it is optional.

Figure 2.4 (a) shows a circular intersection which by definition places it in the category of "Rotary." Figure 2.4 (b) shows a typical traffic circle in Kabul. The difference is seen as rotaries are relatively bigger and include weaving sections as per their size $[1,4]$.
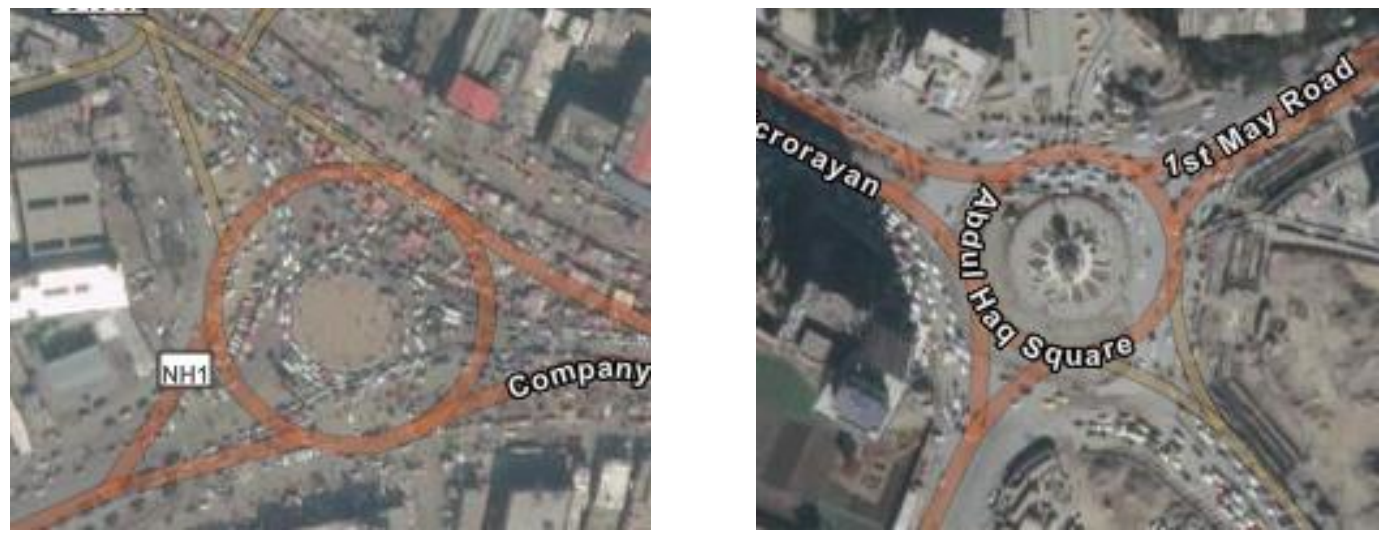

Figure 2.4: (a) On the left, Medan Arghande Rotary in Kabul, Afghanistan, ( $b$ On the right, Abdul Haq Traffic Circle in Kabul, Afghanistan 


\subsection{Roundabout Capacity}

Capacity is defined as maximum sustainable number of vehicles to traverse a location within a given time period under prevailing conditions [7]. A capacity analysis show how efficiently a roundabout is serving the entering flow. There are two vital factors that influence the capacity of entering flow: the circulating flow in front of the entering traffic and the geometry of the roundabout. For a roundabout, capacity is always dynamic, depending on the number and proportion of turning vehicles, traffic composition (heavy vehicles, bicycles, and motorcycles) and weather conditions. These conditions vary from time to time, but for design considerations, traffic flow during peak periods is used to determine the capacity of a roundabout [1]. Analysis tools and methods for modern roundabouts may differ from country to country, but in general, they are divided between "Analytical or Gap Acceptance" model and the "Empirical or Regression" model. The selection of a particular method depends on local preferences and data availability.

\subsubsection{Capacity Analysis Methods}

In general, the "Analytical model" is based on traffic flow theory and results in a formulation of the relationship between field measures (such as a driver's behavior in accepting gaps) and performance measures, such as queue length and delay. The method is considered easier to work with, but it requires a reliable gap-acceptance behavior model, which is complex to develop. Examples of this method include the Swiss Model and the HCM model in the United States (both based on gap-acceptance theory).

The "Empirical model," on the other hand, correlates roundabout capacity to geometric characteristics of a roundabout [8]. Empirical models, such as the one in the UK, require extensive data entries. There is also a hybrid model using a combination of inputs from both driver behaviors (gap-acceptance method) and geometry (empirical method) such as in the French model [9].

Table 2.2 shows some differences between the well-known methods used in the United States and the UK. 
Table 2.2: Summary of analytical and empirical Methods.

\begin{tabular}{|c|c|c|c|c|c|}
\hline Method & Country & Author & Type & Applicability & Input Parameter \\
\hline $\begin{array}{l}\text { Analytical } \\
\text { Method }\end{array}$ & USA & $\mathrm{HCM}[1]$ & $\begin{array}{l}\text { Gap } \\
\text { Accepta } \\
\text { nce }\end{array}$ & $\begin{array}{l}\text { One lane } \\
\text { Two lanes }\end{array}$ & $\begin{array}{l}\text { - Circulating flow } \\
\text { - Critical headway } \\
\text { - Follow-up } \\
\text { headway }\end{array}$ \\
\hline $\begin{array}{l}\text { Empirical } \\
\text { Method }\end{array}$ & UK & Kimber [9] & $\begin{array}{l}\text { Linear } \\
\text { Regress } \\
\text { ion }\end{array}$ & All & $\begin{array}{l}\text { - Circulating flow } \\
\text { - Entry width } \\
\text { - Approach half } \\
\text { width } \\
\text { - Effective flare } \\
\text { length } \\
\text { - Entry angle } \\
\text { - Entry radius } \\
\text { - Diameter }\end{array}$ \\
\hline
\end{tabular}

\subsubsection{Analytical or Gap-Acceptance Method:}

In modern roundabouts, the conflict between entering and circulating traffic raises the concept of "gap acceptance." The theory is based on one traffic stream getting priority over another conflicting traffic stream. The same theory is used in other unsignalized intersections, such as two-way stop-controlled or yield-controlled intersections. The larger the gap between entering vehicles and circulating vehicles, the more entering vehicles can be accommodated. Similarly, when the circulating flow increases and gaps become shorter, it becomes difficult for the entering vehicles to find the critical gap (minimum gap a vehicle can accept) to enter, decreasing the entering flow. The roundabout geometry also has a critical impact on the capacity of a modern roundabout. An entry width accommodating two streams of entering traffic will have twice the entering capacity compared to a single lane entry [9].

The Highway Capacity Manual (HCM) assumes that drivers who wait on the yield line need a minimum gap, also called "critical headway" $\left(\mathrm{t}_{c}\right)$, in the circulating stream to enter the roundabout. As soon as they find a gap in the circulating stream, more than one driver might enter the roundabout, and subsequent drivers enter with headways called the "follow-up headway" ( $\mathrm{t}_{\mathrm{f}}$ ), which are typically less than critical gaps (Fig. 2.5). In situations when the circulating stream travels bumper-to-bumper, it becomes hard for an entry vehicle to find the critical gap, and queues are formed.

When the conflicting flow rate approaches zero, the maximum entry flow is given by $3,600 \mathrm{~s} / \mathrm{hr}$ divided by the follow-up headway ( $\mathrm{t}_{\mathrm{f}}$ ). This is analogous to the saturation flow rate for a movement receiving a green indication at a signalized intersection. 

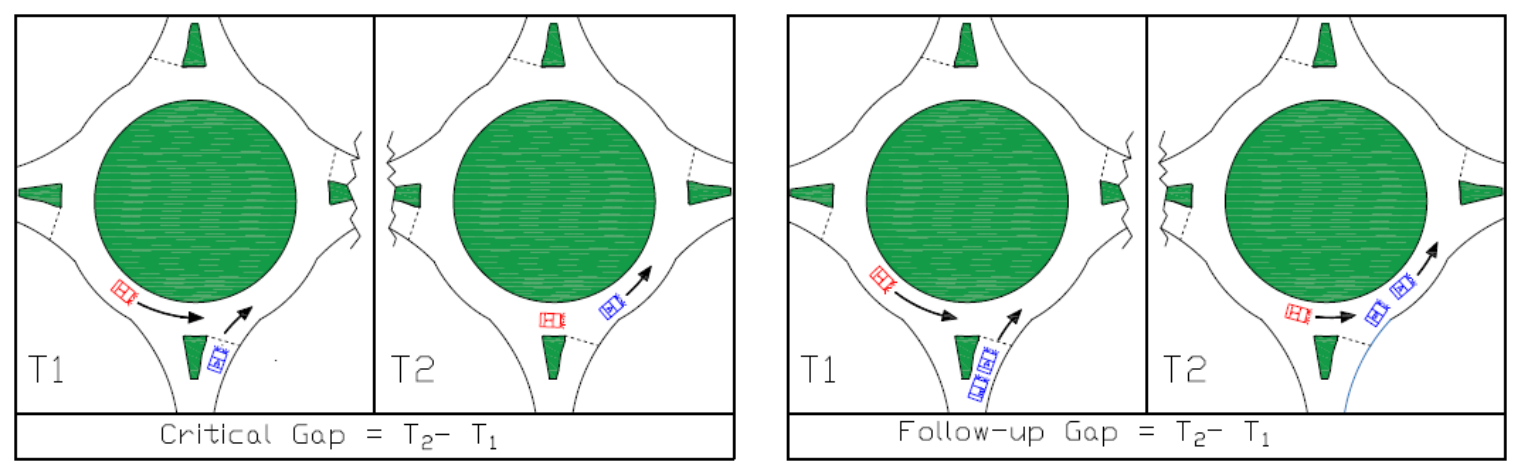

Figure 2.5: (a) on the left, Critical Gap. (b) on the right, Follow-up Gap [9]

HCM 2010 provides equations for estimating the entering flow capacity based on circulating flow. The equations are derived from gap-acceptance data and recommended to get calibrated for local driver behaviors. HCM 2010 is capable of analyzing both single lane and two-lane roundabouts. In addition, the HCM 2010 defines six "Levels of Service" as part of measurement of effectiveness for "Average queue delay". LOS is tabulated from " $\mathrm{A}$ " to "F" where "A" illustrates a free-flow environment and " $\mathrm{F}$ " represent breakdown flow or volume exceeds capacity.[7]

\subsubsection{Empirical Method}

The empirical method uses regression models with inputs from roundabout geometry to estimate or predict roundabout capacity.

The UK's Transportation Research Laboratory (TRL) undertook a substantial research program back in the 1970s to study 86 roundabout entries in the UK. This extensive research was meant to find practical links between geometry, capacity/delay, and accidents in a modern roundabout.

Gap acceptance methods were rejected in the initial stages of the research for being overcomplicated and sensitive to small parameter changes and also for giving a weak link between roundabout geometry and performance. It was also reasoned that factors such as "gap forcing" and "priority reversal" make it further complicated to use an analytical method. "Gap forcing" occurs when entering vehicles fail to wait for a suitable gap and "push" into the circulating stream, forcing a circulating (priority vehicle) to modify its chosen path/speed. Priority reversal is noticed for (short) periods when the priority completely reverses or is taken by the entering traffic at times of high demand. These issues caused the TRL to come up with an empirical method to predict roundabout capacity.

Various geometric parameters were collected along with entry and circulating flow during peak hours. The research used linear regression to determine statistically significant relationships between entry capacity and various geometric parameters. The regression analysis found that there are only six significant geometric parameters that play a role in determining capacity. They were entry width, approach width, flare length 
(the length over which local widening of the approach is developed), entry angle, inscribed circle diameter, and the radius of the curb at entry. Of these six parameters, the first three showed stronger relationship with capacity while all other parameters proved statistically insignificant. The research also discussed that under constant circulating flow, the greater the entry width, the higher entry capacity is expected. It also showed that the greater the flare length, the greater the entry capacity.

The UK model, as discussed above, is a regression model derived from an extensive database and based on the formula or Kimber's equation:

$\mathrm{C}=\mathrm{k}\left(\mathrm{F}-\mathrm{f}_{\mathrm{c}} \times \mathrm{Q}_{\mathrm{c}}\right)$

where $\mathrm{k}, \mathrm{F}$, and $\mathrm{f}_{\mathrm{c}}$ are constants derived from the geometry of the roundabout, and $\mathrm{Q}_{\mathrm{c}}$ is the circulating flow. The geometry variable used to find the constants (Fig 2.6) are:

- The Approach Half-Width

- Average Effective Flare Length (1')

- Sharpness of Flare

- Entry Angle

- Entry Radius

- Vane Island (a pained island that divides lanes entering the roundabout)

The details of the procedure can be found in the Transportation Research Lab journal [8].

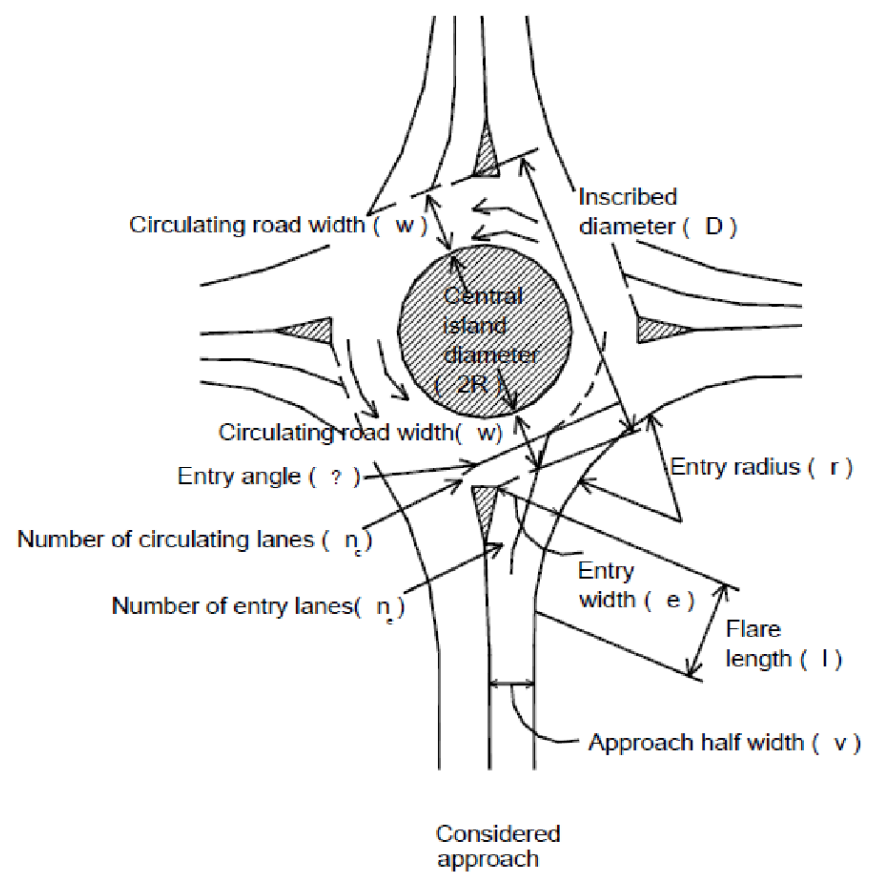

Figure 2.6: U.K. Model Geometric Parameters [8]. 


\title{
2.7 Modern Roundabout Analysis with Microsimulation Tools
}

\begin{abstract}
Along with analytical and empirical operational analysis, microsimulation software such as VISSIM is widely used to analyze the performance of a modern roundabout at specific sites. VISSIM uses car following and lane changing theories and models which enable the extraction of a vehicle's positional information over time, based on a driver's behavior. VISSIM is capable of modelling various type of vehicles and drivers for each distinct location. The outputs include various performance measures, such as queue length, delays, and travel times.
\end{abstract}

VISSIM's "Priority Rule" is used for adding the yielding behavior at a roundabout's entry. The tool allows users to add a minimum gap time in seconds for entering traffic on the yield line to accept. Minimum gap is one of the critical inputs to microsimulation software and has a noticeable effect on the performance of the roundabout. Typically, this value is derived for distinct locations based on the driver's behavior experienced. Timid drivers might take a longer gap than risk-tolerant or aggressive drivers. In other locations, the gap can decrease where drivers are confident and experienced with merging into a roundabout's circulating traffic [8].

Countries and territories define minimum gaps based on their actual traffic data observed on site and subsequently use them for analysis. The minimum gap in the United States ranges from " $4.5 \mathrm{~s}$ to $6.5 \mathrm{~s}$ " [1]. A study in Qatar observed a minimum gap of " $2.55 \mathrm{~s}$ " for a two-lane roundabout [10] and a sensitivity analysis in India, studying roundabouts at five distinct locations, estimated a minimum gap between 1.36 to $2.52 \mathrm{~s}$ [11].

\subsection{Modern Roundabout versus Signalized Intersection Capacity}

Studies have shown that delays are greater in signalized intersections than in roundabouts during low volumes of operation. However, under high volume, traffic signals will perform more efficiently than roundabouts [12]. In medium to high volumes, site specific conditions, such as network analysis and queue storage spacing, need to be considered to judge signalized intersections' performance over roundabouts. Microsimulation tools can fulfill several roles in giving a reliable model of the actual conditions. It can also analyze whether queues and delays built up in one intersection affect the performance of an adjacent intersection. If the results are statistically significant, this gives a clearer picture for choosing one option over another [13].

Research conducted as part of the 1985 HCM showed that the capacity for the critical lanes at a signalized intersection was approximately 1,400 vehicles per hour [14]. For a roundabout, HCM 2010 states that if conflicting flow is zero, the maximum entering flow is estimated as 3,600 vehicles divided by the average follow-up headway. This 
approximately equates to 1,130 vehicles per hour per lane. However, this is more a theoretical value and a threshold to entering capacity [7].

For a four-legged single-lane roundabout, total entry capacity is between 2,400 and 2,600 vehicles per hour (veh/h) and for two-lane roundabout the total entry capacity is more than 4,000 veh/hr [15]. In addition, a study using a microsimulation tool found that when a two-lane roundabout with each of the four approaches has a volume less than or equal to 800 passenger cars per hour, the roundabout can operate in an uncongested condition (LOS of A and B). Similarly, if the same roundabout operates with a volume of more than 1,100 on all approaches, it is more likely the roundabout will perform at LOS of E and $\mathrm{F}$ [16]. However, the exact capacity of a two-lane modern roundabout with bypass lanes is not found in the literature.

\subsection{Multilane Roundabout Design}

Multilane roundabouts have at least one approach lane with at least two lanes on entry or exit. The principle rule to design a multilane roundabout is the continuity between the entering, circulating, and existing traffic. Multilane roundabouts need extra consideration for lane arrangement so drivers are enabled to enter the roundabout without changing lanes inside the circulatory roadway. Furthermore, the roundabout geometry should accommodate for side-by-by vehicles inside the roundabout.

The design procedure of single-lane modern roundabouts and multilane roundabouts are identical. The differences are in their inscribed circle and the number of approaching legs. The geometric design of multilane modern roundabouts is determined with consideration of four major criteria: capacity analysis, safety, cost, and site constraints. Roundabout design is an iterative process where the designer comes up with an initial conceptual design based on the above four criteria, and then the stakeholders and reviewers refine the design for project conditions, as applicable. The purpose of this section of literature review is to get familiar with different concepts used in the design of multilane roundabouts. The processes are discussed in detail in NCHRP 672 Roundabout: An information Guide [1].

Key objectives in the design of a multilane modern roundabout include:

- Speed management: One of the primary characteristics of a modern roundabout is operating at a safer and more consistent speed. The geometry will play an important role in controlling the speed both inside the roundabout and at the entry. Reducing the radius of the travel path will make the fastest path operating at a lower speed. In addition, it is essential to make sure the geometry allows the vehicles to travel at a consistent speed.

- Lane arrangement: In all design iterations, the number of lanes and basic pavement marking layouts, indicating the turning movements, are integral parts of the process which will ensure that lane continuity is being provided. 
- Appropriate Path Alignment: As two traffic streams approach the roundabout in adjacent lanes, vehicles will be guided by lane markings up to the entrance line. At the yield point, vehicles will continue along their natural trajectory into the circulatory roadway. The speed and orientation of the vehicle at the entrance line determines what can be described as its natural path. If the natural path of one lane interferes or overlaps with the natural path of the adjacent lane, the roundabout is not as likely to operate as safely or efficiently as desired.

- Design Vehicle: The multilane roundabout should have the capacity to accommodate a design vehicle which is selected from the traffic data.

- Non-motorized users: Pedestrians and bicyclists make up a large number of nonmotorized users. The roundabout design should facilitate splitter islands and sidewalks for safe operation [1].

\subsubsection{Design Features}

During the design process of a modern roundabout, the above-mentioned objectives are taken into consideration. Some key features and characteristics of multilane modern roundabouts are as follows:

Approach Alignment Offset: There are three alignment choices for attaching entry legs to the circulatory roadway (Fig. 2.7). The offset left alignment is most often preferred. It constrains the entry, slowing a vehicle's approach speed, and opens up the exit for efficient egress. The symmetrical alignment (if needed) is acceptable for lower speed contexts such as $30 \mathrm{mph}$. The offset right alignment tends to allow faster entry speeds and constrains the exit. This is often undesirable [17].

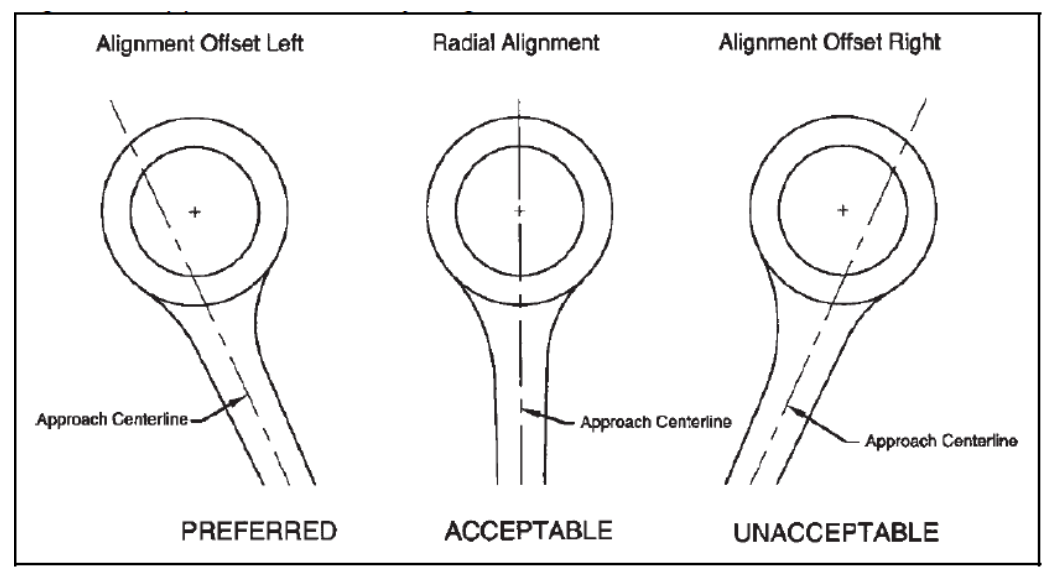

Figure 2.7: Approach Alignment Offset Conditions [1].

Entry Geometry: At multilane roundabouts, the design of the entry curvature should balance the competing objectives of speed control, adequate alignment of the natural paths, and the need for appropriate visibility lines. 
Entry radii should be designed such that they can encourage the natural path and avoid sideswipe collision on entry (Figure 2.8). Keeping them to small radii will control the speed on fastest path alignment. However, overly small radii can lead to vehicle path overlap since vehicles will cut across lanes to avoid running into the central island. This will reduce operational efficiency and increase potential crashes.

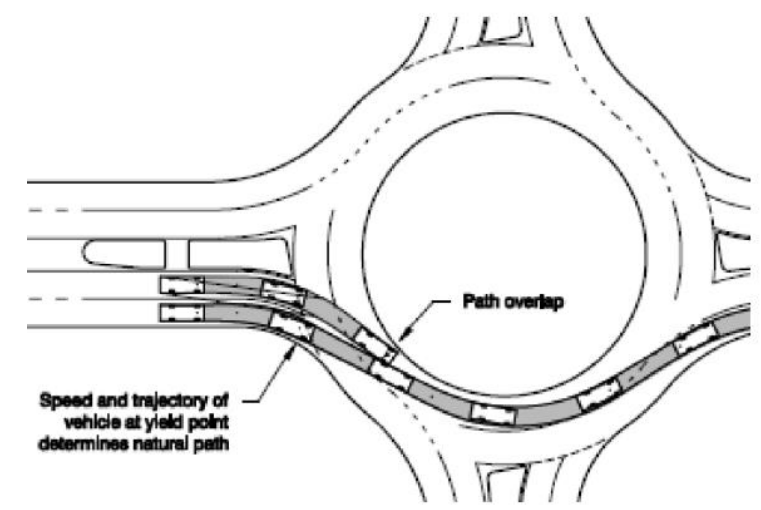

Figure 2.8: Path Overlap Problem at Roundabout Entry [1].

Entry Width: It is dependent on the number of lanes identified in the operational analysis. A width of more than is required will not help the traffic operation.

Circulatory Lane: The width of the circulatory lane is dependent on the type of vehicles that need to be accommodated adjacent to each other. The traffic condition can determine the type of vehicles and the rate at which they will operate in a multilane roundabout. Additionally, the number of circulatory lanes is decided during operational analysis.

Exit Curve: While designing the exit curve, a path overlap between exiting vehicles and circulating vehicles can occur. The design should avoid such conflicts by using larger radii compared to entry geometry. In addition, a large separation between the entry leg and the subsequent exit leg should be avoided as this can also cause conflicts between exiting and circulating traffic.

Central Island: The central island of a roundabout is raised, typically non-traversable area surrounded by the circulatory roadway. It may also include a traversable truck apron. The island is typically landscaped for aesthetic reasons and to enhance driver recognition of the roundabout upon approach. The size of the central island plays a key role in determining the fastest path. In addition, it is also constrained by the size of the inscribed circle and need for adequate circulatory roadway width.

Splitter Island: The entry geometry is developed first to control fastest path alignment. Then the splitter island is designed in conjunction with exit design to provide adequate pedestrian refuge and sign posts. 


\subsubsection{Performance Checks:}

Two important performance checks are required in the design of multilane modern roundabouts.

a) Fastest Path: The fastest path allowed by the geometry determines the negotiation speed for that particular movement entering, moving through, and exiting the roundabout. It is the smoothest, flattest path possible for a single vehicle, in the absence of other traffic and ignoring all lane markings. The fastest path is drawn for a vehicle traversing through the entry, around the central island, and out the relevant exit (Figure 2.9). The fastest paths must be drawn for all approaches and all movements, including left-turn movements (which generally represent the slowest of the fastest paths) and right-turn movements (which may be faster than the through movements at some roundabouts) [1].

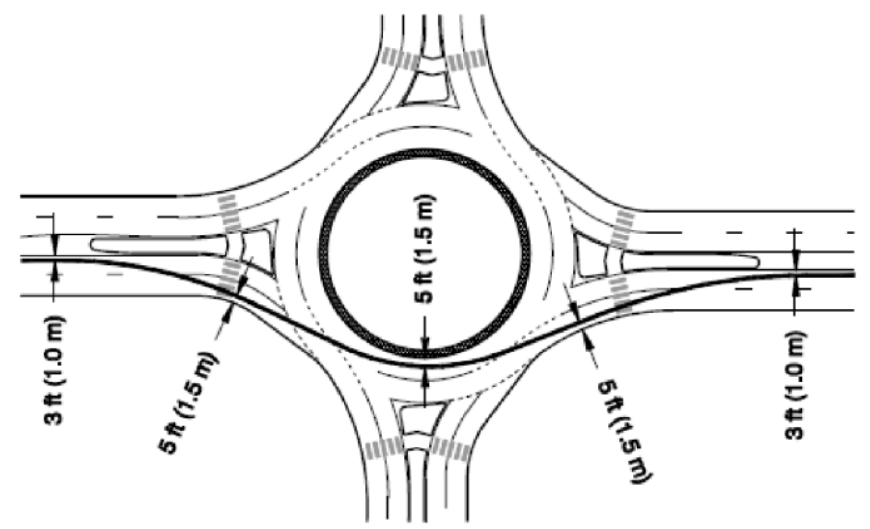

Figure 2.9: Fastest path through multilane roundabout.[1]

\section{b) Natural Path Consideration:}

Besides the fastest path, the designer should check for the natural path. It is the path that the driver will naturally take while negotiating the roundabout. Any sudden changes in curve radius or lack of transitions between curves or reverse curves will put the driver in an uncomfortable position. The situation will also affect the vehicle adjacent to the path in a multilane roundabout. It is necessary that the natural path be sketched and any potential instantaneous vehicle movements be pointed out [1].

\subsection{Upgrading traffic circles to modern roundabouts to improve safety and efficiency - Case studies from Italy}

A case study conducted in Italy investigated three intersections initially developed as ultra large traffic circles and later converted to modern roundabouts. After almost four decades of operation, the traffic circles had an inferior operational performance which motivated their conversion to modern roundabouts. 
After the change in the Italian Highway Code, the Levante traffic circle was functioning with priority to circulating traffic with yield signs at the entry. However, the geometry of the roundabout was still the same. Authorities aimed to define the optimum solution to improve both safety and operation by changing the geometry. In addition to the initial 3lane circulating design (also called Design A), three other designs were developed for comparison. Figure 2.10 (a) shows the initial design of the traffic circle and Figure (b) shows the proposed solution (Design D) as a modern roundabout, followed by brief introduction of each design.
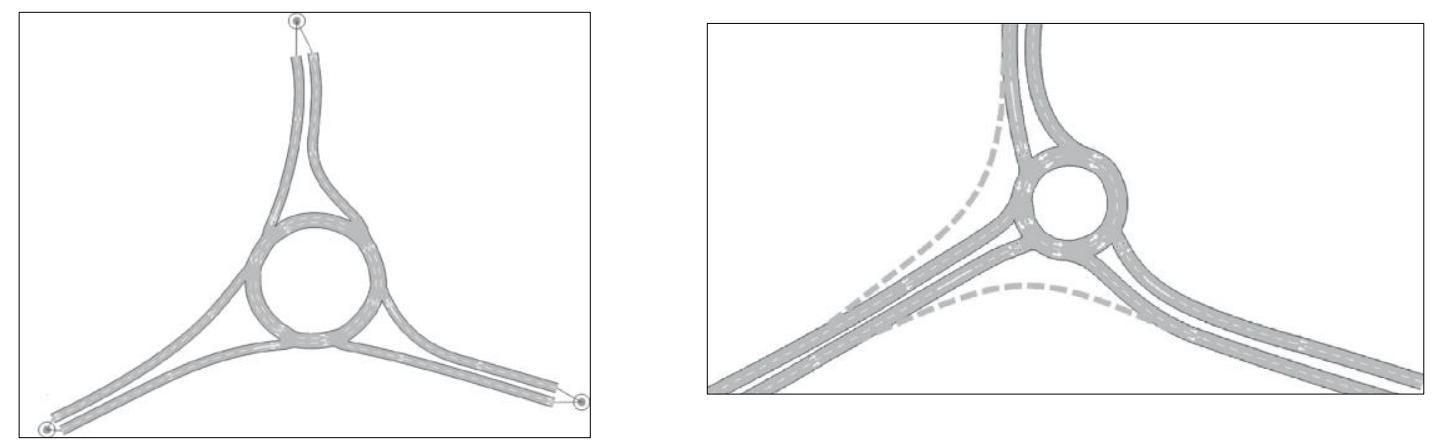

Figure 2.10: (a) On the right, initial design of traffic circle (Design A). (b) On the left, proposed modern roundabout with bypass lanes (Design D).[4]

- Design A (The initial design): The initial design with three circulating lanes and $104 \mathrm{~m}$ roundabout diameter.

- Design B: Variant of the Design A with two circulating lanes.

- Design C: Two circulating lanes with roundabout diameter of $54 \mathrm{~m}$ which is $47 \%$ less than current diameter.

- Design D: A variant of Design C, in which two bypass lanes are added: one for the North to South-West direction, and one for the South-West to South-East direction.

Design D (which has two bypass right lanes) offers the best safety performance with approximately half of the expected conflicts when compared with other designs. Similarly, in terms of operation, designs C and D show the best LOS compared to other designs. This indicates that, where practically applicable, converting a large, old roundabout to a relatively smaller diameter roundabout with additional bypass right lanes gives far more efficient results.

In another case study, a traffic circle in Sesto Fiorentino initially had an inscribed circle of $54 \mathrm{~m}$, central island of $26 \mathrm{~m}$, two circulating lanes each $3.8 \mathrm{~m}$ wide, and four single-lane entries of different widths. The traffic circle had inferior performance in terms of traffic operation. In 2004, the traffic circle was redesigned to a modern roundabout with a central island of $13 \mathrm{~m}$, two circulating lanes each $6.3 \mathrm{~m}$ wide, and two lanes at each entry. The new geometry improved the LOS from F to A, and the queue lengths decreased to one third of their initial values. 
The third case was an ultra large traffic circle in Luca with a diameter of $85 \mathrm{~m}$ located at the old gateways of the city. It had a central island of $78 \mathrm{~m}$ and a circulating carriageway of $6 \mathrm{~m}$ ( $3 \mathrm{~m}$ per lane), and two circulating lanes (Figure 2.11-a). During peak hours, the buses and trucks were making one lane unavailable for cars. In 2010, the traffic circle was upgraded, its diameter was reduced from $85 \mathrm{~m}$ to $55 \mathrm{~m}$, and circulating lanes were enlarged to $4.75 \mathrm{~m}$, widening the carriage to $9.5 \mathrm{~m}$ Figure $(2.11-\mathrm{b})$. The new design reduced the delays and queue length, increased safety, and showed an overall better performance. The extra space created from the new design was used for parking 80 cars [4].
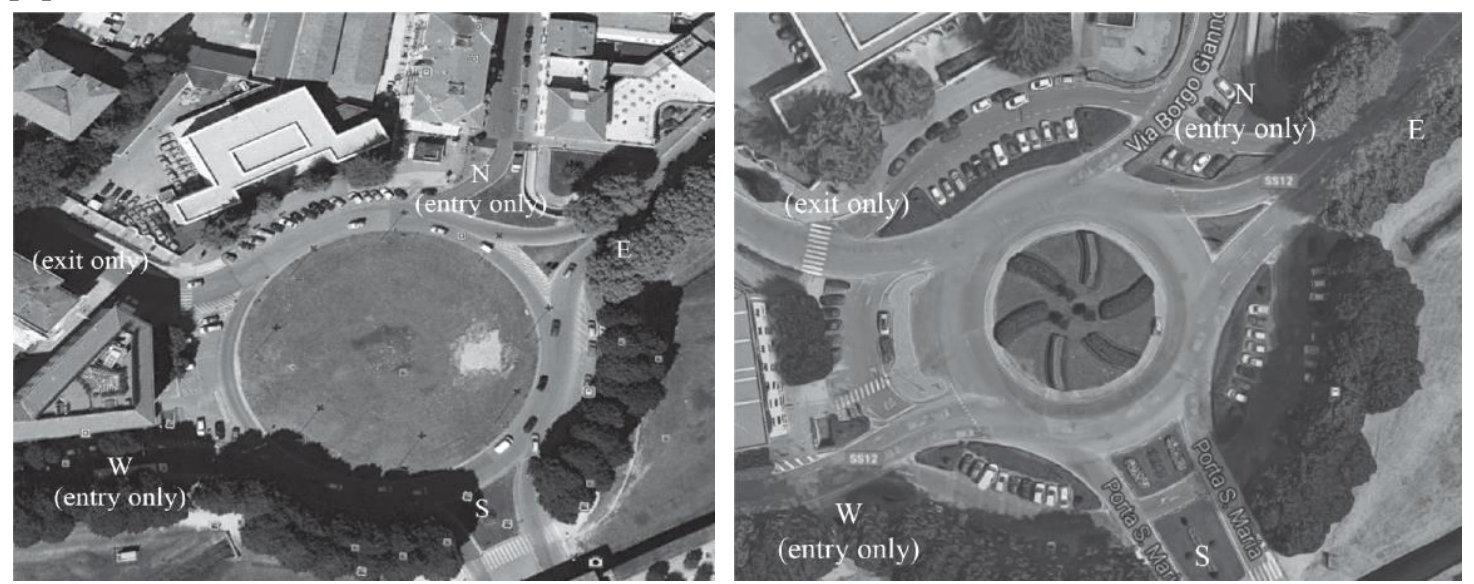

Figure 2.11: On the left (a), initial large traffic circle in Luca. On the right $(b)$, modern roundabout after improvement in Luca. [4]

\subsection{Other Traffic Circle Conversion Examples}

In the US, California DOT, converted a long island traffic circle into a modern roundabout in 1993 by adding yield signs, a yield ahead signs, and entry deflections to reduce long queues, delays, and severe injuries at the traffic circle. Similarly, at the campus of Michigan State University, three traffic circles were taken under observation where regular accidents were recorded even though they were operating at a reliable level of service. One of the circles with the most accidents, Bogue-Shaw traffic circle, had 76 cases in a period of 5 to 6 years. At that particular time, there were no guidelines available from FHWA, so the team used the British standards for the application of modern roundabouts. The study found that most of the accidents were right angle crashes at the entry and sideswipe crashes at the exits. British researchers had shown that entrycirculating crashes correlate significantly with entry width. Thus, the researchers proposed better channelization, reducing the entry width. To deal with exit-circulating crashes, the researchers proposed reducing excessive circulatory roadway width. The recommended circulatory width was 1 to 1.2 times the maximum entry width as per standards. Other improvements included adding splitter islands, a zebra style pedestrian crosswalk, yield lines, yield signs, and chevron signs [18]. 


\section{Methodology}

A four-step methodology was used in my study of Kabul roundabouts. The first step involved listing Kabul's traffic circle/rotaries and collecting their physical geometric data using aerial images. The information was used to score these intersections for their suitability to modern roundabout conversion as part of preliminary analysis. The list of traffic circles/rotaries with potential suitability scores was used as foundation for an online survey of Kabul traffic engineers who have background and/or experience in transportation engineering. The main objective was to obtain their input on the perceived problems in Kabul traffic circles/rotaries and the suitability of modern roundabouts as an alternative solution.

The survey was followed by an interview with one of the respondents in which further thoughts were discussed. Finally, one of the traffic circles was selected for a microsimulation case study using PTV VISSIM. Due to limited and uncertain input parameters, the case study was done as sensitivity analysis for various parameters. These results can be used to get preliminary feedback on performance.

Figure 3.1 provides a flowchart of the steps, tools, objectives and activities for the study. 


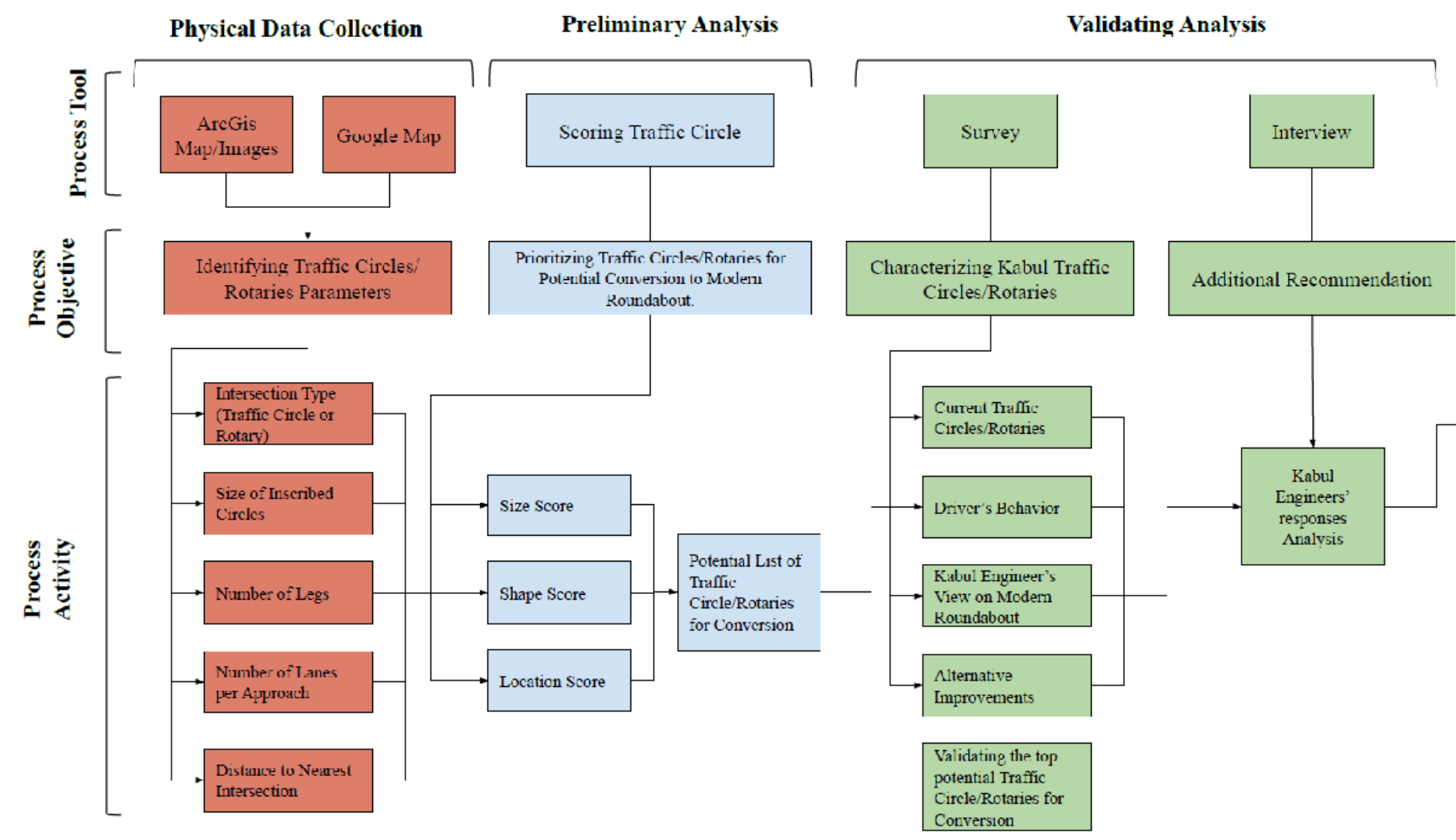

Microsimulation Analysis

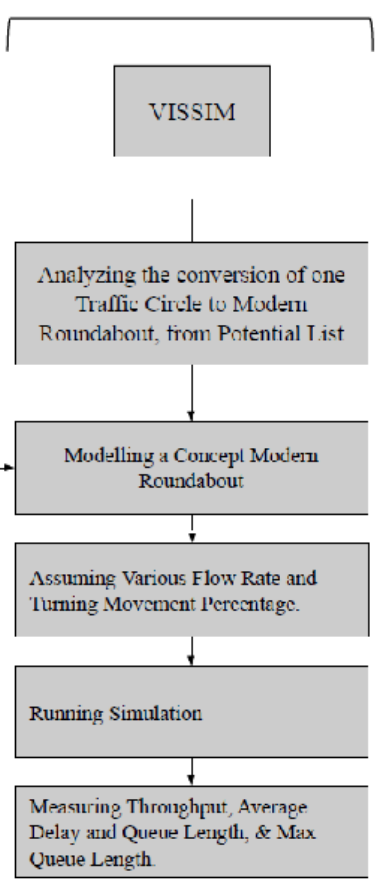

Figure 3.1: Study Methodology Flowchart. 


\subsection{Physical Data Collection}

Before determining if a Kabul traffic circle/rotary is a potential candidate for a modern roundabout conversion, it is essential to understand core geometric information, such as size, location within a road network, shape of traffic circle/rotary, number of legs, and number of lanes approaching. Aerial maps and images by ESRI, Google Earth Pro were used to collect the following information:

- The name, type, location, and distance of each traffic circle from the nearest intersection.

- Number of legs, number of lanes approaching.

- Inscribed circle size.

- Shapes of the traffic circle/rotaries based on the angles between approaching legs.

\subsubsection{Google Earth Pro}

Early pictures seen on Google Earth Pro from the year 2011 were used to verify all traffic circles/rotaries in Kabul City. These images were taken before the decision was made by Kabul municipality to convert some of them to signalized intersections. Figure 3.2 shows the 33 traffic circles in Kabul in 2011.

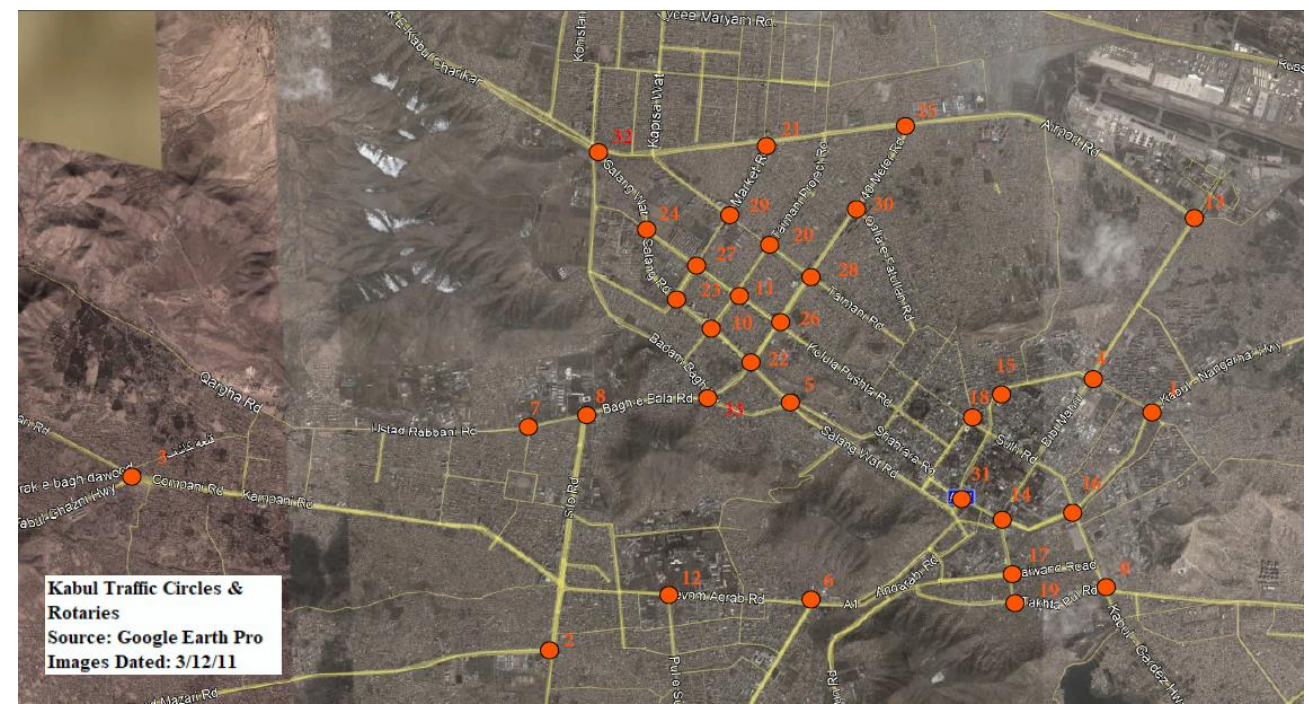

Figure 3.2: 33 Kabul rotaries/traffic circles (Image by Google Earth Pro, Image Captured:

[Mar-12-2011]

\subsubsection{ArcGIS Map \& World Imagery Wayback}

ArcGIS Maps and World Imagery Wayback provide access to the most up-to-date images and maps, but they also show the changes that occurred in the past. For each traffic circle/rotary, location, size, shape, number of entry and exit lanes, and number of legs were derived from these maps and images. Ten traffic circle/rotaries (out of a total of 33) were identified that have been converted to signalized intersections (Fig 3.3.) 
The list of all traffic circles/rotaries in Kabul with their basic geometric data is presented in Table 3.1. The number of legs and the size of the central island is easily identifiable from aerial images. However, the diameters of inscribed circles are only rough measurements, as there are no fixed boundaries delineated with curbs or markings. 


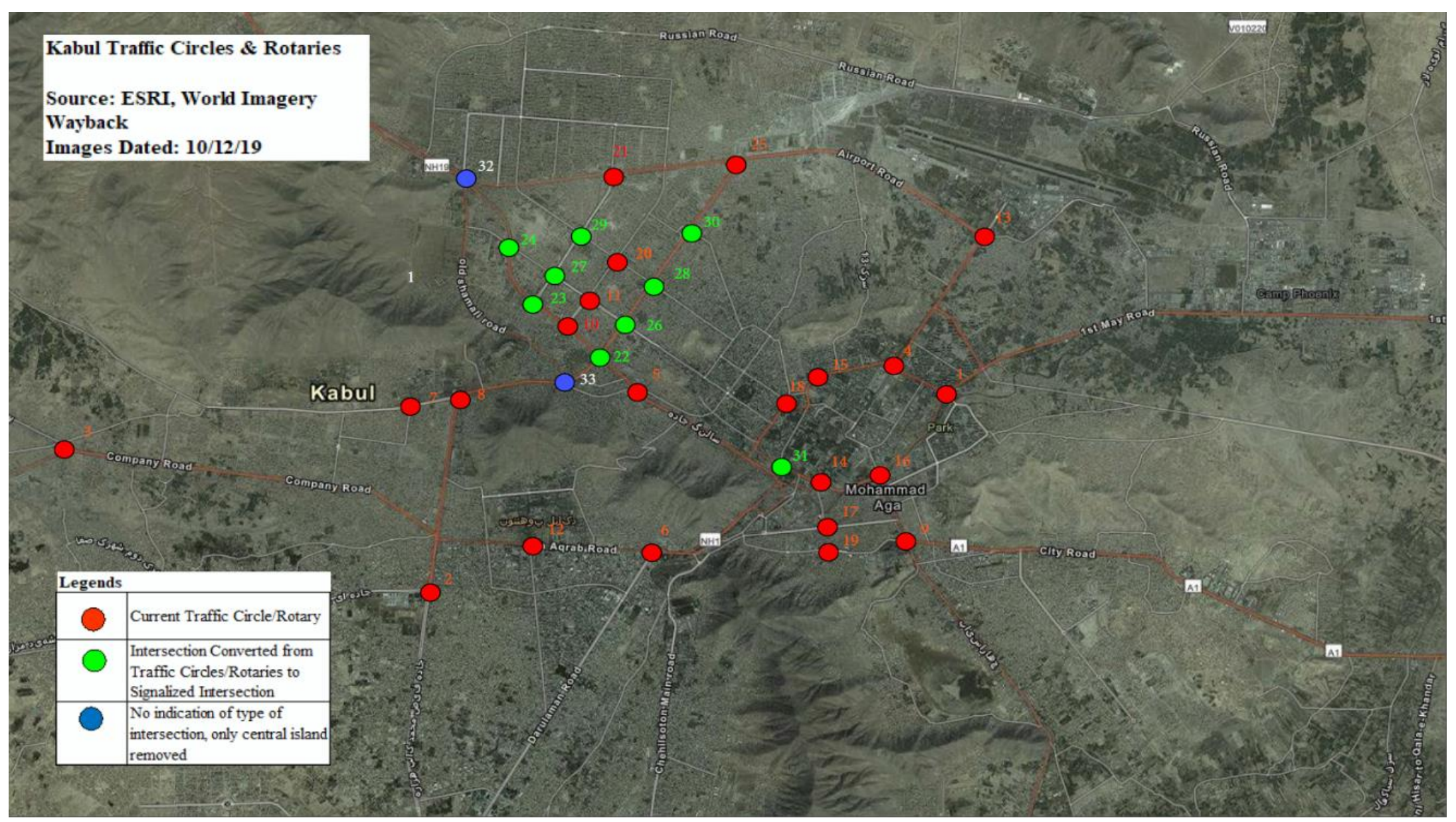

Figure 3.3: Most Recent Image Identifying Current State of Kabul Traffic Circles/Rotaries, By: ES RI, World Imagery Wayback. Captured on [Oct-12-2019] 
Table 3.1: List of Kabul Traffic Circles \& Rotaries

\begin{tabular}{|c|c|c|c|c|c|c|c|}
\hline$S / N$ & Intersection Name & $\begin{array}{l}\text { Intersection } \\
\text { Type }\end{array}$ & Total Lanes & $\begin{array}{l}\text { Number } \\
\text { of Legs }\end{array}$ & $\begin{array}{l}\text { Circular } \\
\text { Island; M } \\
\text { (ft) }\end{array}$ & $\begin{array}{l}\text { Inscribed } \\
\text { Circle } \\
\text { M (ft) }\end{array}$ & $\begin{array}{l}\text { Distance to } \\
\text { the Nearest } \\
\text { Intersectior } \\
\quad \mathrm{M}(\mathrm{ft})\end{array}$ \\
\hline 1 & Abdul Haq Circle & Traffic Circle & 2 Lanes Each Entry and Exit & 4 & $46(150)$ & $79(260)$ & $201(660)$ \\
\hline 2 & Shahid Mazari Chowk & Rotary & 2 Lanes Each Entry and Exit & 3 & $40(130)$ & $67(220)$ & $793(2600)$ \\
\hline 3 & Medan Arghandi & Rotary & 2 Lanes Each Entry and Exit & 3 & $40(130)$ & $110(360)$ & $1434(4700)$ \\
\hline 4 & Masood Circle & Traffic Circle & 2 Lanes Each Entry and Exit & 4 & $40(130)$ & $63(205)$ & $854(2800)$ \\
\hline 5 & $\begin{array}{l}\text { Dahane Bagh Traffic } \\
\text { Circle }\end{array}$ & Traffic Circle & $\begin{array}{l}4 \text { Legs, } 6 \text { exit and } 6 \text { entry in } \\
\text { total }\end{array}$ & 4 & $52(170)$ & $85(280)$ & $198(650)$ \\
\hline 6 & Dahmazang square & Traffic Circle & 2 Lanes Each Entry and Exit & 3 & $37(120)$ & 59 (195) & $915(3000)$ \\
\hline 7 & $\begin{array}{l}\text { Education University } \\
\text { Traffic Circle }\end{array}$ & Traffic Circle & 2 Lanes Each Entry and Exit & 3 & $24(78)$ & $49(160)$ & $702(2300)$ \\
\hline 8 & Karte Mamureen & Traffic Circle & 2 Lanes Each Entry and Exit & 3 & $18(60)$ & $43(140)$ & $702(2300)$ \\
\hline 9 & Minar Nejat & Traffic Circle & 2 Lanes Each Entry and Exit & 4 & $15(50)$ & $35(115)$ & $320(1050)$ \\
\hline 10 & Parwan 2 Square & Traffic Circle & $\begin{array}{l}2 \text { Lanes Each Entry and Exit, } \\
\text { Except from eastbound ( } 1 \\
\text { lane exit and } 1 \text { lane entry) }\end{array}$ & 4 & $58(190)$ & $87(285)$ & $519(1700)$ \\
\hline 11 & Gul Surkh Square & Traffic Circle & 2 Lanes Each Entry and Exit & 4 & $44(145)$ & $70(230)$ & $519(1700)$ \\
\hline 12 & Dehbori Traffic Circle & Traffic Circle & 2 Lanes Each Entry and Exit & 4 & $18(60)$ & $50(165)$ & $140(460)$ \\
\hline 13 & Airport Circle & Traffic Circle & 2 Lanes Each Entry and Exit & 4 & $20(65)$ & $50(165)$ & $1342(4400)$ \\
\hline 14 & Pashtunistan Circle & Traffic Circle & $\begin{array}{l}4 \text { Legs, } 6 \text { exit and } 6 \text { entry in } \\
\text { total }\end{array}$ & 4 & $27(90)$ & $55(180)$ & $122(400)$ \\
\hline 15 & $\begin{array}{l}\text { Char Rahi Wazir Akbar } \\
\text { Khan }\end{array}$ & Rotary & $\begin{array}{l}5 \text { Legs, } 7 \text { exit and } 7 \text { entry } \\
\text { lanes in total }\end{array}$ & 5 & $\begin{array}{c}27 * 15 \\
(90 * 50)\end{array}$ & $\begin{array}{l}44 * 24 \\
(145 * 78)\end{array}$ & $107(350)$ \\
\hline
\end{tabular}




\begin{tabular}{|c|c|c|c|c|c|c|c|}
\hline$S / N$ & Intersection Name & $\begin{array}{l}\text { Intersection } \\
\text { Type }\end{array}$ & Total Lanes & $\begin{array}{c}\text { Number } \\
\text { of Legs }\end{array}$ & $\begin{array}{l}\text { Circular } \\
\text { Island; M } \\
\text { (ft) }\end{array}$ & $\begin{array}{l}\text { Inscribed } \\
\text { Circle } \\
\text { M (ft) }\end{array}$ & $\begin{array}{c}\text { Distance to } \\
\text { the Nearest } \\
\text { Intersection } \\
\mathrm{M}(\mathrm{ft})\end{array}$ \\
\hline 16 & $\begin{array}{l}\text { Pule- Mahmood Khan } \\
\text { Circle }\end{array}$ & Traffic Circle & 2 Lanes Each Entry and Exit & 4 & $18(60)$ & $44(145)$ & $107(350)$ \\
\hline 17 & Sare-Chowk Circle & Traffic Circle & 2 Lanes Each Entry and Exit & 4 & $15(50)$ & $40(130)$ & $214(700)$ \\
\hline 18 & Char rahi Sher Por & Traffic Circle & 2 Lanes Each Entry and Exit & 4 & $5(16)$ & $27(90)$ & $305(1000)$ \\
\hline 19 & Bagh Qazi Square & Traffic Circle & 2 Lanes Each Entry and Exit & 4 & $12(40)$ & $35(115)$ & $122(400)$ \\
\hline 20 & Nasir Khesro Square & Traffic Circle & 2 Lanes Each Entry and Exit & 4 & $21(70)$ & $31(100)$ & $275(900)$ \\
\hline 21 & Lab Jar Square & Traffic Circle & 2 Lanes Each Entry and Exit & 4 & $40(130)$ & $61(200)$ & $763(2500)$ \\
\hline \multicolumn{8}{|c|}{ Traffic Circles Recently Changed to Signalized Intersection. } \\
\hline 22 & Baraki Square & $\begin{array}{l}\text { Central Island } \\
\text { Removed }\end{array}$ & 2 Lanes Each Entry and Exit & 4 & & & \\
\hline 23 & Parwan 3 Square & $\begin{array}{l}\text { Central Island } \\
\text { Removed }\end{array}$ & 2 Lanes Each Entry and Exit & 4 & & & \\
\hline 24 & Salang Watt Square & $\begin{array}{l}\text { Central Island } \\
\text { Removed }\end{array}$ & 2 Lanes Each Entry and Exit & 4 & & & \\
\hline 25 & Charahi Shaheed & $\begin{array}{l}\text { Central Island } \\
\text { Removed }\end{array}$ & $\begin{array}{l}2 \text { Lanes Each Entry and Exit, } \\
\text { except from eastbound ( } 1 \\
\text { lane exit and } 1 \text { lane entry) }\end{array}$ & 4 & & & \\
\hline 26 & Traffic Square & $\begin{array}{l}\text { Central Island } \\
\text { Removed }\end{array}$ & 2 Lanes Each Entry and Exit & 4 & & & \\
\hline 27 & Market Square & $\begin{array}{l}\text { Central Island } \\
\text { Removed }\end{array}$ & 2 Lanes Each Entry and Exit & 4 & & & \\
\hline
\end{tabular}




\begin{tabular}{|c|c|c|c|c|c|c|c|}
\hline $\mathrm{S} / \mathrm{N}$ & Intersection Name & $\begin{array}{c}\text { Intersection } \\
\text { Type }\end{array}$ & Total Lanes & $\begin{array}{c}\text { Number } \\
\text { of Legs }\end{array}$ & $\begin{array}{c}\text { Circular } \\
\text { Island; M } \\
\text { (ft) }\end{array}$ & $\begin{array}{c}\text { Inscribed } \\
\text { Circle } \\
\text { M (ft) }\end{array}$ & $\begin{array}{c}\text { Distance to } \\
\text { the Nearest } \\
\text { Intersection } \\
M(\mathrm{ft})\end{array}$ \\
\hline 28 & Sabaqa Taimani -Square & $\begin{array}{l}\text { Central Island } \\
\text { Removed }\end{array}$ & 2 Lanes Each Entry and Exit & 4 & & & \\
\hline 29 & Sarsabzi Square & $\begin{array}{l}\text { Central Island } \\
\text { Removed }\end{array}$ & 2 Lanes Each Entry and Exit & 4 & & & \\
\hline 30 & Saleem Karwan Square & $\begin{array}{l}\text { Central Island } \\
\text { Removed }\end{array}$ & 2 Lanes Each Entry and Exit & 3 & & & \\
\hline 31 & Malik Asghar Square & $\begin{array}{l}\text { Central Island } \\
\text { Removed }\end{array}$ & 2 Lanes Each Entry and Exit & 4 & & & \\
\hline 32 & Sare-Shamali Rotary & $\begin{array}{l}\text { Central Island } \\
\text { Removed }\end{array}$ & 2 Lanes Each Entry and Exit & 3 & & & \\
\hline 33 & Karte-Parwan Circle & $\begin{array}{l}\text { Central Island } \\
\text { Removed }\end{array}$ & 2 Lanes Each Entry and Exit & 4 & & & \\
\hline
\end{tabular}




\subsection{Preliminary Analysis}

Since the data on traffic volumes, turning movements, and other traffic characteristics were not available, the physical characteristics collected as part of the "Physical Data Collection" were used to create a preliminary list of traffic circles that seemed most suitable for modern roundabout conversion from geometric perspective. The preliminary analysis was done by creating a quantitative scoring of three physical parameters (network location, size and shape) identified from the images for each traffic circle. The top four with the highest overall score were then used in the survey of "Kabul Engineers" to inquire whether they concurred with the selection.

\subsubsection{Road Network Score}

Modern roundabouts that are located further from adjacent intersections (that is, they are isolated) function more effectively, as vehicles will arrive randomly rather than in platoons. In addition, the queue storage spaces of a roundabout built in close proximity with another intersection may cause spillback. The objective of this particular scoring parameter was to identify the most isolated traffic circles/rotaries as having the highest potential, while the ones closer to other intersections received a lower number.

The minimum spacing between any intersections on arterial roads is recommended between 8,00 meters ( $1 / 2$ miles) and 400 meters ( $1 / 4$ miles) [19]. Taking this particular analogy, I considered 600 meters of spacing as the minimum space between a traffic circle and the nearest intersection if converted to a modern roundabout. The distances are divided into five categories for the scoring (Table 3.2). The shorter the distance from minimum distance, the lower the score assigned.

Table 3.2: Score for distance from the nearest intersection.

\begin{tabular}{|l|l|}
\hline $\begin{array}{l}\text { Traffic Circle/Rotary Distance } \\
\text { From Nearest Intersection }\end{array}$ & $\begin{array}{l}\text { Road Network } \\
\text { Score }\end{array}$ \\
\hline$<150$ meters & 1 \\
\hline 150 to 300 meters & 2 \\
\hline 300 to 450 meters & 3 \\
\hline 450 to 600 meters & 4 \\
\hline$>600$ meters & 5 \\
\hline
\end{tabular}


Figures 3.4 and 3.5 show two examples of the scoring process. Abdul Haq traffic circle is 200 meters away from the nearest intersection. Referring to the Table 3.2, it received an adjacency score of two. Education University Traffic Circle (Figure 3.4), on the other hand, is approximately 702 meters $(2,300$ feet $)$ from the nearest intersection and hence received an adjacency score of five.

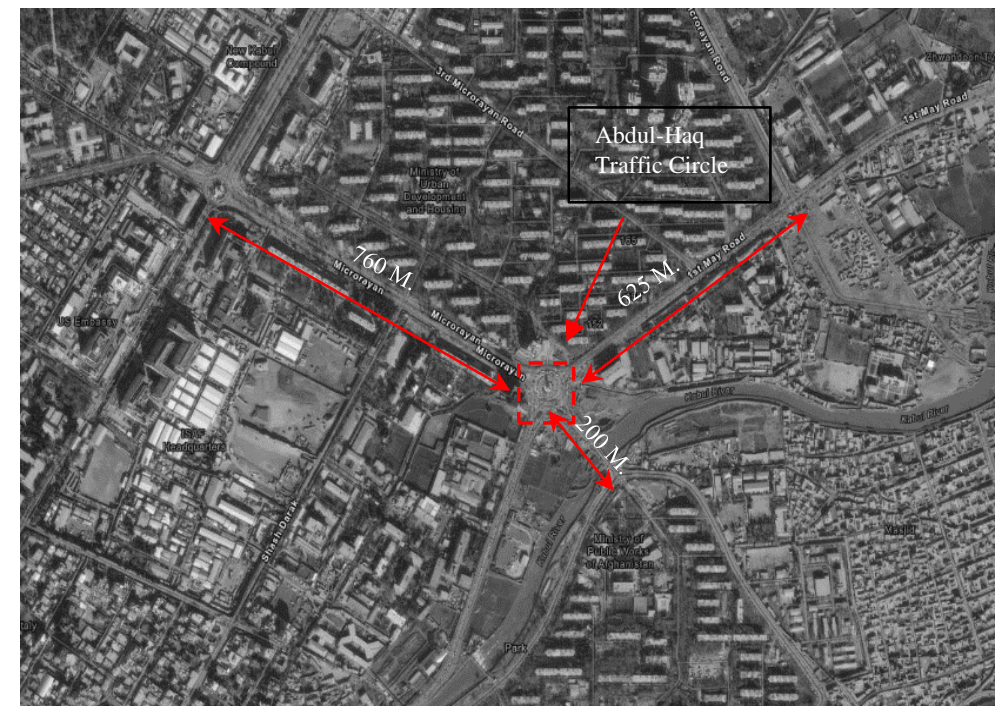

Figure 3.4: Distance of nearby intersection from Abdul-Haq Traffic Circle.

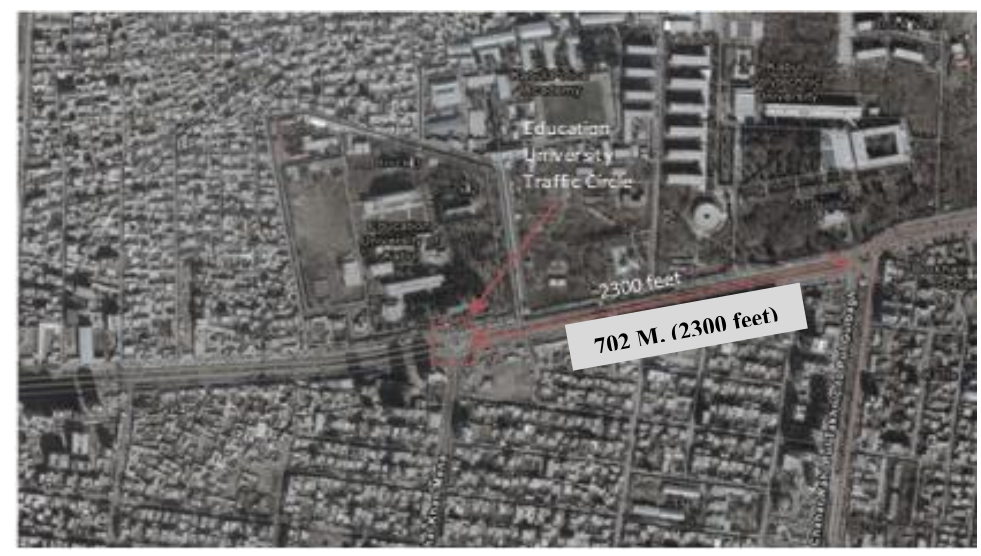

Figure 3.5: Distance of nearby intersection from Education University Traffic Circle.

\subsubsection{Size Parameter}

Typically, modern roundabouts are smaller than the old traffic circles/rotaries. In the conversion process, the space unused for geometrics can be used to relocate the center island, to decrease the acuteness of the approach angles, and/or to introduce a right-turn bypass lane for better operational performance. The traffic circles/rotaries were scored for their particular inscribed circle sizes. Based on typical roundabout design guidelines, it is difficult to fit a roundabout with an extra right lane if inscribed circle is less than 30 
meters. Table 3.3 provides the scoring rubric based on the inscribed circle diameter and Figure 3.6 shows the inscribed circle of Abdul-Haq traffic circle (approximately 80 meters), which received a size score of four.

Table 3.3: Inscribed Circle Diameter Score

\begin{tabular}{|l|l|}
\hline $\begin{array}{l}\text { Traffic Circle/Rotary } \\
\text { Inscribed Circle Diameter }\end{array}$ & Size Score \\
\hline$<30$ meters & 1 \\
\hline 30 to 45 meters & 2 \\
\hline 45 to 60 meters & 3 \\
\hline$>60$ meters & 4 \\
\hline
\end{tabular}

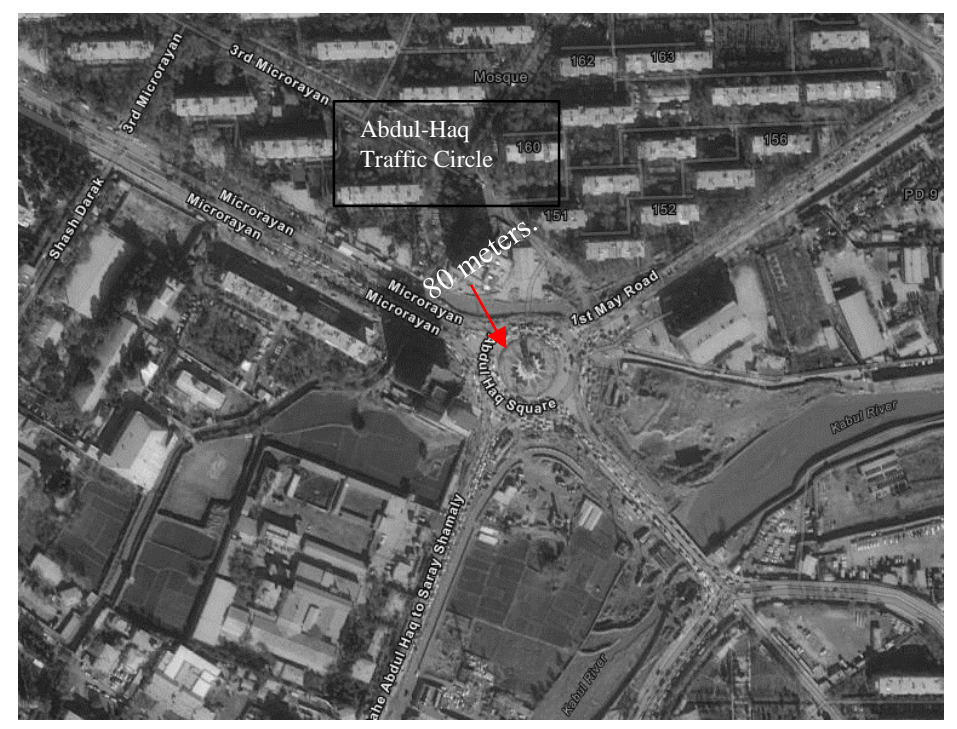

Figure 3.6: Inscribed circle size of Abdul Haq traffic circle.

\subsubsection{Shape Parameter:}

Another aspect impacting traffic circle/rotary conversion is its particular shape created from the number of legs and the angles between them. Intersections with acute angles (> $90^{\circ}$ ) cause vehicles to take longer left or right turns. Compared to traditional 
intersections, modern roundabouts operate at safer and slower speeds, which decreases the risk of accidents. In addition, the number of potential conflict points increases with the number of legs, and since modern roundabouts have fewer conflict points, they can become a preferable option in locations with acute angles between legs (causing greater travel time) and increased number of legs (causing more conflict points).

Table 3.4 provides scores for four distinct shapes and number of legs. Shape group " 1 " is used for traffic circles where there is no acuteness in approach angles, and they are scored "1" for acuteness. For shape group " 2 ," the number of conflicts is less, but often there are acute angles between legs, thus posing a greater risk than shape group "1." Shape groups " 3 " and " 4 " create more conflict points and larger angles, yielding greater risks to users.

Figure 3.7 shows Gul-Surkh Traffic Circle with 90 degrees of angle, and thus, it was scored "1" based on Table 3.4. Similarly, Figure 3.8, 3.9 and 3.10 show Dahmazang, Minar Nejat, and Abdul Haq Traffic Circles would come under shape scores of 2, 3, and 4 respectively.

Table 3.4: Traffic Circles/Rotaries categories based on shapes

\begin{tabular}{|l|l|l|}
\hline Traffic Circle/Rotary Shape & Shape & $\begin{array}{l}\text { Shape } \\
\text { Score }\end{array}$ \\
\hline $\begin{array}{l}\text { Four-legged, Minor \& Major roads in 90 } \\
\text { Angle }\end{array}$ & 1 \\
\hline Three-legged & & 2 \\
\hline $\begin{array}{l}\text { Four-legged, Minor \& Major Interaction } \\
\text { making skewed intersection }\end{array}$ & & 3 \\
\hline $\begin{array}{l}\text { Four or more legs with different approach } \\
\text { angles }\end{array}$ & & 4 \\
\hline
\end{tabular}




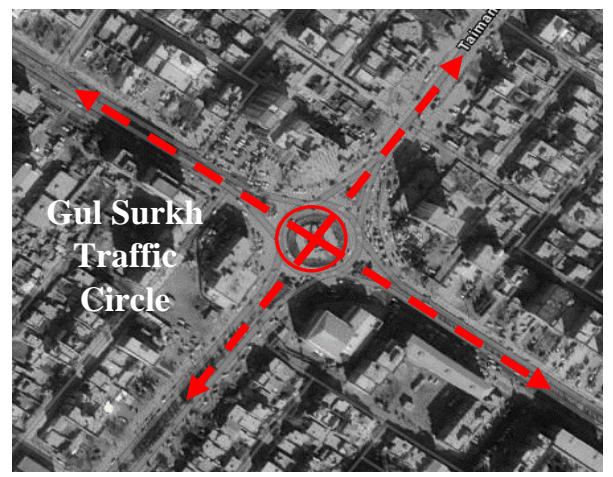

Figure 3.7: Gul Surkh Traffic Circle, with shape score of (1)

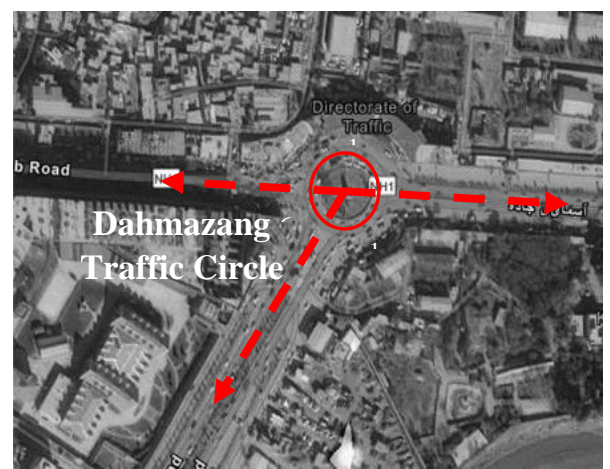

Figure 3.8: Dahmazang Traffic Circle, with shape score of (2)

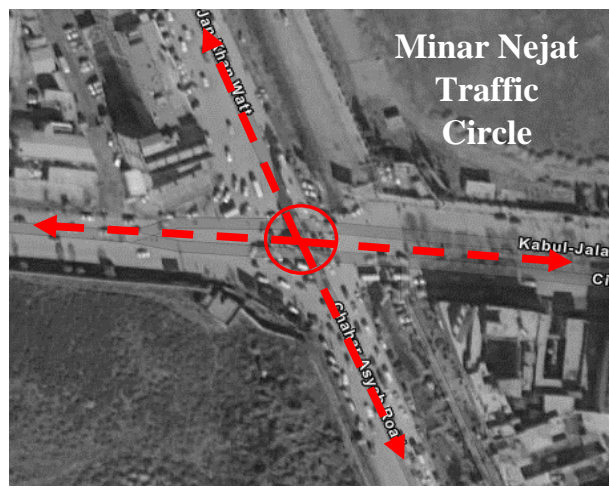

Figure 3.9: Minar Nejat Traffic Circle, with shape score of (3) 


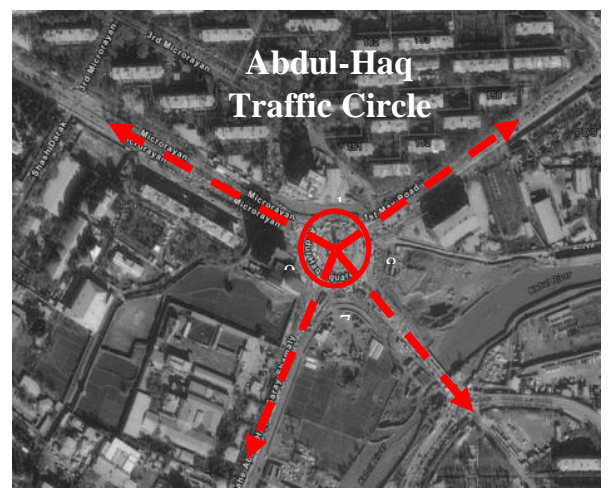

Figure 3.10: Abdul Haq Traffic Circle, with shape score (4).

\subsubsection{Total Suitability Score}

The final total preliminary suitability scores were derived by multiplying each parameter score with each other (Total Score = Road Network Score x Size Score x Shape Score). Since there was no clear indication in the literature on differences in the relative importance of selected three parameters, each parameter was weighted equally in the analysis. The individual scores for each traffic circle/rotary are presented in the results section.

\subsection{Survey of Kabul Engineers}

Selecting traffic circles for modern roundabout conversion purely based on physical characteristics has significant shortcomings. In the absence of any traffic volume data, I used a survey of Kabul engineers experienced in the field of transportation to obtain feedback and insight on our preliminary selections. I consider the respondents a reliable source for feedback since they have insight on the driver behavior, status of current infrastructure, and main problems to Kabul congestion in traffic circles. However, they may also have their own perception on how these problems can be solved. My focus was to link their responses to the application of modern roundabouts and further analyze whether the opinions of Kabul engineers support the general likelihood of converting traffic circles to modern roundabouts. In addition to characterizing the current traffic circles, the survey was used to evaluate whether the engineers agreed with the top four potential traffic circles/rotaries I had selected in our preliminary analysis as the most likely candidates for conversions.

The survey was divided into four sections, as follows. The complete survey is provided in Appendix A:

a. The operational rules in the traffic circles/rotaries. Understanding what traffic rules are prevalent currently, how traffic is guided through the traffic circle/rotary, and what are the main causes for congestion.

b. The drivers' behavior at current traffic circles/rotaries. Obtaining Kabul engineers' perspective based on their driving experience in these 
traffic circles/rotaries. First, I wanted to understand how often they see aggressive drivers. For a modern roundabout to work efficiently, the drivers need to respect the set of rules to avoid locking the roundabout or bringing other safety concerns. In addition, I was keen to understand the likelihood of Kabul drivers to respect the new rules associated with installation of modern roundabouts.

c. Overall opinion on modern roundabouts as an improvement option for these traffic circles/rotaries. Since we are looking for the option of modern roundabouts, the Kabul engineers might have gone or would go through a thought process with the option we present (modern roundabout). Their inputs on the challenges that might hinder the application of modern roundabouts, or on certain criteria that might advocate the application of modern roundabouts in Kabul City, will be valuable information to know.

d. The option of modern roundabouts among other alternatives. Recently, approximately ten traffic circles/rotaries have been converted to signalized intersections. As commuter and transportation engineers, Kabul engineers have formed a perception on how effective these changes have been. In addition, this portion of the survey also includes the view of Kabul engineers on the top four potential traffic circles/rotaries I selected. They will be asked to share their views as to what degree they agree or disagree with the results.

The possibility of bias from Kabul engineers was recognized based on their perception, but with the limitations on quantitative data, it was felt important to obtain insight from those working with these challenges on a daily basis. In addition to the survey results, a follow-up interviews were requested with those available. One respondent accepted the invitation to share more of their preferences, experiences, and opinions on the subject matter.

\subsection{Microsimulation Case Study}

Based on the preliminary rankings and the survey results, one traffic circle that was perceived as having high potential for conversion to a modern roundabout was selected for microsimulation analysis. Prior to the analysis, a concept for a modern roundabout using design criteria from NCHRP's modern roundabout guidelines was developed [1]. PTV VISSIM version $\mathrm{xx}$ that was used for the microsimulation analysis needs to be calibrated based on actual drivers' behavior and traffic flow data for accurate results. Since the lack of actual traffic flow data and other input values leaves uncertainty in the analysis, a sensitivity analysis was performed to investigate the importance of various parameters on different traffic flow scenarios. This provides a reference that can be used in later evaluations of the performance and thresholds to modern roundabout capacity, once accurate input values are determined. It also allows replication of the exercise with proper input values. 


\subsubsection{Geometric Design of the Modern roundabout.}

For the analysis, a tool called "vehicle tracking" in Autodesk Civil 3D was used to make sure the roundabout meets the fastest path criteria and the roundabout entering speed is limited to $40 \mathrm{~km} / \mathrm{hr}$ ( $25 \mathrm{mph}$ ), as recommended by NCHRP guidelines. The rest of the geometric criteria are also controlled by the "vehicle tracking" tool as per given guidelines. In addition, the roundabout was designed to fit within the existing traffic circle footprint, based on aerial images.

\subsubsection{Modelling in VISSIM}

After the geometric design, the proposed modern roundabout was modelled and analyzed in PTV VISSIM. The roundabout was coded such that just before reaching the dedicated bypass lane, the vehicles have to decide what lane to choose on the approach leg, based on their downstream destination. Vehicles taking the right turn will choose the right lane while vehicles intending to turn left or take a U-turn will approach through the left lane before entering the roundabout. After taking the appropriate entry lane, the vehicle will not change their lane until they exit the roundabout.

\subsubsection{Entry Flow Rate, Relative Turning Movement, and Lane Arrangement:}

Literature shows that a roundabout can work adequately if the entering flow rate is kept under 1,000 vehicles per hour (vph) in a two-lane modern roundabout [15]. In addition, a modern roundabout works more efficiently in areas with higher left turns and U-turns.

Since the actual traffic volumes and their directional distribution were unknown, five scenarios were created for the analysis with varying percentages of right turns, left turns, and through movements.

\subsubsection{Priority Rule \& Minimum Gap:}

Since Kabul does not have any minimum gap acceptance study, an analogy was made with the study performed in India. From the range observed in India, taking the lower gap acceptance value would yield better throughput but would raise questions regarding the safety of the roundabout and eventual traffic lockup under higher traffic flow. Therefore, a slightly more conservative value of $2.6 \mathrm{~s}$ was used (Indian study values were 1.36s to $2.52 \mathrm{~s}$ ) for analysis.

\subsubsection{Reduced Speed}

Modern roundabouts are designed for a maximum entry speed of $40 \mathrm{~km} / \mathrm{hr}$ (25 $\mathrm{mph}$ ) [1]. So, the roundabout modelled in VISSIM with the "Reduced Speed Area" tool was used with which the vehicle would slow down to maximum $40 \mathrm{~km} / \mathrm{hr}(25 \mathrm{mph})$ on all entries. 


\section{Results and Discussion}

As noted before, I used "physical geometric data" to collect data and rank each traffic circle for conversion suitability, followed by a survey of Kabul engineers to obtain their input. The survey questionnaire was sent to 16 transportation engineers living in Kabul City. 13 of them responded. Based on the survey results, one location was selected as a case study for PTV VISSIM microsimulation and sensitivity analysis.

\subsection{Preliminary Analysis Results}

Table 4.1 presents the preliminary ranking of all traffic circles for modern roundabout conversion, in descending order. The ranking is purely based on the equally weighed shape, size, and location scores, as explained in Section 3.2. The top four traffic circle/rotaries from the table were further used in the Kabul Engineers' survey to obtain their perception on the suitability.

Based on the scores at Table 4.1, the top seven traffic circles/rotaries received much higher score than the rest of the circle/rotaries. They all scored 30 or above and did not score " 1 " in any of the categories indicating that they possess characteristics suitable for modern roundabout conversion. The majority of traffic circle/rotary where the score is less than 20 has at least one individual score of (1) which makes them less desirable towards modern roundabout conversion. Each one of the higher ranked traffic circles/rotaries could have been included as alternatives to collect Kabul engineer's input, but providing too many options to responders would provide a lengthier survey, so only the top four were included in the survey. 
Table 4.1: Traffic Circles/Rotaries Total Score for Conversion Appropriateness

\begin{tabular}{|c|c|c|c|c|c|c|c|c|c|}
\hline $\mathbf{S} / \mathbf{N}$ & Intersection Name & $\begin{array}{l}\text { Number } \\
\text { of Legs }\end{array}$ & $\begin{array}{l}\text { Circular } \\
\text { Island; M (ft) }\end{array}$ & $\begin{array}{l}\text { Inscribed } \\
\text { Circle; M } \\
\text { (ft) }\end{array}$ & $\begin{array}{l}\text { To the } \\
\text { Nearest } \\
\text { Intersection; } \\
M \text { (ft) }\end{array}$ & $\begin{array}{l}\text { Road } \\
\text { Network } \\
\text { Score }\end{array}$ & $\begin{array}{l}\text { Size } \\
\text { Score }\end{array}$ & $\begin{array}{l}\text { Shape } \\
\text { Score }\end{array}$ & $\begin{array}{l}\text { Total } \\
\text { Score }\end{array}$ \\
\hline 1 & Masood Circle & 4 & $40(130)$ & $63(205)$ & $854(2800)$ & 5 & 4 & 2 & 40 \\
\hline 2 & Medan Arghandi & 3 & $40(130)$ & $110(360)$ & $1434(4700)$ & 5 & 4 & 2 & 40 \\
\hline 3 & Shahid Mazari Chowk & 3 & $40(130)$ & $67(220)$ & $793(2600)$ & 5 & 4 & 2 & 40 \\
\hline 4 & Abdul Haq Circle & 4 & $46(150)$ & $79(260)$ & $201(660)$ & 2 & 4 & 4 & 32 \\
\hline 5 & Dahane Bagh Traffic Circle & 4 & $52(170)$ & $85(280)$ & $198(650)$ & 2 & 4 & 4 & 32 \\
\hline 6 & $\begin{array}{l}\text { Education University Traffic } \\
\text { Circle }\end{array}$ & 3 & $24(78)$ & $49(160)$ & $702(2300)$ & 5 & 3 & 2 & 30 \\
\hline 7 & Dahmazang square & 3 & $37(120)$ & $59(195)$ & $915(3000)$ & 5 & 3 & 2 & 30 \\
\hline 8 & Lab Jar Square & 4 & $40(130)$ & $61(200)$ & $763(2500)$ & 5 & 4 & 1 & 20 \\
\hline 9 & Karte Mamureen & 3 & $18(60)$ & $43(140)$ & $702(2300)$ & 5 & 2 & 2 & 20 \\
\hline 10 & Minar Nejat & 4 & $15(50)$ & $35(115)$ & $320(1050)$ & 3 & 2 & 3 & 18 \\
\hline 11 & Gul Surkh Square & 4 & $44(145)$ & $70(230)$ & $519(1700)$ & 4 & 4 & 1 & 16 \\
\hline 12 & Parwan 2 Square & 4 & $58(190)$ & $87(285)$ & $519(1700)$ & 4 & 4 & 1 & 16 \\
\hline 13 & Airport Circle & 4 & $20(65)$ & $50(165)$ & $1342(4400)$ & 5 & 3 & 1 & 15 \\
\hline 14 & Pashtunistan Circle & 4 & $27(90)$ & $55(180)$ & $122(400)$ & 1 & 3 & 4 & 12 \\
\hline 15 & Pule- Mahmood Khan Circle & 4 & $18(60)$ & $44(145)$ & $107(350)$ & 1 & 2 & 4 & 8 \\
\hline 16 & Char Rahi Wazir Akbar Khan & 5 & $27 * 15(90 * 50)$ & $\begin{array}{l}44 * 24 \\
(145 * 78)\end{array}$ & $107(350)$ & 1 & 2 & 4 & 8 \\
\hline
\end{tabular}




\begin{tabular}{|c|c|c|c|c|c|c|c|c|c|}
\hline $\mathbf{S} / \mathbf{N}$ & Intersection Name & $\begin{array}{l}\text { Number } \\
\text { of Legs }\end{array}$ & $\begin{array}{l}\text { Circular } \\
\text { Island; M (ft) }\end{array}$ & $\begin{array}{l}\text { Inscribed } \\
\text { Circle; } M \\
\text { (ft) }\end{array}$ & $\begin{array}{l}\text { To the } \\
\text { Nearest } \\
\text { Intersection; } \\
\text { M (ft) }\end{array}$ & $\begin{array}{l}\text { Road } \\
\text { Network } \\
\text { Score }\end{array}$ & $\begin{array}{l}\text { Size } \\
\text { Score }\end{array}$ & $\begin{array}{l}\text { Shape } \\
\text { Score }\end{array}$ & $\begin{array}{l}\text { Total } \\
\text { Score }\end{array}$ \\
\hline 17 & Nasir Khesro Square & 4 & $21(70)$ & $31(100)$ & $275(900)$ & 2 & 2 & 1 & 4 \\
\hline 18 & Sare-Chowk Circle & 4 & $15(50)$ & $40(130)$ & $214(700)$ & 2 & 2 & 1 & 4 \\
\hline 19 & Char rahi Sher Por & 4 & $5(16)$ & $27(90)$ & $305(1000)$ & 3 & 1 & 1 & 3 \\
\hline 20 & Dehbori Traffic Circle & 4 & $18(60)$ & $50(165)$ & $140(460)$ & 1 & 3 & 1 & 3 \\
\hline 21 & Bagh Qazi Square & 4 & $12(40)$ & $35(115)$ & $122(400)$ & 1 & 2 & 1 & 2 \\
\hline
\end{tabular}




\subsection{Kabul Engineers Survey Findings}

The following sections presents results of the Kabul Engineers survey that collected opinions of the Kabul engineers regarding the current condition of traffic circles/rotaries, identified causes of congestion problem, inquired whether the modern roundabout can be solution to consider, and lastly asked about their opinion on the suitability of our preselected traffic circles for a modern roundabout conversion.

\subsubsection{Rules for Current Traffic Circles/Rotaries}

Kabul engineers were asked to select how traffic priority rules are set in traffic circles/rotaries. Based on their responses (Table 4.2), the most common method to provide guidance is by human traffic officers. Other types of traffic guidance seems to be rarely provided, as second most common response was "no rules applied.

Table 4.2: Survey result for "Priority rule" in traffic circle/rotaries in Kabul.

\begin{tabular}{|l|l|l|}
\hline S/N & Traffic priority rules set as & $\begin{array}{l}\text { Number of times } \\
\text { responded (Out of 13 } \\
\text { total responses) }\end{array}$ \\
\hline 1 & $\begin{array}{l}\text { Traffic Officer controls and } \\
\text { decides the movement. }\end{array}$ & 10 \\
\hline 2 & No rules are applied. & 7 \\
\hline 3 & $\begin{array}{l}\text { Entering traffic should yield to } \\
\text { circulating traffic. }\end{array}$ & 3 \\
\hline 4 & $\begin{array}{l}\text { Traffic Signals control and decide } \\
\text { the movement. }\end{array}$ & 2 \\
\hline 5 & $\begin{array}{l}\text { Circulating traffic should yield to } \\
\text { entering traffic. }\end{array}$ & 1 \\
\hline
\end{tabular}

Next question asked engineers to provide a ranking of the different perceived causes for congestion at traffic circles/rotaries. Table 4.3 shows the average ranks in decreasing order of importance. As evident from the table, lack of strict traffic rules in the traffic circles/rotaries was ranked as the main concern, followed by the lack of proper planning by Kabul transportation authorities. 
Table 4.3: Survey result for ranked causes of congestion in Traffic circles and Rotaries.

\begin{tabular}{|l|l|l|l|}
\hline $\begin{array}{l}\text { Ranking } \\
\text { No. } *\end{array}$ & $\begin{array}{l}\text { Cause of Congestion at Traffic } \\
\text { Circles/Rotaries }\end{array}$ & $\begin{array}{l}\text { Average } \\
\text { Rank }\end{array}$ & $\begin{array}{l}\text { STD. } \\
\text { Dev. }\end{array}$ \\
\hline 1 & Lack of strict traffic rules. & 3.23 & 2.05 \\
\hline 2 & $\begin{array}{l}\text { Lack of proper planning from the } \\
\text { transportation authorities. }\end{array}$ & 3.31 & 2.29 \\
\hline 3 & Unawareness or ignorance of traffic rules. & 3.77 & 1.59 \\
\hline 4 & Lack of proper geometric design. & 4.23 & 1.59 \\
\hline 5 & Aggressive driving behaviors. & 4.38 & 2.14 \\
\hline 6 & Demand beyond capacity. & 4.54 & 1.94 \\
\hline 7 & Lack of signs and pavement markings. & 4.54 & 2.33 \\
\hline
\end{tabular}

* $1=$ highest rank, 7 = lowest rank

\subsubsection{Driver's Behavior at Current Traffic Circles/Rotaries}

Engineers were also asked to rate how often aggressive drivers are noticed in these traffic circles. Figure 4.1 shows that in total, over $92 \%$ agreed that either all the time or most of the time these drivers are present.

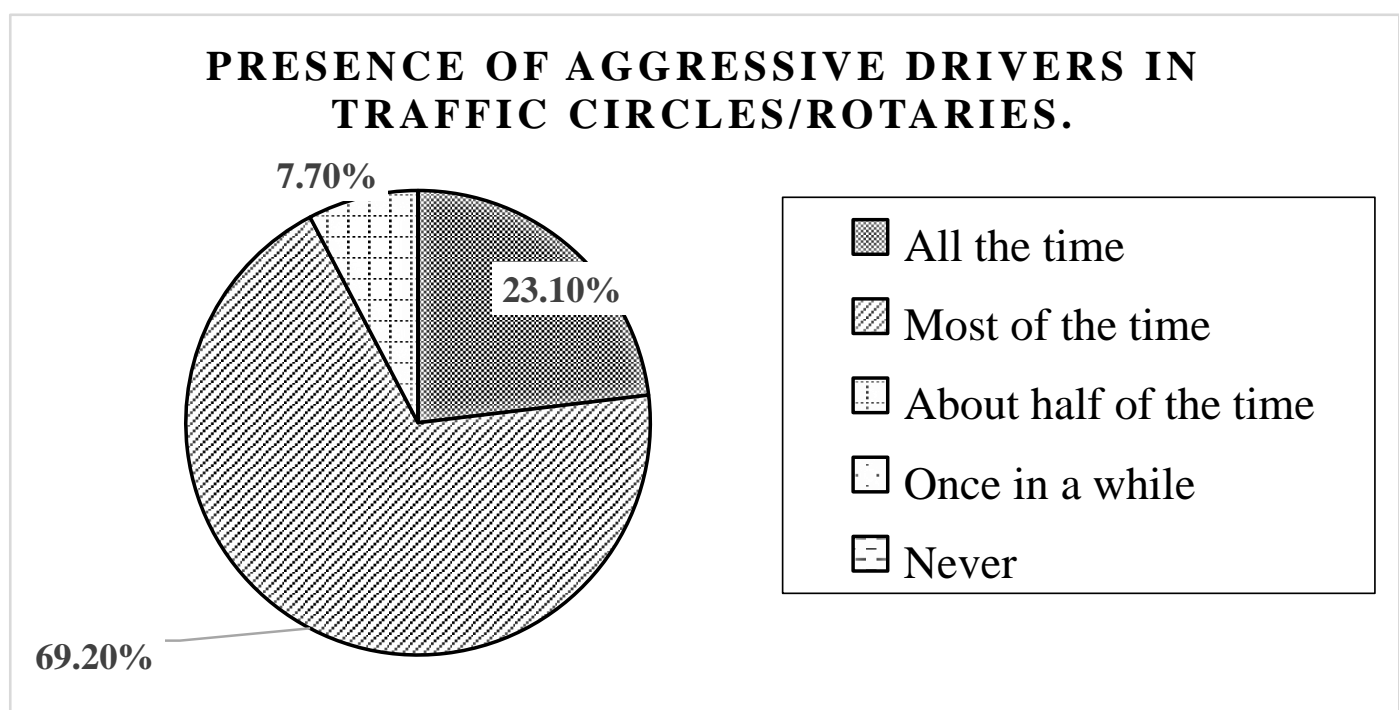

Figure 4.1: Survey result for presence of aggressive drivers in traffic circles/rotaries. 


\subsubsection{View on Modern Roundabout Application}

The Kabul engineers were asked to rate whether users would adhere to the new rules, such as entering traffic yielding to circulating traffic, choosing entry lane based on destination, and prohibiting change of lanes inside the circulatory roadway in a modern roundabout. Figure 4.2 shows that the majority of the respondents believed that the drivers can adjust to new rules. However, they commented that proper and extensive public awareness of modern roundabout usage and more strict traffic rules need to be applied along with the roundabout's application.

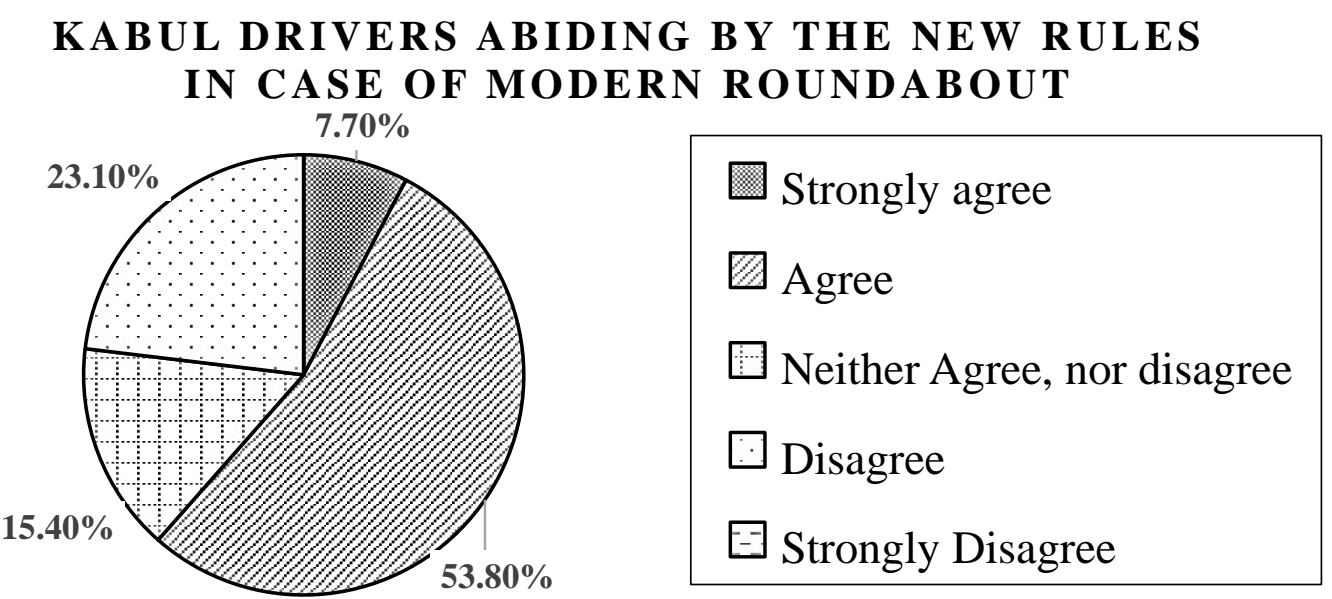

Figure 4.2: Survey results for whether Kabul drivers will abide by the rules in modern roundabout.

The respondents were also asked their view of suitability of converting current traffic circles/rotaries to modern roundabouts. More than one-third agreed and commented that old traffic circles are outdated and need to be improved with a reliable alternative such as a modern roundabout (Figure 4.3). Those who disagreed were mainly concerned that the modern roundabout might not meet the traffic flow demand. The final third did not take a certain position but were skeptical of the modern roundabout. They believed that a thorough assessment needs to be conducted at the specific location before a decision can be made. 


\section{KABUL ENGINEERS RESPONSES ON WHETHER MODERN ROUNDABOUT CAN BEA GOOD FIT}
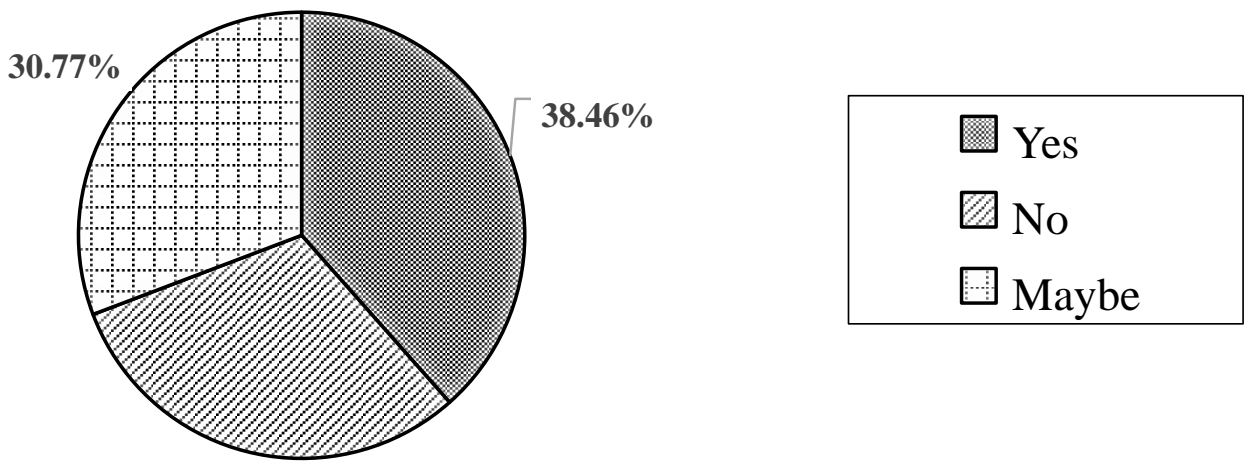

$30.77 \%$

Figure 4.3: Kabul drivers' responses on whether modern roundabout can be a good fit.

When asked about their thoughts on how important certain factors are in hindering the application of modern roundabouts (1-4 Likert scale where 1 is "least important" and 4 means "very important"), driver behavior was at the top of the list, followed by excessive and unbalanced traffic flow (Figure 4.4).

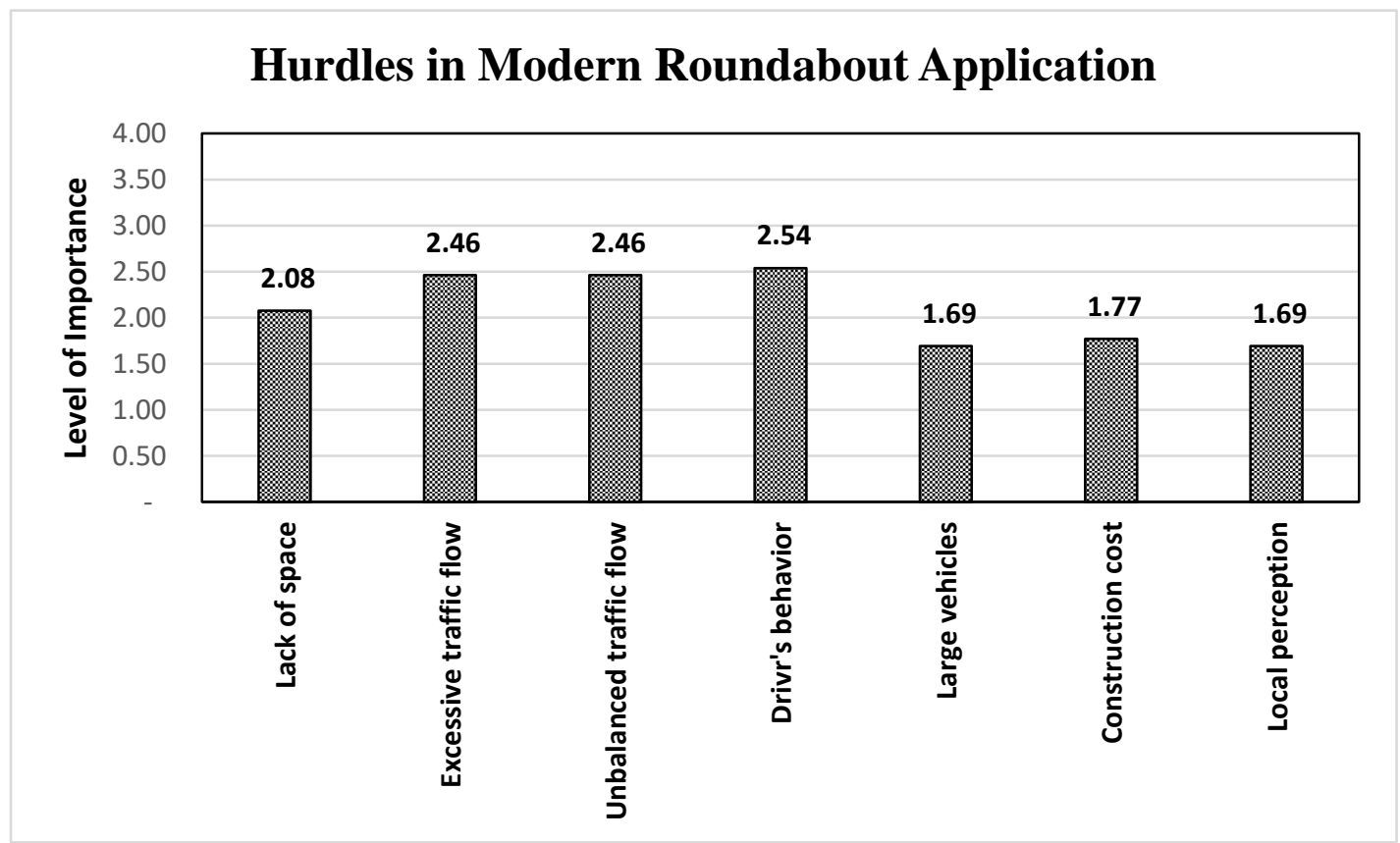

Figure 4.4: Average rating of Hurdles in Modern Roundabout Application in Kabul (1= Least important, $4=$ Very important).

When asked for the significant modern roundabout benefits (used the same 1-4 Likert scale as previous question, "safety reason" is the most important benefit of modern 
roundabouts. This was followed by improving access to business and residence areas and environmental friendliness (Figure 4.5).

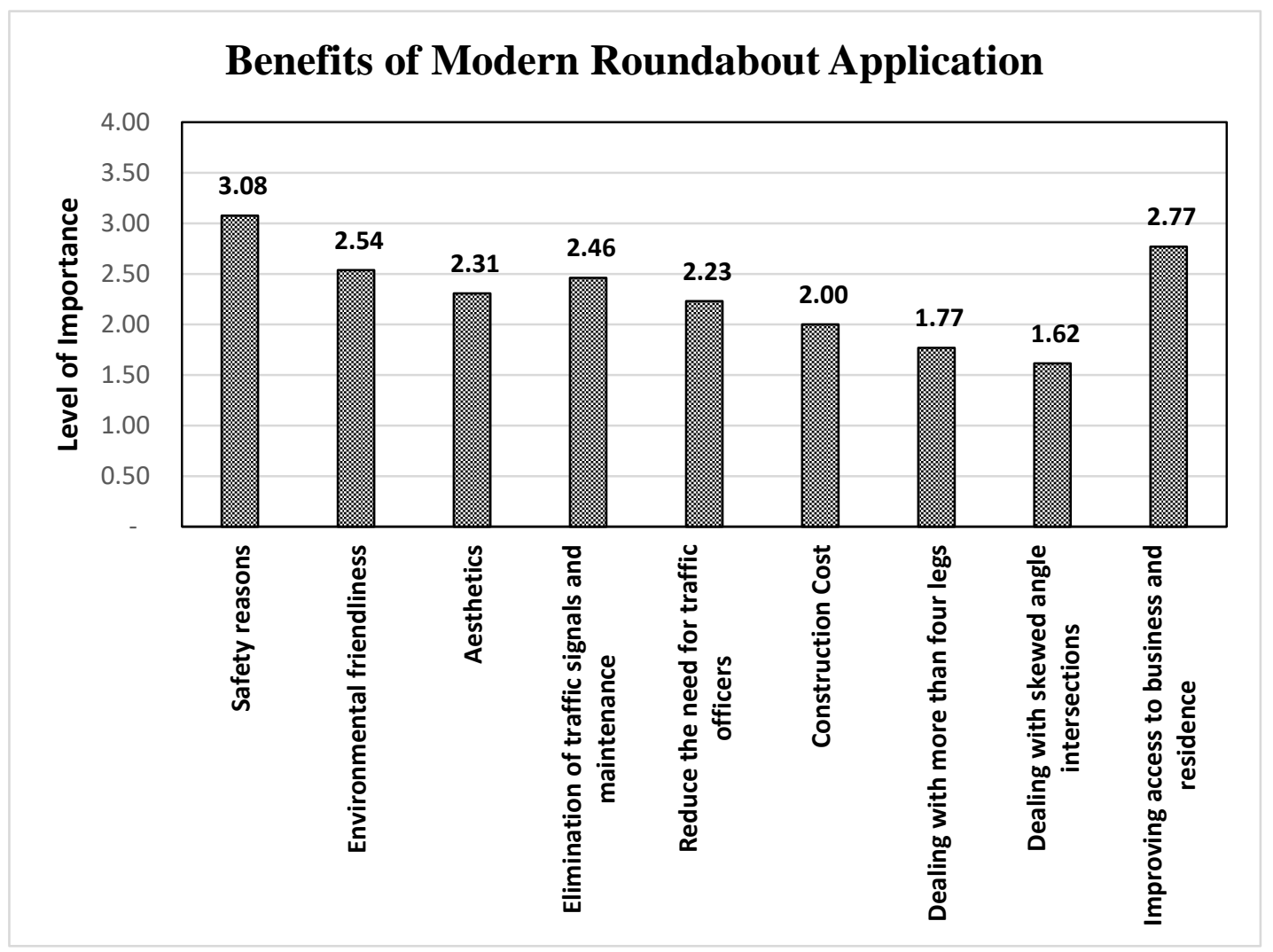

Figure 4.5: Average rating of Benefits of Modern Roundabouts in Kabul ( $1=$ Least important, 4= Very important).

\subsubsection{Latest Changes to Kabul Traffic Circles/Rotaries}

Recently, ten of the traffic circles were converted to signalized intersections in Kabul, such as Baraki square, Parwan Seh Square, Charahi Shaeed, and Traffic Square.

Respondents were asked for their assessment of the operational performance after the changes were made. The question was on a Likert scale to ask the respondent for their satisfaction level on the recent improvements, from very satisfied to very dissatisfied, on scale (1 to 5). The largest group, making 5 out of the 13 responders, are "somewhat satisfied" with the improvements (Figure 4.6). Followed by 3 responders "somewhat dissatisfied". Overall, the group was fairly equally split between those satisfied and dissatisfied at varying level. Hence, the results do not provide a conclusive evidence on whether the latest improvements have truly been efficient. In addition, three of the respondents said in the comments that despite the claim by Kabul Municipality, the new intersections are not actuated in reality, and sometimes signals are off due to power outages. While two others have commented that the new changes in some places have negatively impacted the performance. 


\section{KABUL ENGINEERS VIEW ON LATEST IMPROVEMENTS}

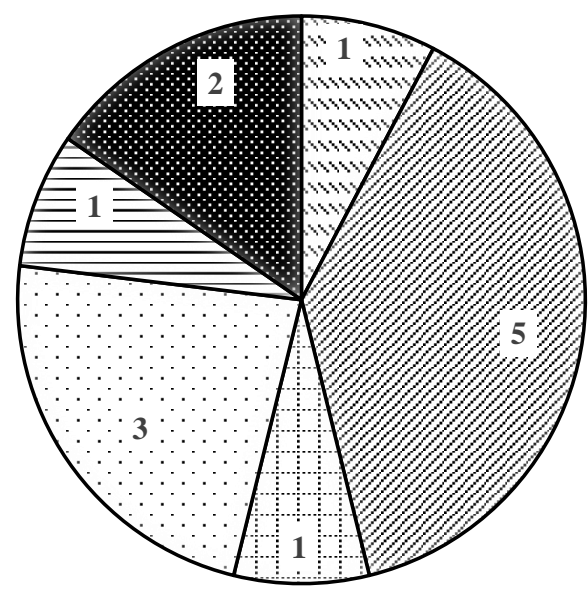

Very Satisfied

$\mathbb{Z}$ Somewhat Satisfied

Neither Satisfied nor dissatisfied

Somewhat dissatisfied

目 Very dissatisfied

图 Not aware

Figure 4.6: Number of Kabul Engineers' Views on Traffic Circle/Signalized Intersection Conversions.

The survey also asked on specific performance area with latest improvements. Figure 4.7 shows the responses, on a Likert scale of (1 to 5), for what has happened to delays, queues, and accident likelihoods at these intersections after the improvements took place.

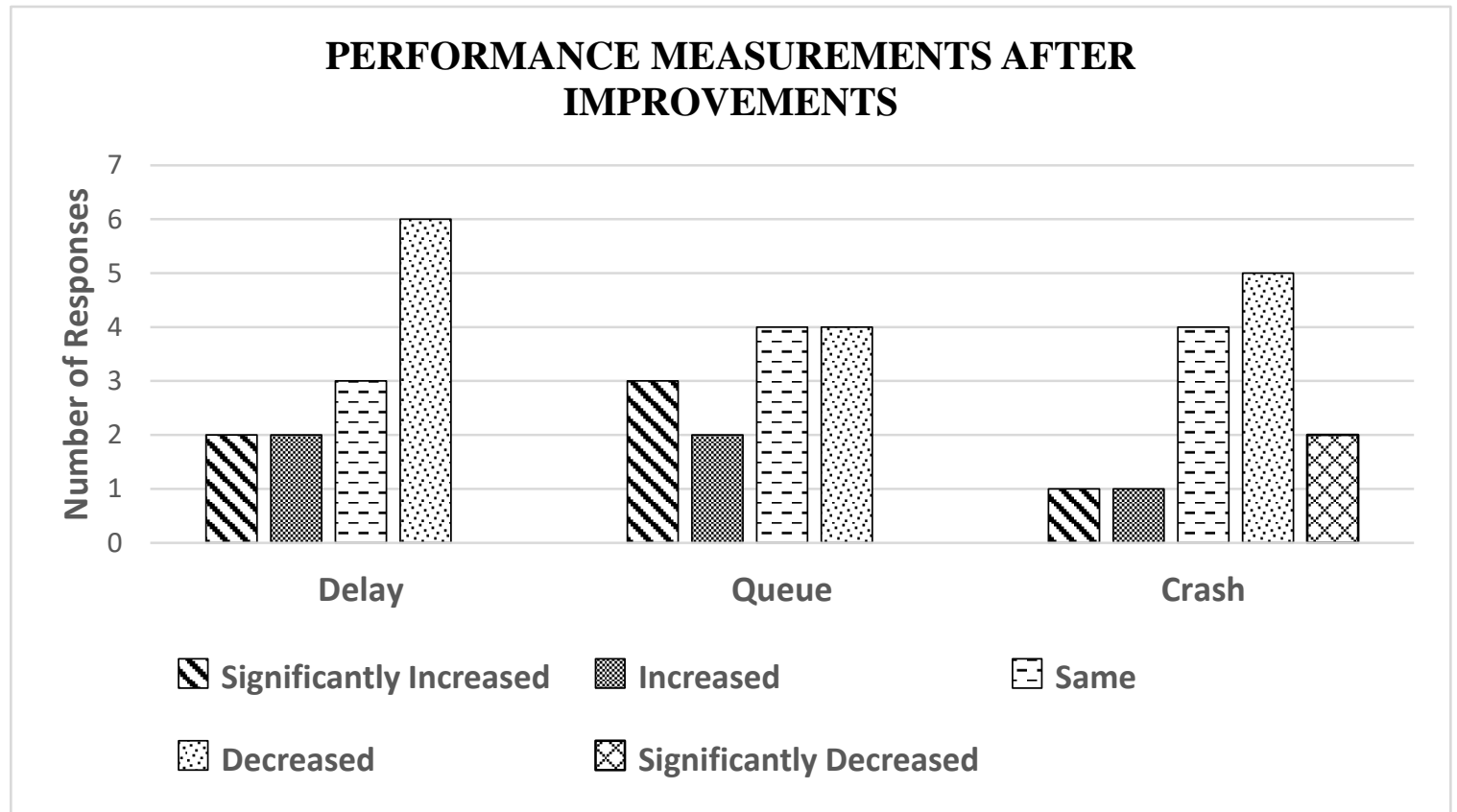

Figure 4.7: Kabul Engineers' Thoughts on Recent Improvements of Traffic Circle/Rotaries to Signalized Intersections. 
The improvements were initially meant to bring substantial changes in operation of underperforming traffic circles. However, the responses offer inconclusive evidence that the improvements have actually enhanced the performance. For delays and queues, engineers' perception was divided almost equally between positive and negative impacts. For crashes, the majority perceived a reduction after the conversions. Overall, it is difficult to conclude that the improvements have led to significant improvements in alleviating congestion problems at these locations. An in-depth analysis might shed a better light on the current status.

In a separate question, respondents were asked to rank the alternatives to improve the operational performance of the existing traffic circles and rotaries. They ranked either a modern roundabout or signalized intersection highest, depending on their location (Table 4.4). These answers suggest that Kabul engineers are welcoming the possibility of using modern roundabouts, but only after analysis of their suitability in Kabul environment.

Table 4.4: Average Ranking for Improvement Options.

\begin{tabular}{|l|l|l|}
\hline $\begin{array}{l}\text { Ranking } \\
\text { Number } *\end{array}$ & Options & Average Ranking \\
\hline 1 & $\begin{array}{l}\text { Either signalized intersection or modern } \\
\text { roundabout based on location }\end{array}$ & 1.62 \\
\hline 2 & Convert them to signalized intersections & 1.85 \\
\hline 3 & Convert them to modern roundabouts & 2.54 \\
\hline
\end{tabular}

* 1= Highest rank, 3 = Lowest rank

Finally, engineers were asked to rate whether the four traffic circles/rotaries that had scored highest in our preliminary analysis (Table 4.1) were suitable for modern roundabout conversion. On a scale of 1 to 5 , score (1 meaning "Strongly agree" while 5 meaning "Strongly disagree"), Abdul Haq traffic circle received the highest rating from Kabul engineers and all four locations received fairly high ranking (Figure 4.8). This demonstrates clear agreement from the engineers that modern roundabout might provide alterative solution at selected Kabul locations. 


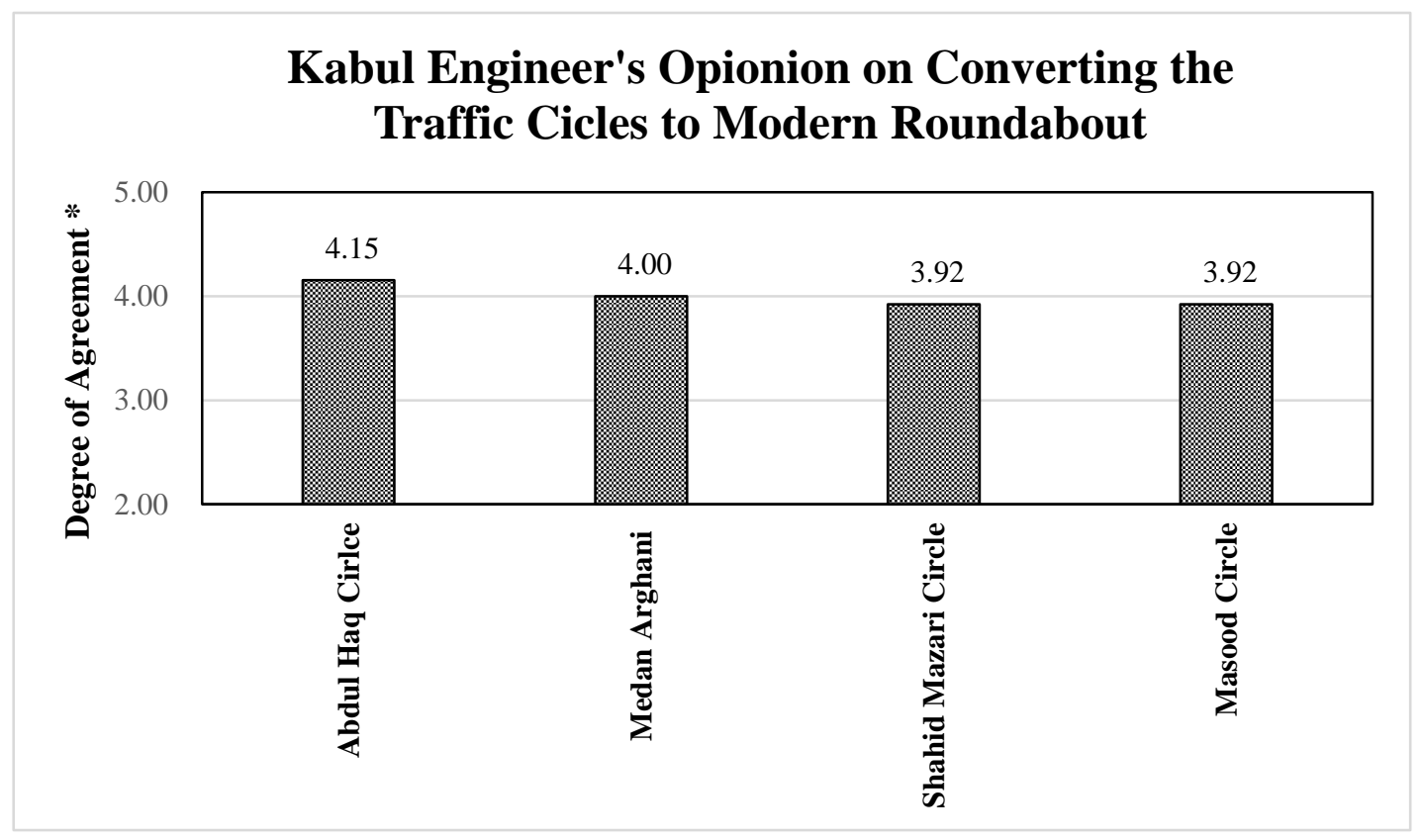

* $1=$ strongly disagree, 5 = strongly agree

Figure 4.8: Kabul Engineers' Opinions on Converting the Traffic Circles to Modern Roundabouts

\subsection{Follow-up Interview}

A follow-up interview was conducted with one engineer who was interested to provide more in sight to traffic circles/rotaries in Kabul City. When asked whether the roundabout option was considered during the decision making for changing 33 traffic circles and roundabouts' geometries, he replied that the option of a modern roundabout was neglected since the authorities presumed based on their engineering judgement that it would not satisfy the traffic flow requirement. In their perception, these traffic circles/rotaries experience high traffic volume and are congested most of the time. He also pointed towards the complexity of the matter such that there is a lack of reliable and accurate traffic data that can serve as an input to proper planning, modeling, and analyzing the intersections which can eventually generate a result that can be used in technical evaluation of intersection designs. The traffic circles/rotaries intended to be converted to signalized intersections were modelled with assumed traffic input data and the authority used these judgements in its decision to change the geometries of traffic circles to signalized intersections and to later install signals, proper road markings, and signs. However, the signals and signs are yet to be installed.

When asked regarding the option of modern roundabouts from a safety perspective, he replied that since the vehicle speed in Kabul City is presumed to be low, mobility is preferred over safety factors in decision making. However, the respondent was confident 
that a modern roundabout can be a preferable option, if it meets the traffic flow requirement and is modelled based on accurate driver behavior inputs for Kabul City.

\subsection{Summary of Survey/Follow-Up Interview Findings}

The survey and follow-up interview provided good solid insight to the expert opinions on the Kabul traffic circle/rotary situation and development options. Altogether, the following provides a brief summary of key findings from the survey and interview:

- The current operations in traffic circles/rotaries are characterized by the lack of traffic rules and aggressive driver behavior. The results suggest that main "control" at the locations is provided by traffic officer and that the combination of insufficient traffic rules/planning and aggressive driver behavior to be the main causes for congestion and other operational challenges.

- Engineers indicated an openness for considering modern roundabouts as alternative solution in Kabul, but with reservations. They believe that safety would provide the main justification for modern roundabout applications, while driver's aggressive behavior is the main threat to the application. In general, they believe that Kabul drivers can be expected to abide by the new rules of the modern roundabout and stated that either signalized intersection or modern roundabout would be their preferred solution. However, they are hesitant to jump into implementation of modern roundabouts, unless an in-depth analysis is conducted at each location. The follow-up interview further highlighted the concern of applying modern roundabout solutions when traffic data is absent or insufficient.

- The engineers provided mixed response for the level of success demonstrated by the recent conversions of traffic circles to signalized intersections. Some reported positive impacts while others considered impacts mainly negative. The follow-up interviewee also noted that some of the marking/signs haven't been installed, and signals haven't been operating consistently making it challenging to evaluate the impacts.

- Finally, the engineers considered all four traffic circles provided in the survey as solid candidates for modern roundabout conversion. Abdul Haq traffic circle was ranked the highest and when hence selected for the microsimulation case study.

\subsection{Abdul Haq Square Case Study}

In the survey, Kabul engineers were asked to respond with their engineering judgement on the potential conversion of four traffic circles/rotaries. "Abdul Haq" traffic circle (Fig. 4.9) was ranked higher than other locations. In Figure 4.9, Abdul Haq traffic circle is shown, which also reveals a lack of proper markings both leading to and within the traffic circle. Due to its high ranking, Abdul Haq Square was selected for the modeling case study that designed the location as a modern roundabout and conducted performance analysis with various traffic scenarios through VISSIM simulation. 


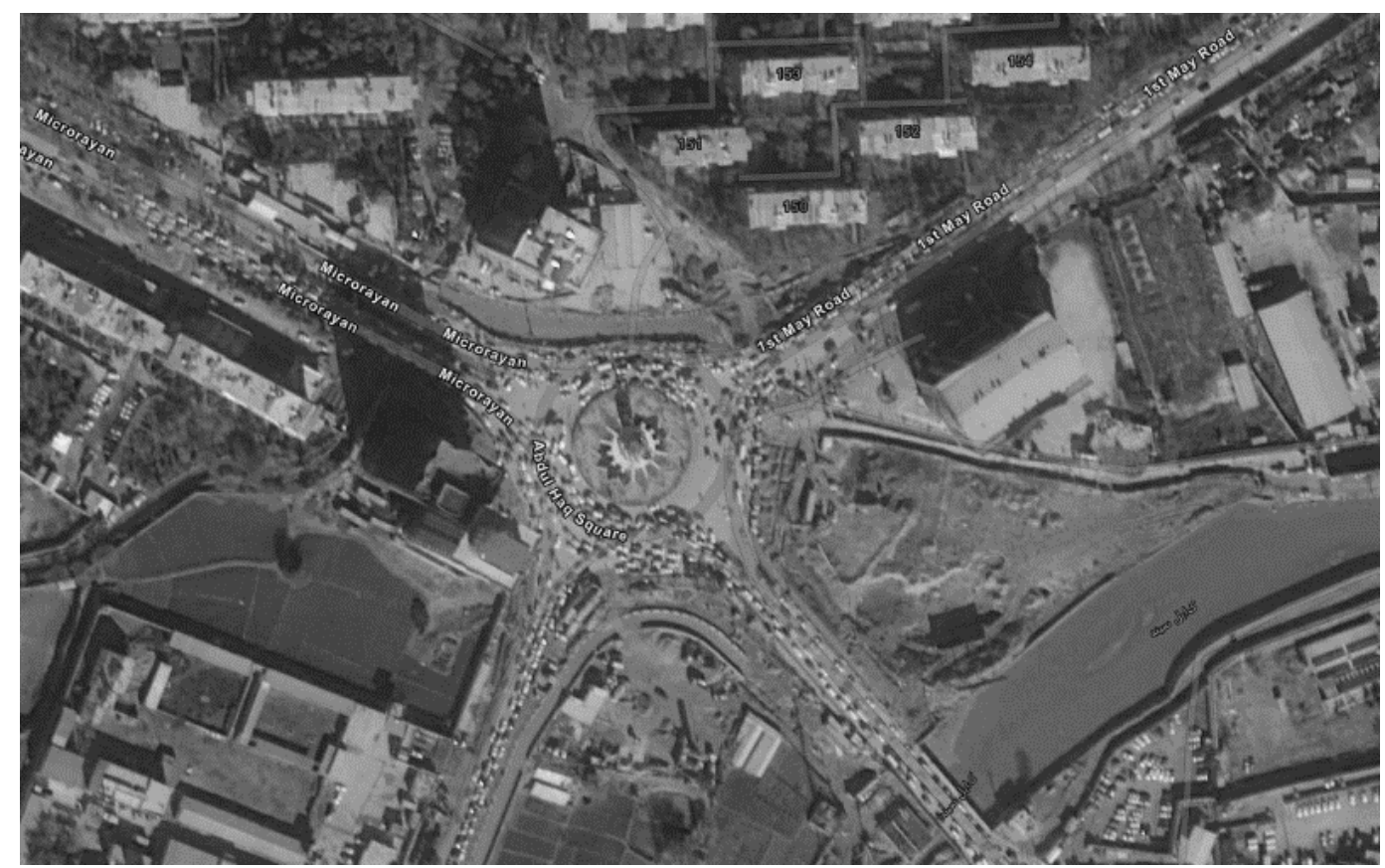

Figure 4.9: Abdul-Haq Traffic Circle

\subsubsection{Design and Modelling Abdul Haq Modern Roundabout}

The essence of the modern roundabout is to operate at lower speeds, which makes designers use smaller radiuses for the central island than traditional traffic circles. When converting traffic circles to modern roundabouts, this aspect provides extra space that can then be used to improve roundabout operational performance. In the study in Italy, the extra space from a large traffic circle was used to add a bypass right lane (slip lane) as part of the conversion process, which resulted in improved operational capacity [4]. I used the same approach of adding a by-pass lane on all approaches at this particular location. If the bypass lanes are deemed redundant, once analysis are repeated with accurate traffic flow and turning movement data in the future, they can be dropped in redesign.

There can be numerous geometric design alternatives for a roundabout. The geometric design used for the case study was developed based on NCHRP's guideline for Modern Roundabout. Figure 4.10 presents geometric design used for microsimulation analysis, followed by design parameters in Table 4.5. Appendix B includes the detail of radiuses used for concept design of the modern roundabout. 
Table 4.5: Design criteria and values for Abdul Haq simulation

\begin{tabular}{|c|c|c|c|}
\hline S.N & Design parameter & Value & Criteria \\
\hline 1 & Central Island & 35 meters & $\begin{array}{l}\text { No criteria, adjusted to } \\
\text { control speeds in } \\
\text { roundabout }\end{array}$ \\
\hline 2 & Inscribed circle & 59.6 meters & 46 67 meters \\
\hline 3 & $\begin{array}{l}\text { Circulatory roadway } \\
\text { width }\end{array}$ & 9.8 meters & 8.5 9.8 meters \\
\hline 4 & $\begin{array}{l}\text { No. of lanes on each } \\
\text { approach }\end{array}$ & 2 & $\begin{array}{l}\text { Suggest from measured } \\
\text { width of approach } \\
\text { upstream. }\end{array}$ \\
\hline 5 & No. of circulatory lanes & 2 & $\begin{array}{l}\text { Suggested based on the } \\
\text { number of entering lanes }\end{array}$ \\
\hline 7 & Entry Speed & $\begin{array}{l}\text { Less than } 40 \\
\mathrm{Km} / \mathrm{hr} \text {. on all } \\
\text { approaches }\end{array}$ & $40 \sim 50 \mathrm{Km} / \mathrm{hr}$ \\
\hline 8 & No. of legs & 4 & As per aerial images \\
\hline 9 & Approach lane width & 3.6 & $\begin{array}{l}\text { Typical recommended } \\
\text { width in urban areas. }\end{array}$ \\
\hline 10 & Entry width & 3.6 & $3.6 \sim 4.6$ meters \\
\hline
\end{tabular}




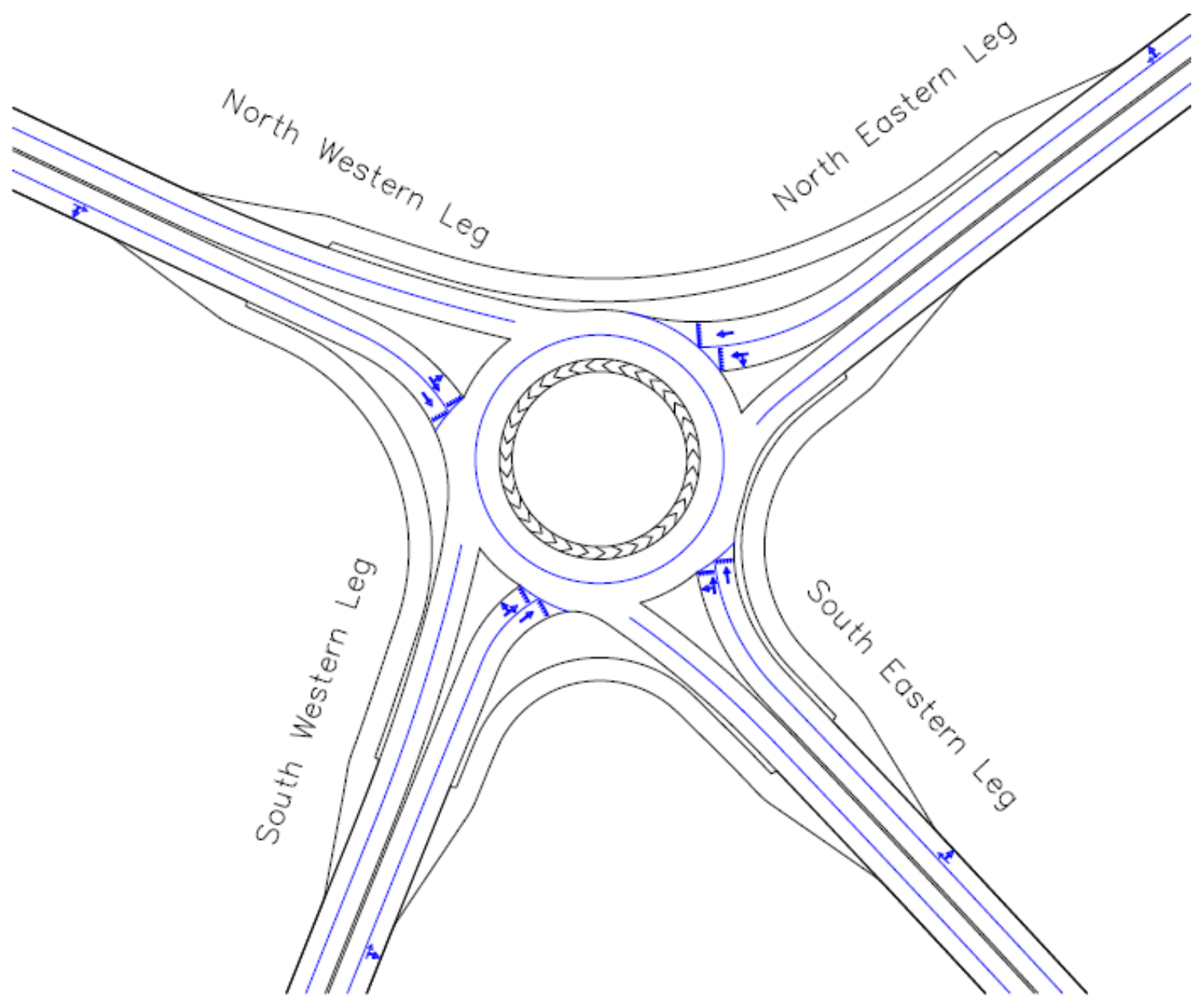

Figure 4.10: Concept Modern Roundabout at Abdul-Haq Traffic Circle

Five traffic scenarios with varying flow rates and relative turning percentages were identified for the analysis (Table 4.6). Each scenario was run for five different flow rates with 200 vehicles per hour (vph) increments while the turn movement percentages were held static. All but one scenario used balanced distribution of major and minor flows. In total, 25 simulations were run.

As shown in Figure 4.11, the model for microsimulation analysis is drawn based on the concept design of Figure 4.10. Figure 4.12 shows the centerlines of vehicle travel paths through the simulated roundabout. 
Table 4.6: Scenarios for Simulations Based on Entry Flow Rate, Relative Turning Movement

\begin{tabular}{|c|c|c|c|c|c|c|c|c|c|}
\hline \multirow[t]{2}{*}{ S.N } & \multirow{2}{*}{$\begin{array}{l}\text { Simulation } \\
\text { Name }\end{array}$} & \multicolumn{5}{|c|}{ Turn Movement Percent } & \multirow{2}{*}{$\begin{array}{c}\text { Flow } \\
\text { Balance on } \\
\text { Minor and } \\
\text { Major }\end{array}$} & \multirow[t]{2}{*}{ Flow Rate } & \multirow{2}{*}{$\begin{array}{c}\text { No. of } \\
\text { Simula } \\
\text { tions }\end{array}$} \\
\hline & & Right & $\begin{array}{l}\text { Right- } \\
\text { Bypass }\end{array}$ & Through & Left & $\begin{array}{c}\text { U- } \\
\text { Turn }\end{array}$ & & & \\
\hline 1 & $\begin{array}{l}\text { Moderate } \\
\text { Right, Low } \\
\text { Left, Balanced } \\
\text { Flow. }\end{array}$ & $2.5 \%$ & $20 \%$ & $60 \%$ & $15 \%$ & $2.5 \%$ & Balanced & $\begin{array}{l}600(\mathrm{vph}) \text { to } 1400(\mathrm{vph}) \\
200(\mathrm{vph}) \text { increment. }\end{array}$ & 5 \\
\hline 2 & $\begin{array}{l}\text { High Right, } \\
\text { Moderate Left, } \\
\text { Balanced } \\
\text { Flow. }\end{array}$ & $2.5 \%$ & $35 \%$ & $35 \%$ & $25 \%$ & $2.5 \%$ & Balanced & $\begin{array}{l}600(\mathrm{vph}) \text { to } 1400(\mathrm{vph}) \\
200(\mathrm{vph}) \text { increment. }\end{array}$ & 5 \\
\hline 3 & $\begin{array}{l}\text { Moderate } \\
\text { Right, Low } \\
\text { Left, } \\
\text { Unbalanced } \\
\text { Flow. }\end{array}$ & $2.5 \%$ & $20 \%$ & $60 \%$ & $15 \%$ & $2.5 \%$ & Unbalanced & $\begin{array}{l}600 \text { (vph) to } 1400 \text { (vph), } \\
200 \text { (vph) increment. With } \\
200 \text { (vph) difference btw } \\
\text { Major and Minor Rd. }\end{array}$ & 5 \\
\hline
\end{tabular}




\begin{tabular}{|c|c|c|c|c|c|c|c|c|c|}
\hline 4 & $\begin{array}{l}\text { High Right, } \\
\text { High Left, } \\
\text { Balanced } \\
\text { Flow. }\end{array}$ & $2.5 \%$ & $35 \%$ & $25 \%$ & $35 \%$ & $2.5 \%$ & Balanced & $\begin{array}{l}600(\mathrm{vph}) \text { to } 1400(\mathrm{vph}), \\
200(\mathrm{vph}) \text { increment. }\end{array}$ & 5 \\
\hline 5 & $\begin{array}{l}\text { High Right, } \\
\text { Moderate Left, } \\
\text { Balanced } \\
\text { Flow. (No } \\
\text { Bypass) }\end{array}$ & $37.5 \%$ & $0 \%$ & $35 \%$ & $25 \%$ & $2.5 \%$ & Balanced & $\begin{array}{l}600(\mathrm{vph}) \text { to } 1400(\mathrm{vph}), \\
200(\mathrm{vph}) \text { increment. }\end{array}$ & 5 \\
\hline
\end{tabular}




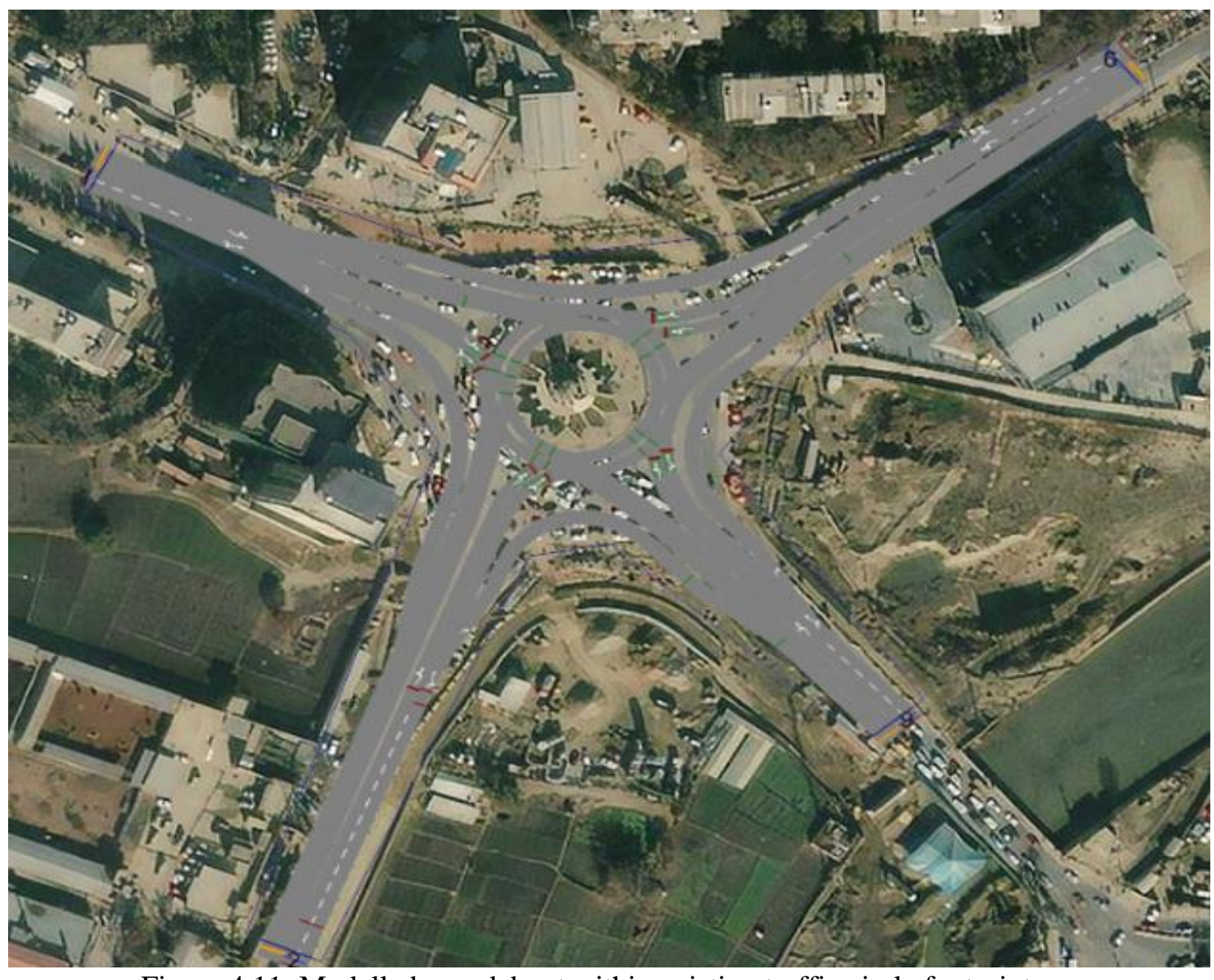

Figure 4.11: Modelled roundabout within existing traffic circle footprint 


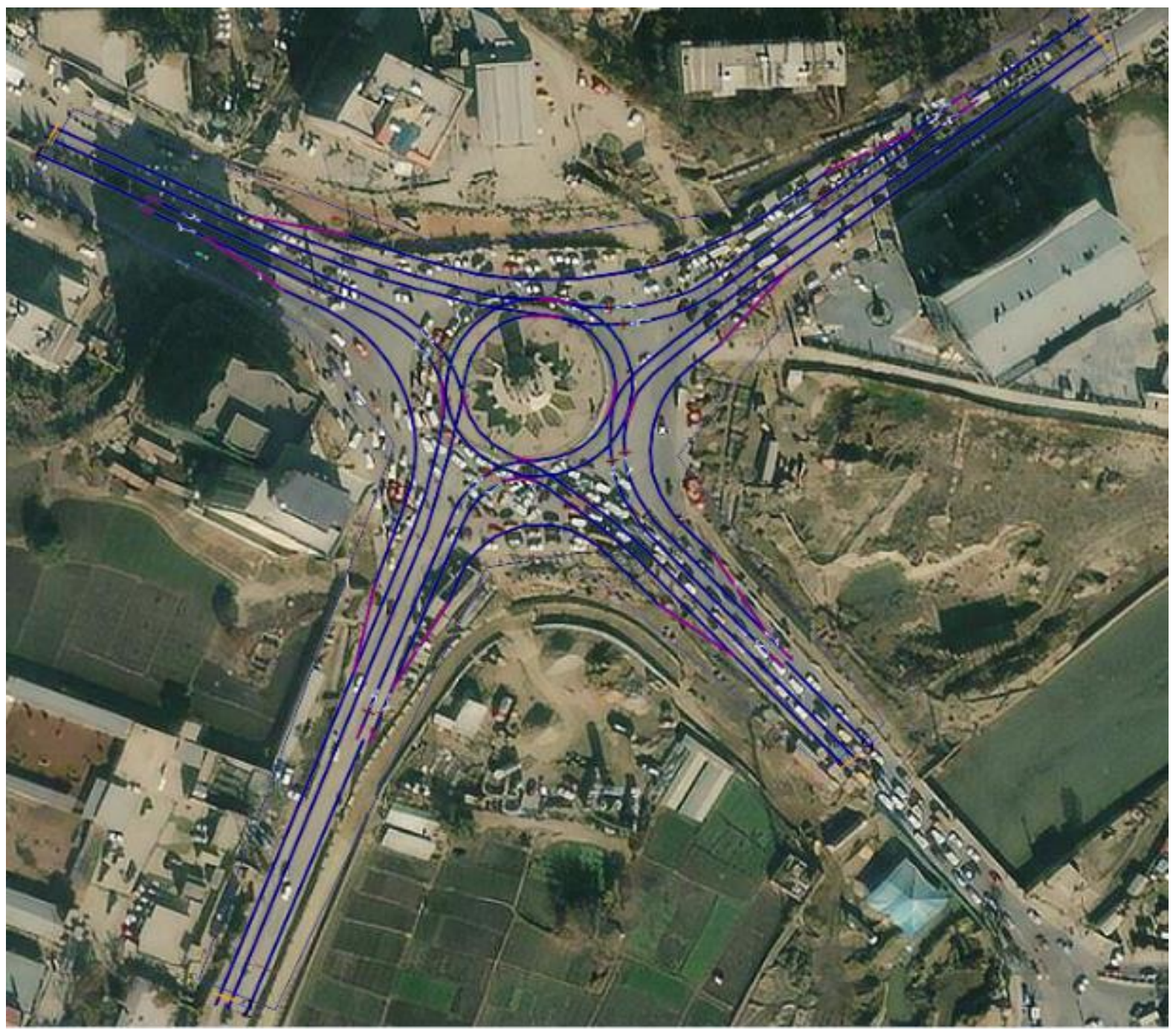

Figure 4.12: The cent6fline of the travel path. 


\subsubsection{Microsimulation Results:}

The results of the simulation runs were compared on the following inputs:

- Total Roundabout Throughput

- Average Vehicle Delay

- Average Queue Length

- Roundabout Maximum Queue Length

\subsubsection{Vehicle Throughput}

Throughput is defined as the number of vehicles successfully exiting the system within the simulation period, which in our case is one hour. Figures (4.12 to 4.16) present throughput for each of the scenarios as discussed in Table 4.5.

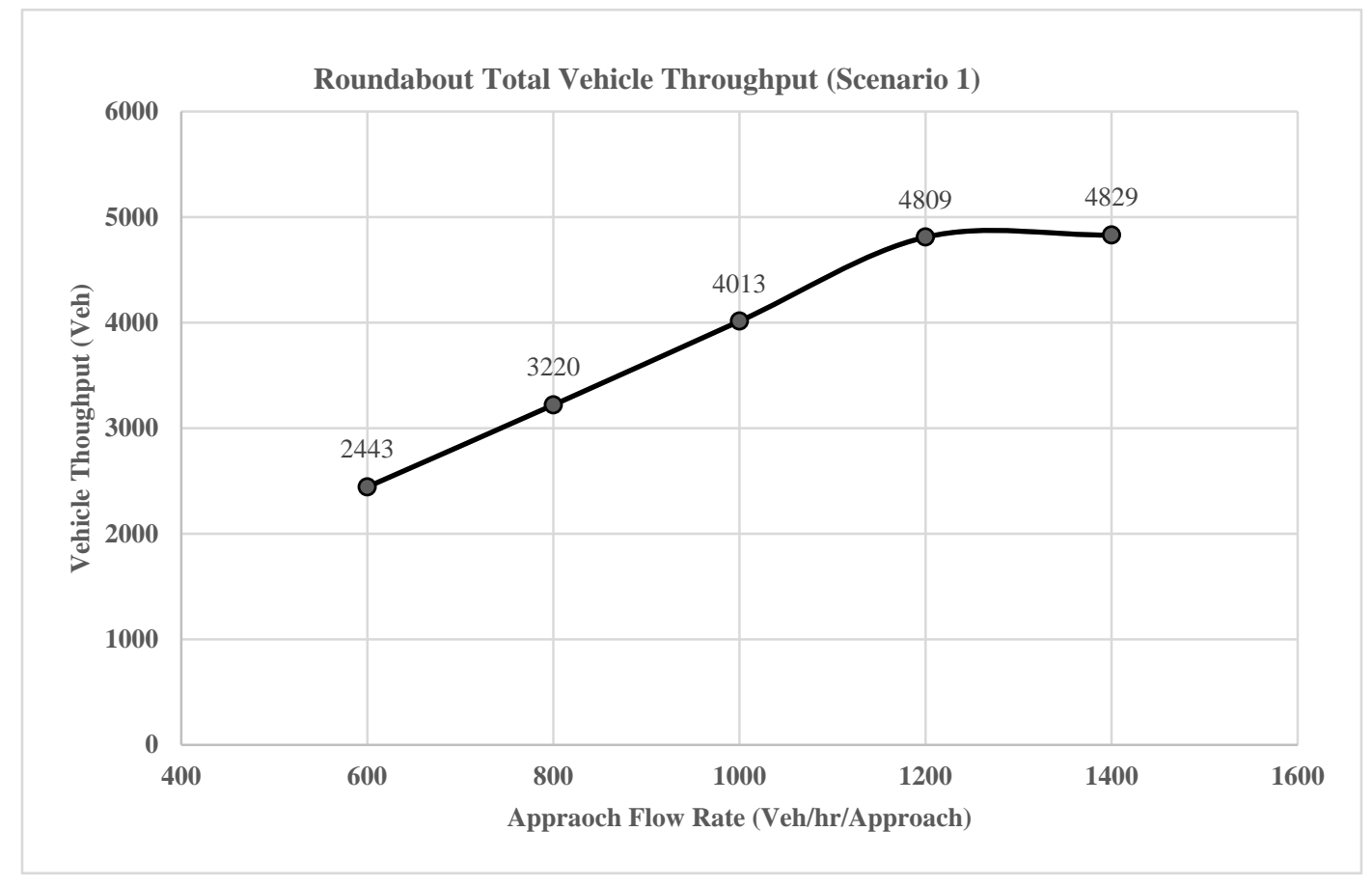

Figure 4.13: Average Throughput Result for Scenario (1) 


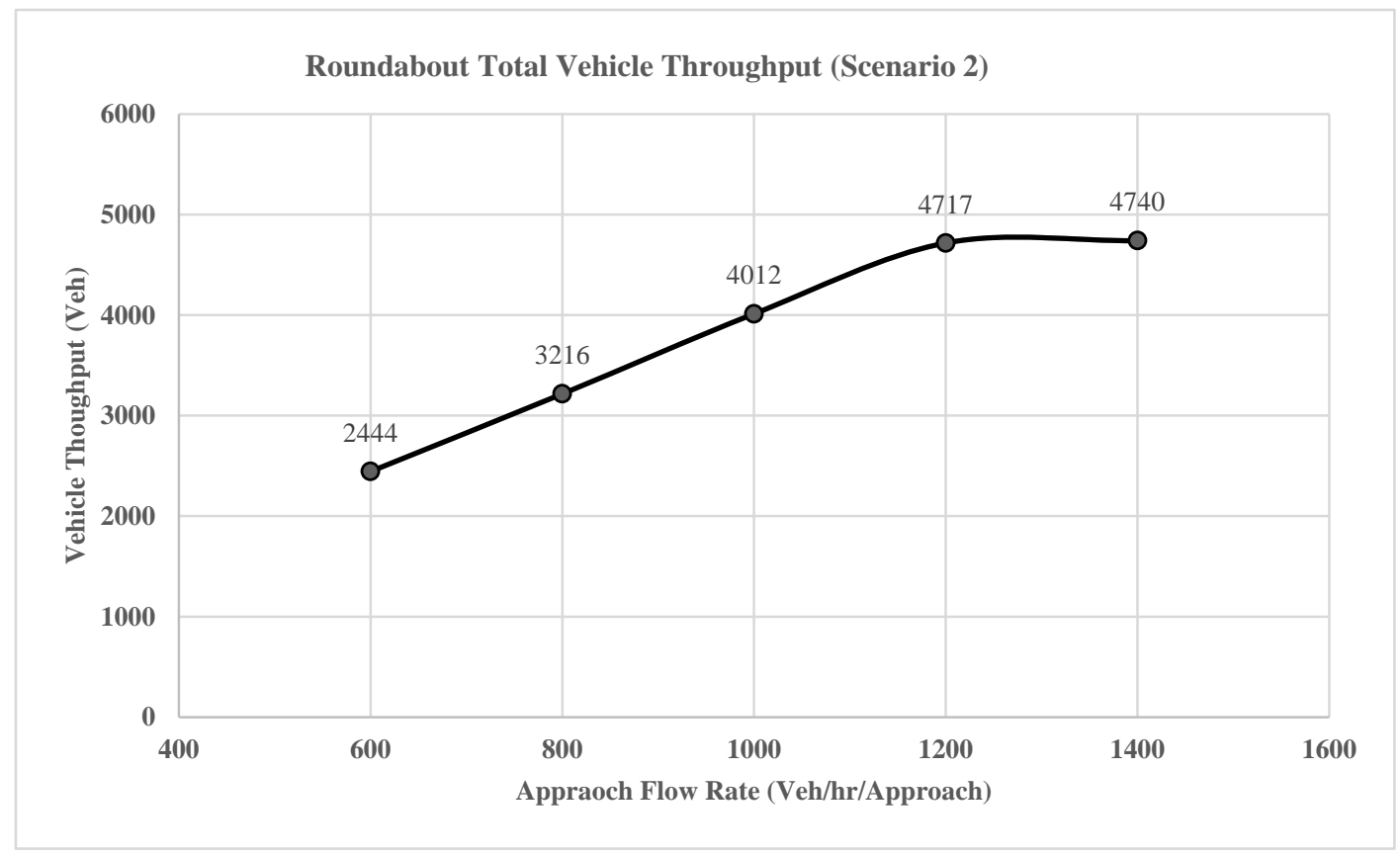

Figure 4.14: Average Throughput Result for Scenario (2)

Roundabout Total Vehicle Throughput (Scenario 3)

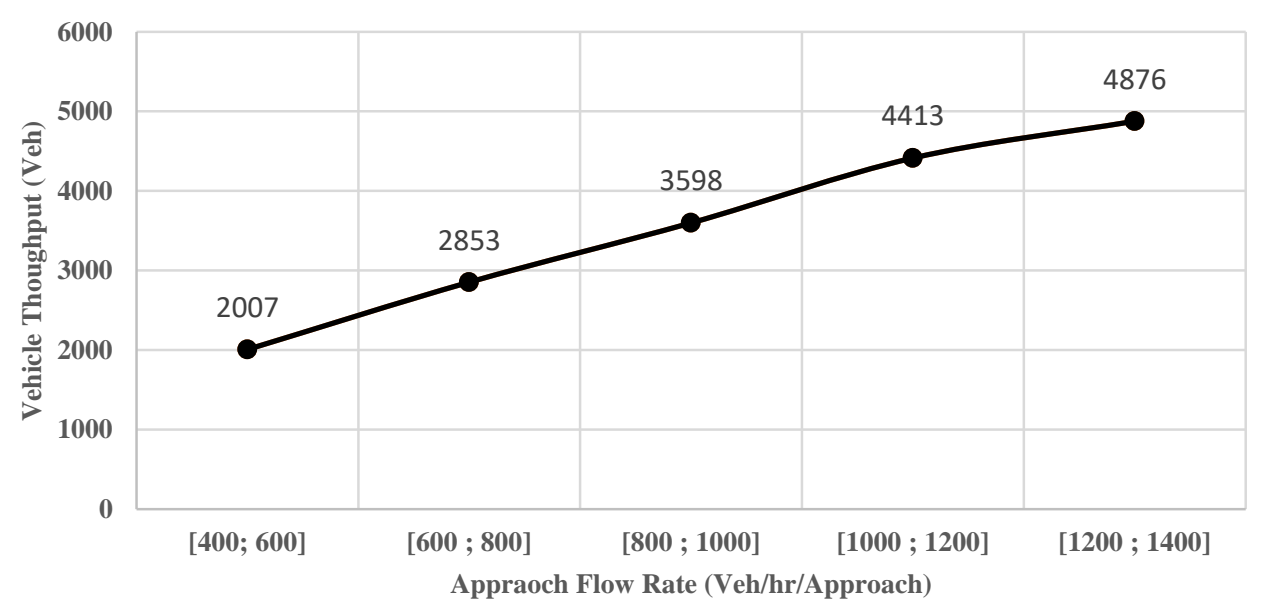

Figure 4.15: Average Throughput Result for Scenario (3) 


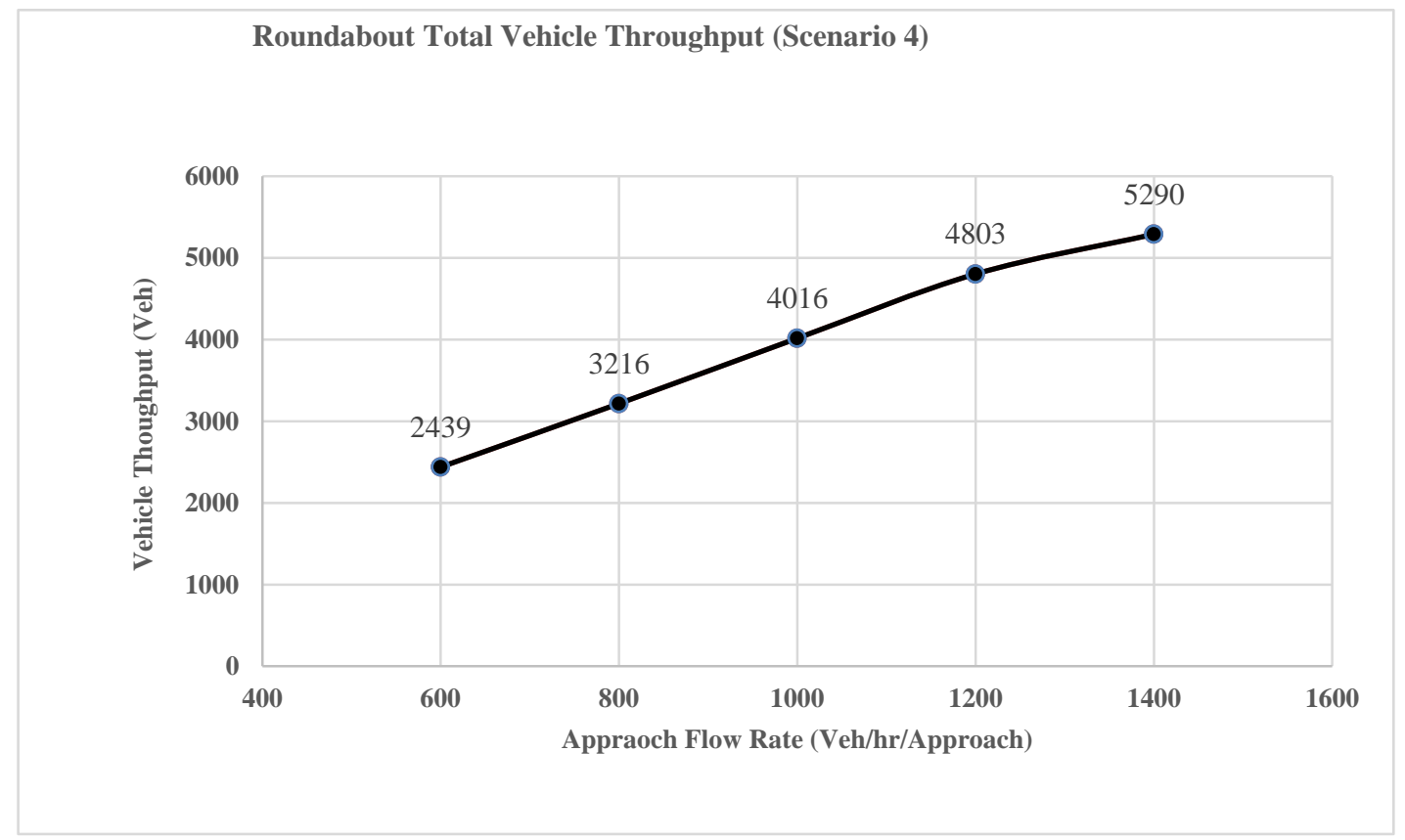

Figure 4.16: Average Throughput Result for Scenario (4)

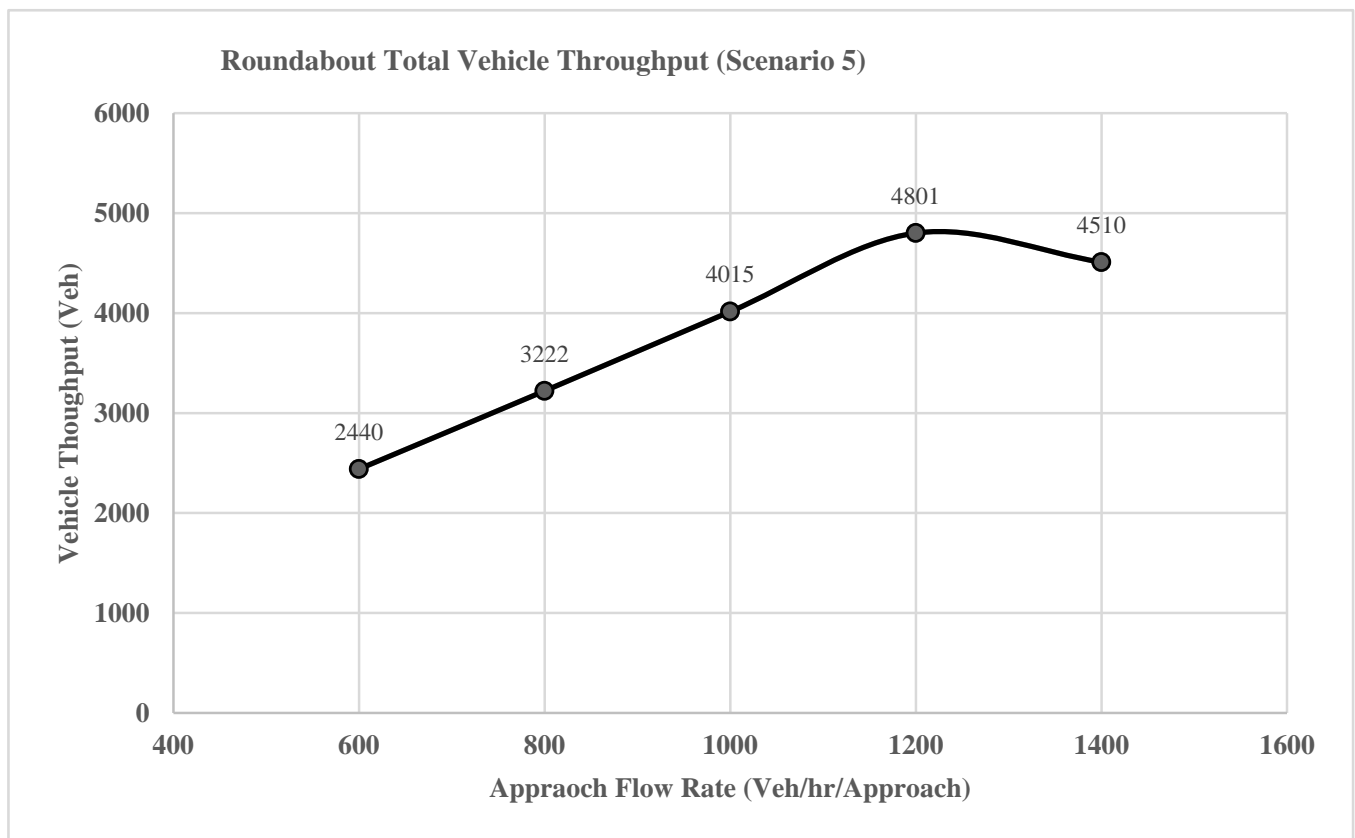

Figure 4.17: Average Throughput Result for Scenario (5) 
From the Figures we can see that:

- In most scenarios (1, 2, and 5), throughput rates increase in a linear fashion up to a certain approach flow volume and then either stop growing or start declining. In these scenarios the throughput growth stopped around 4,800 vehicles per hour, or 1,200 (vph) per approach.

- Under scenario 4 (high left turn), the throughput continues to increase at flow rates beyond 1,200 (vph). Scenario 3 (unbalanced flow) behaves the same, but throughput increases at a slower rate

- In our case study, the addition of a bypass lane had limited effect on throughput (Scenario 2 and 5). 


\subsubsection{Average Queue Delay Results.}

Figures (4.17 to 4.21) show average queue delay for each of the five scenarios. The average queue delay is presented as the arithmetic mean of delays generated at each approach leg. The corresponding level of service (LOS) has also been highlighted in the figures.

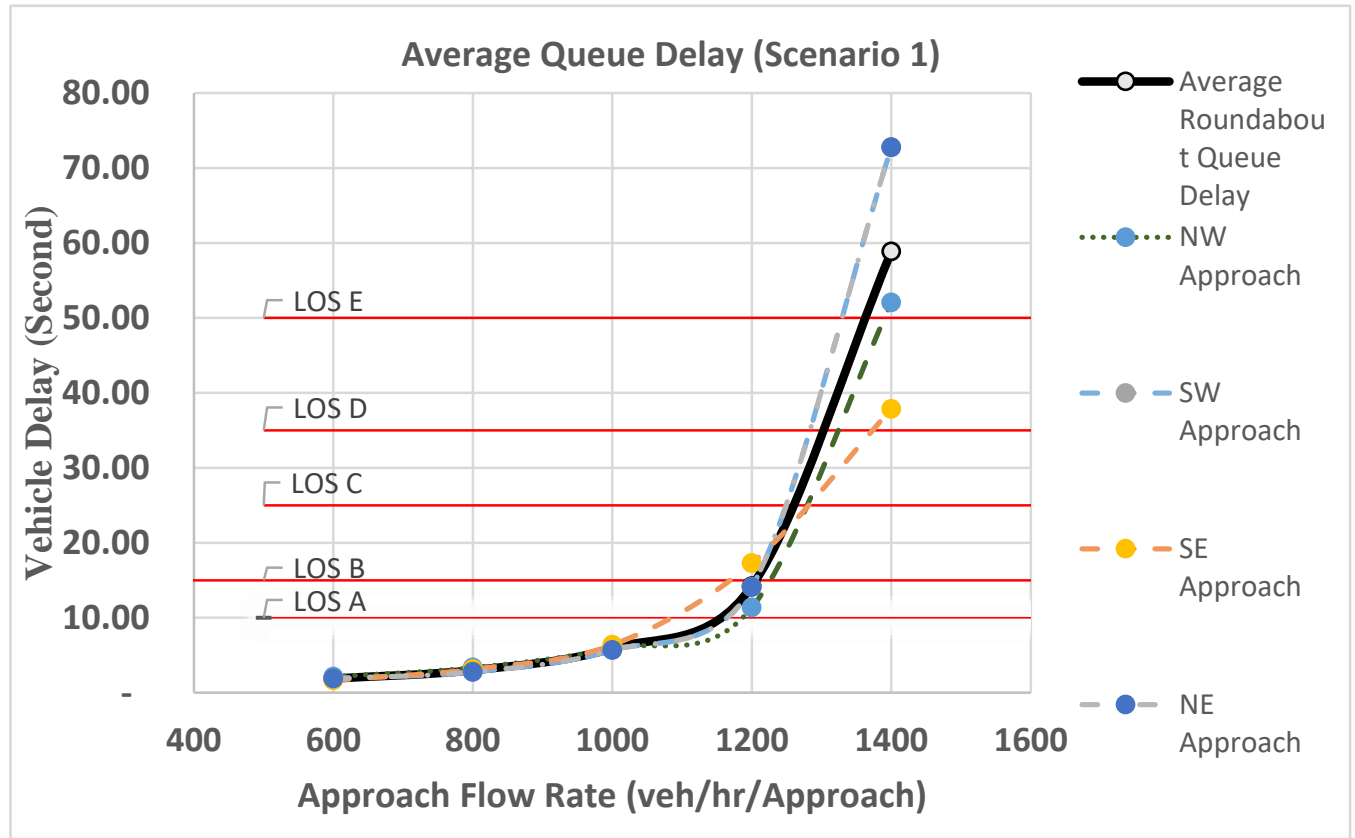

Figure 4.18: Average Queue Delay for Scenario (1)

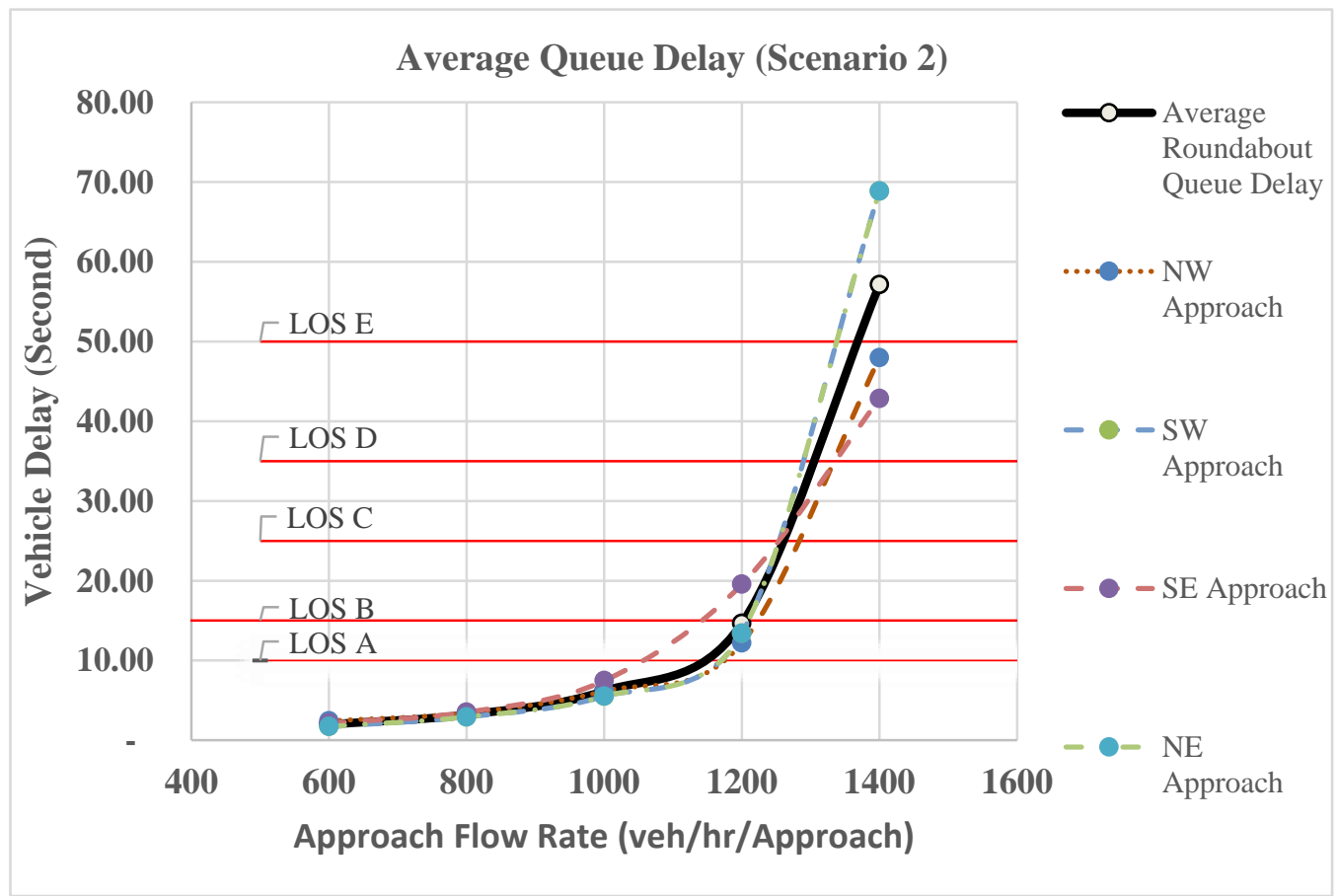

Figure 4.19: Average Queue Delay for Scenario (2) 


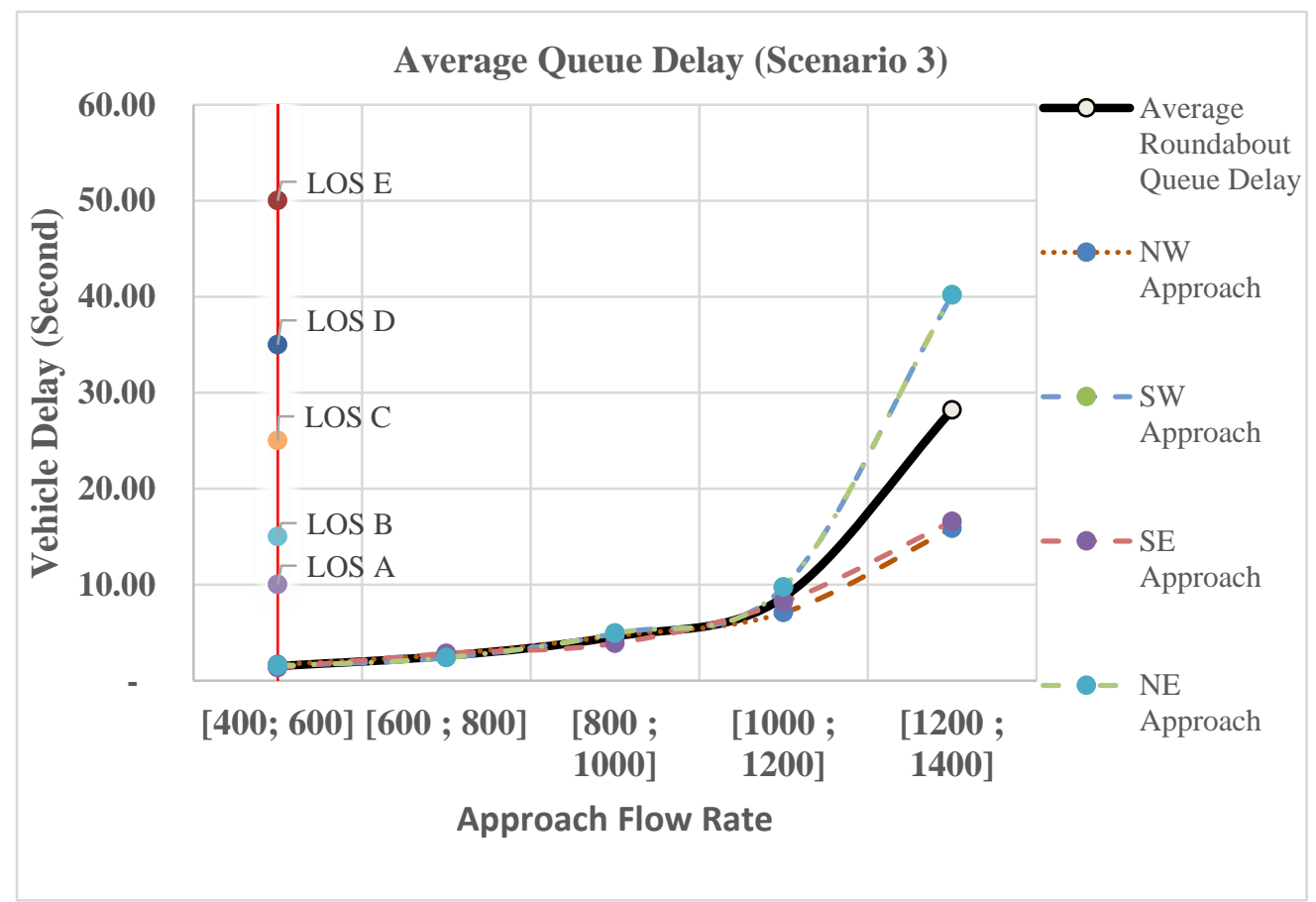

Figure 4.20: Average Queue Delay for Scenario (3)

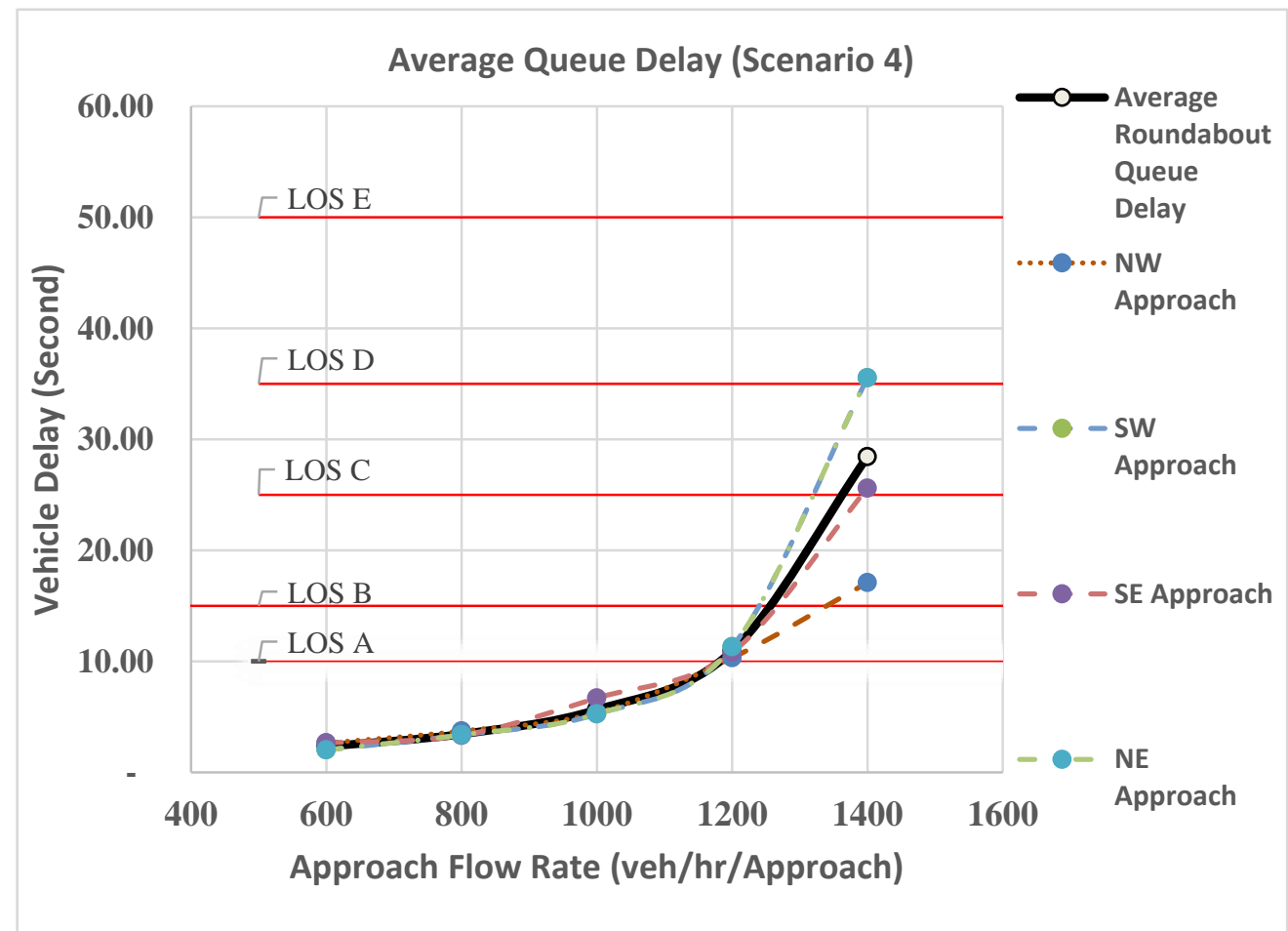

Figure 4.21: Average Queue Delay for Scenario (4) 


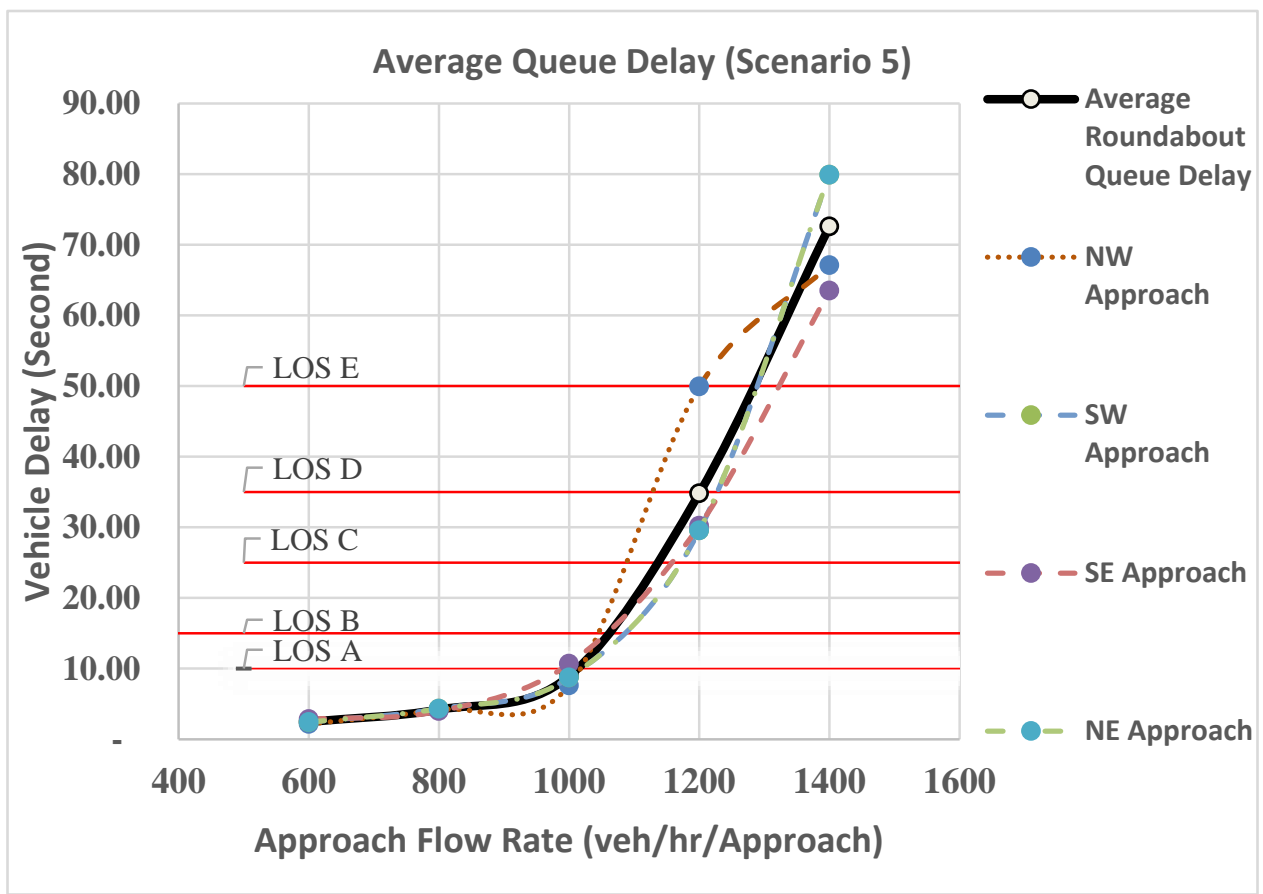

Figure 4.22: Average Queue Delay for Scenario (5)

The figures reveal that:

- Scenarios 1, 2, 3, and 4 show dramatic increase in average queue delay at a flow rates beyond 1,200 (vph), while the abrupt increase in average queue delay for scenario 5 (without bypass lane) starts already at a lower flow rate of 1,000 (vph).

- Scenarios 1, 2, and 5 reach excessive delays or LOS "F" at flow rate 1,400 (vph), while scenario 3 (with unbalanced flow) and scenario 4 (high left turns) perform at acceptable LOS even at 1,400 (vph).

\subsubsection{Average Queue Length Results.}

Figures (4.22 to 4.26 ) show the average queue lengths for each of the five scenarios. The average queue length is considered as the arithmetic mean of average queue length generated on each approach during the simulation time period. 


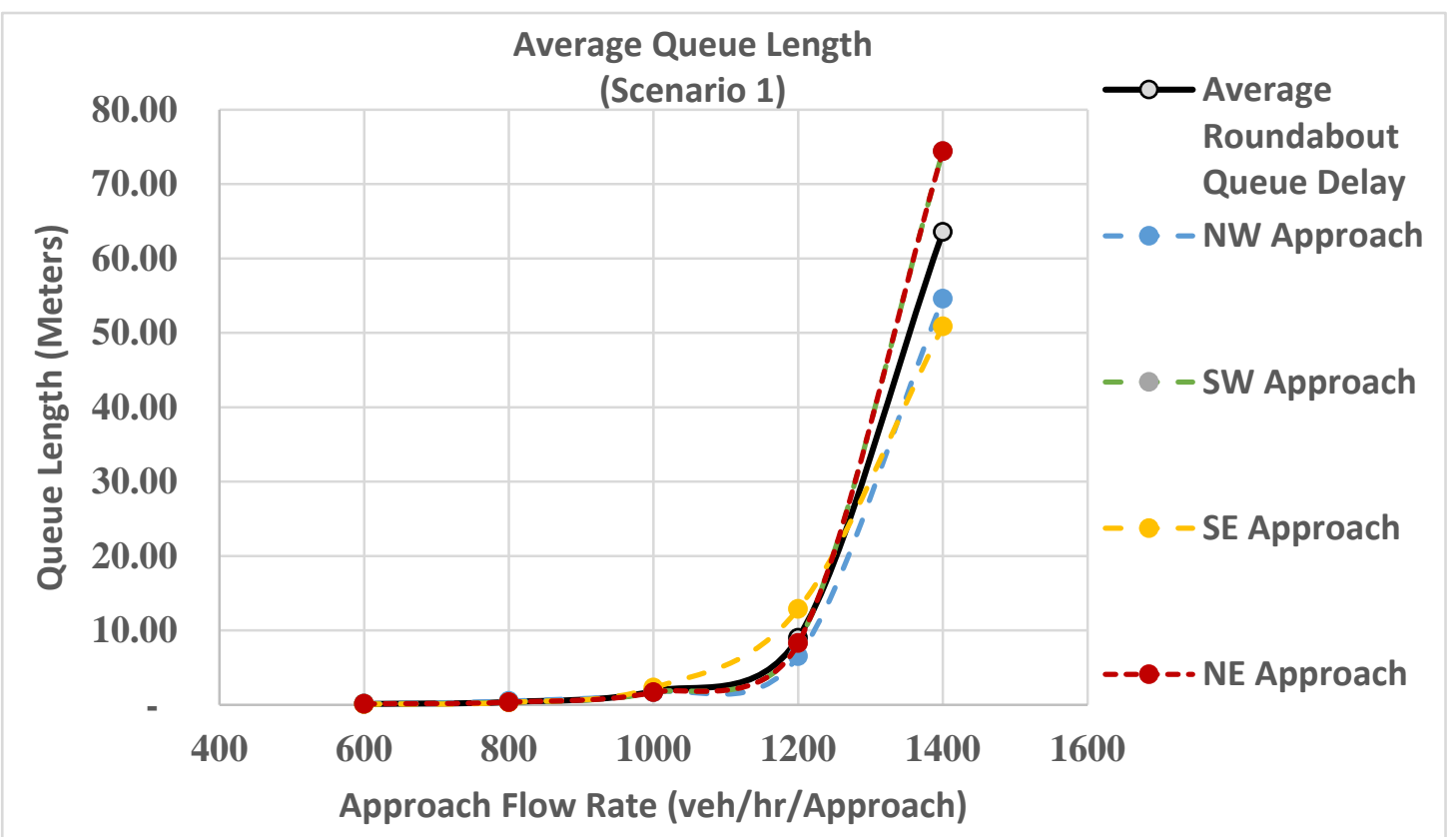

Figure 4.23: Average Queue Length for Scenario (1)

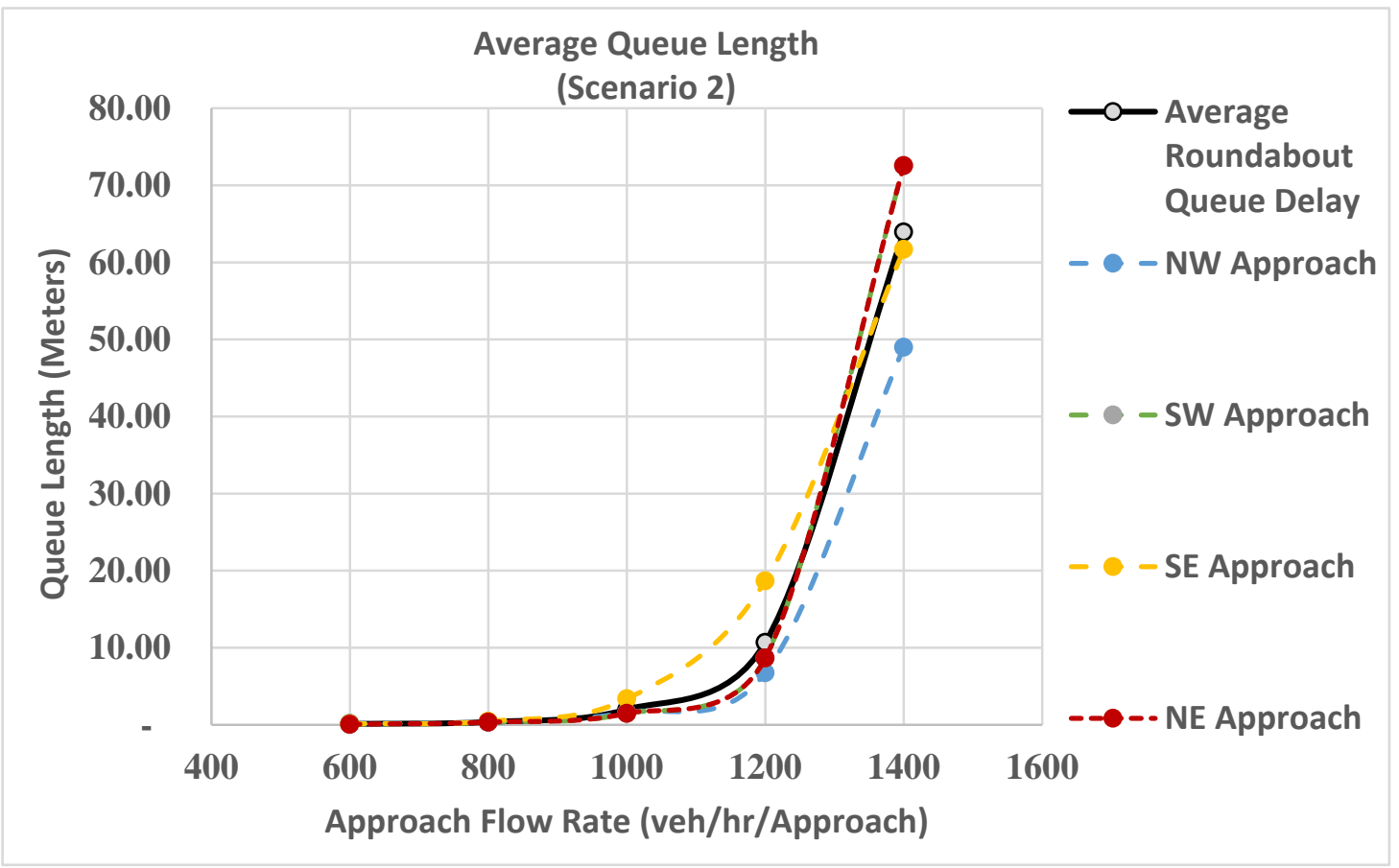

Figure 4.24: Average Queue Length for Scenario (2) 


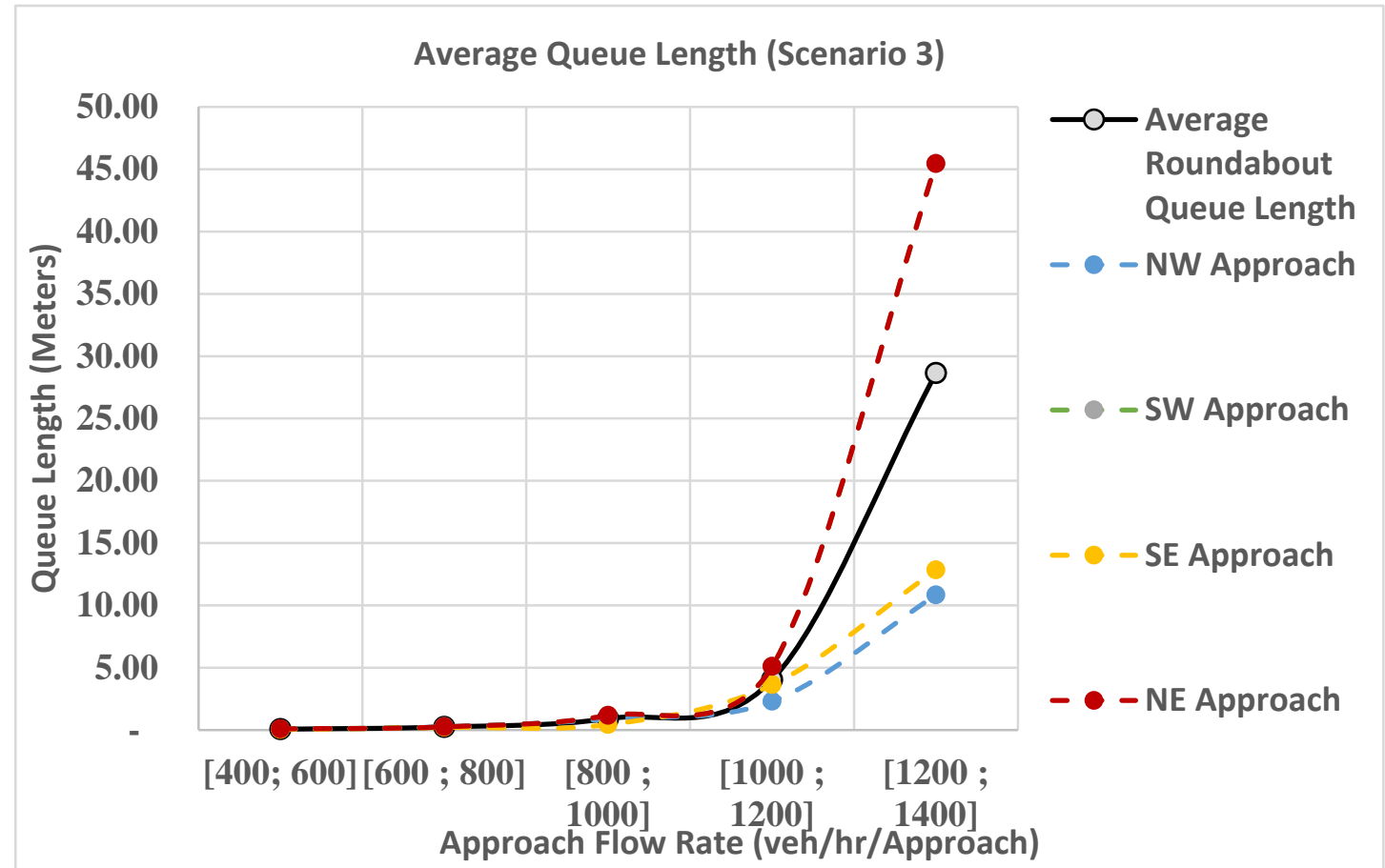

Figure 4.25: Average Queue Length for Scenario (3)

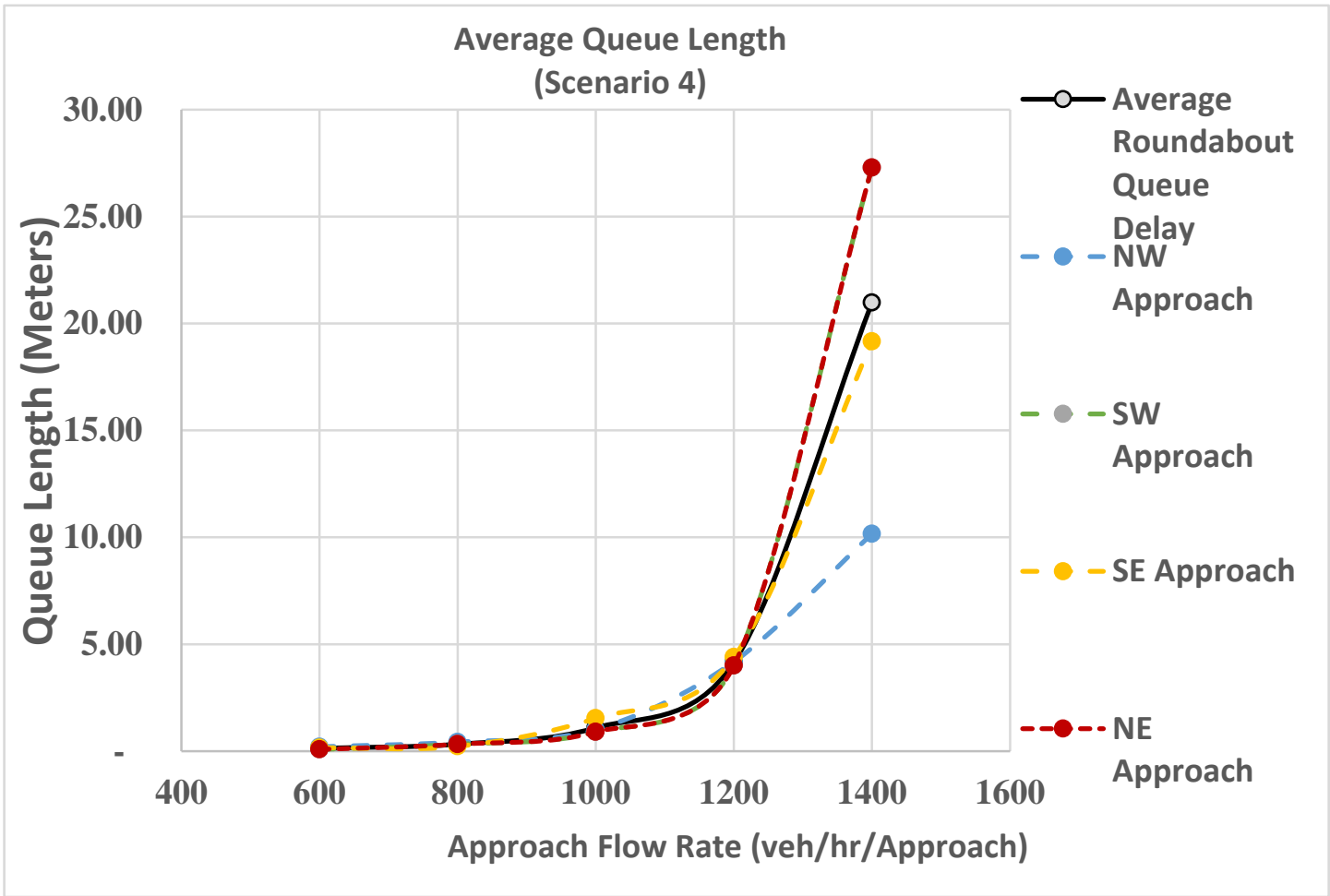

Figure 4.26: Average Queue Length for Scenario (4) 


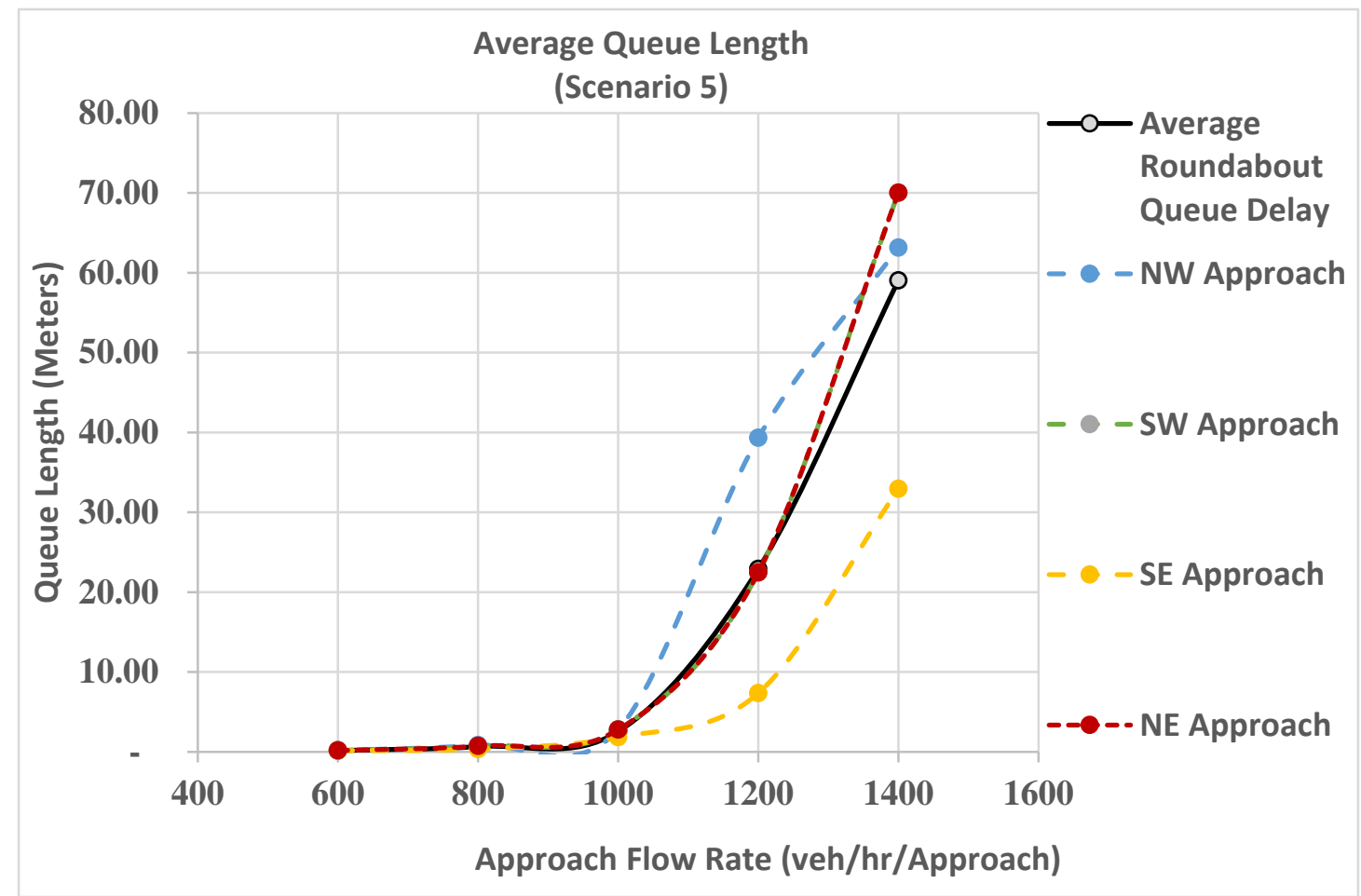

Figure 4.27: Average Queue Length for Scenario (5)

The figure shows that:

- For scenarios 1, 2, 3, and 4, the average queue length at 1,200 (vhp) is no more than 10 meters, while for scenario 5, at 1,200 (vhp), the average queue is more than 20 meters.

- Scenarios 1, 2, 3, and 4 have a sharp increase in average queue length after 1,200 (vhp). In scenario 5, the sharp increase starts already at 1,000 (vhp). 


\subsubsection{Maximum Queue Length:}

Maximum queue length is the longest queue achieved at some point of the simulation time. It can decide if the storage space can cause spillback to the nearest intersection. Figure (14.28 to 14.32) show the maximum queue for each scenario and flow rate.

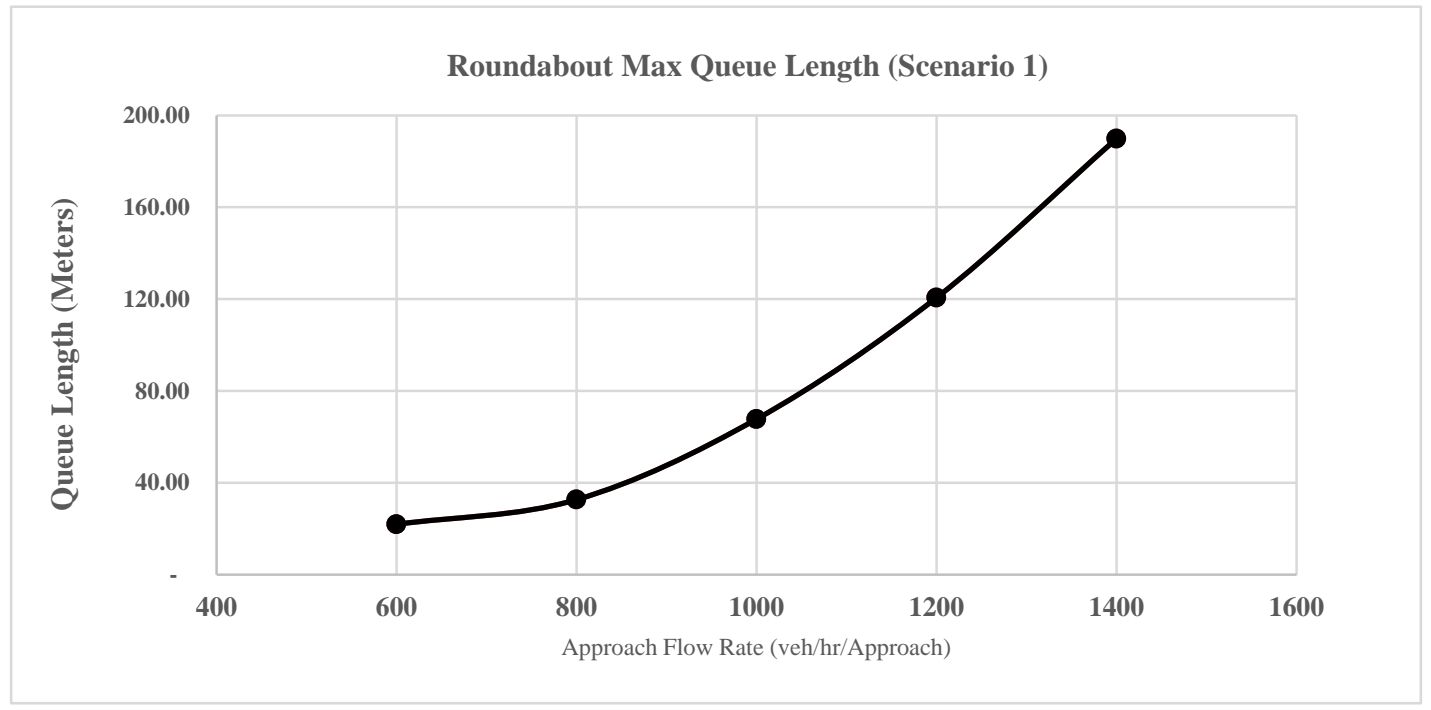

Figure 4.28: Maximum Queue Length for Scenario (1)

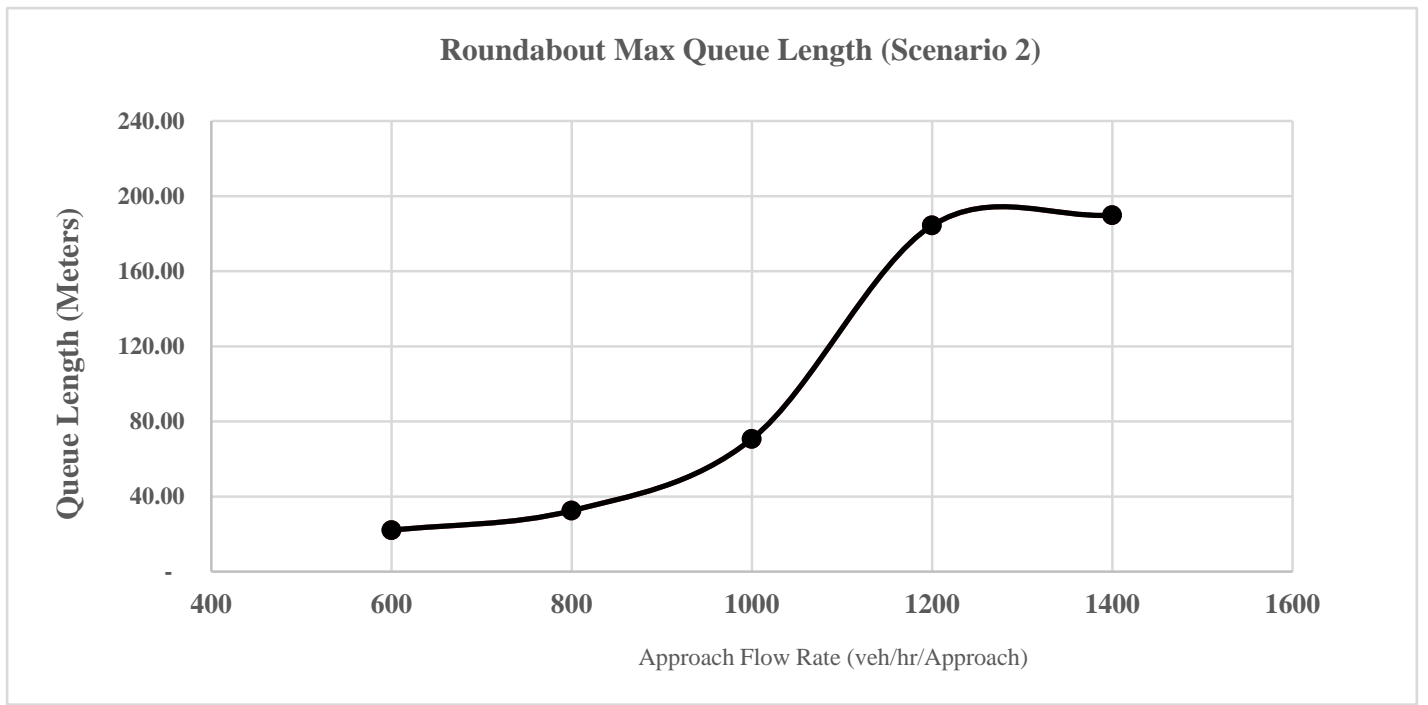

Figure 4.29: Maximum Queue Length for Scenario (2) 


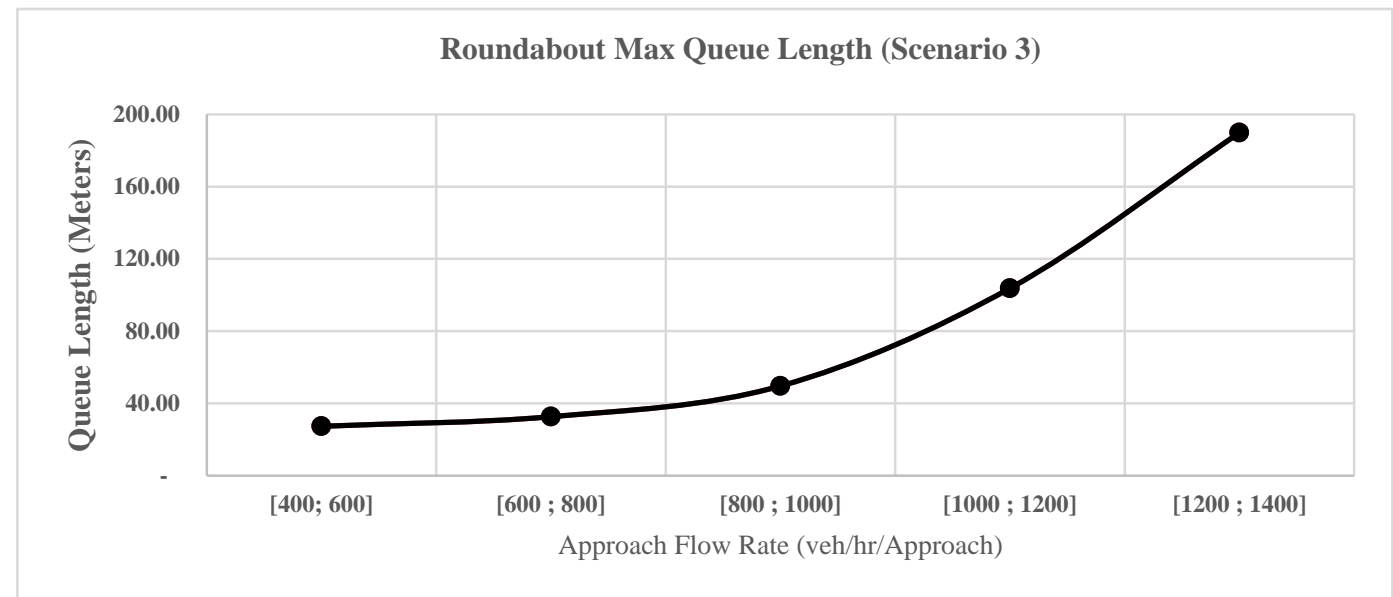

Figure 4.30: Maximum Queue Length for Scenario (3)

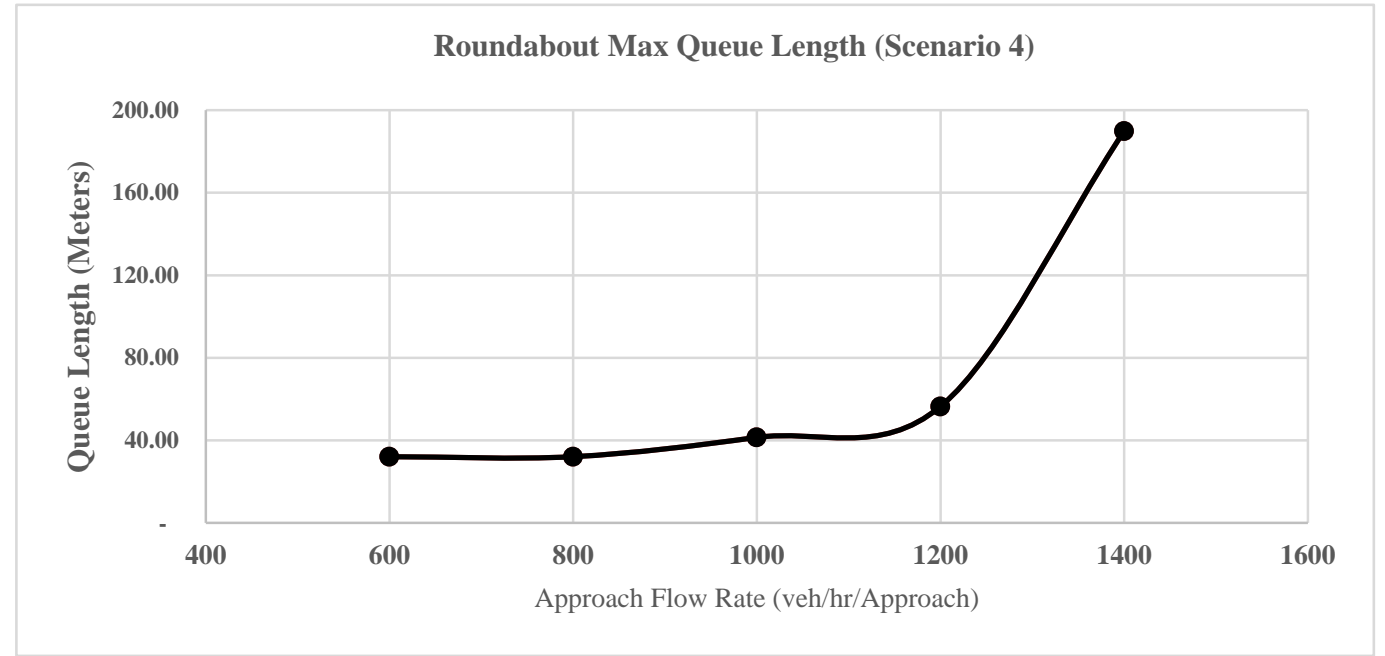

Figure 4.31: Maximum Queue Length for Scenario (4)

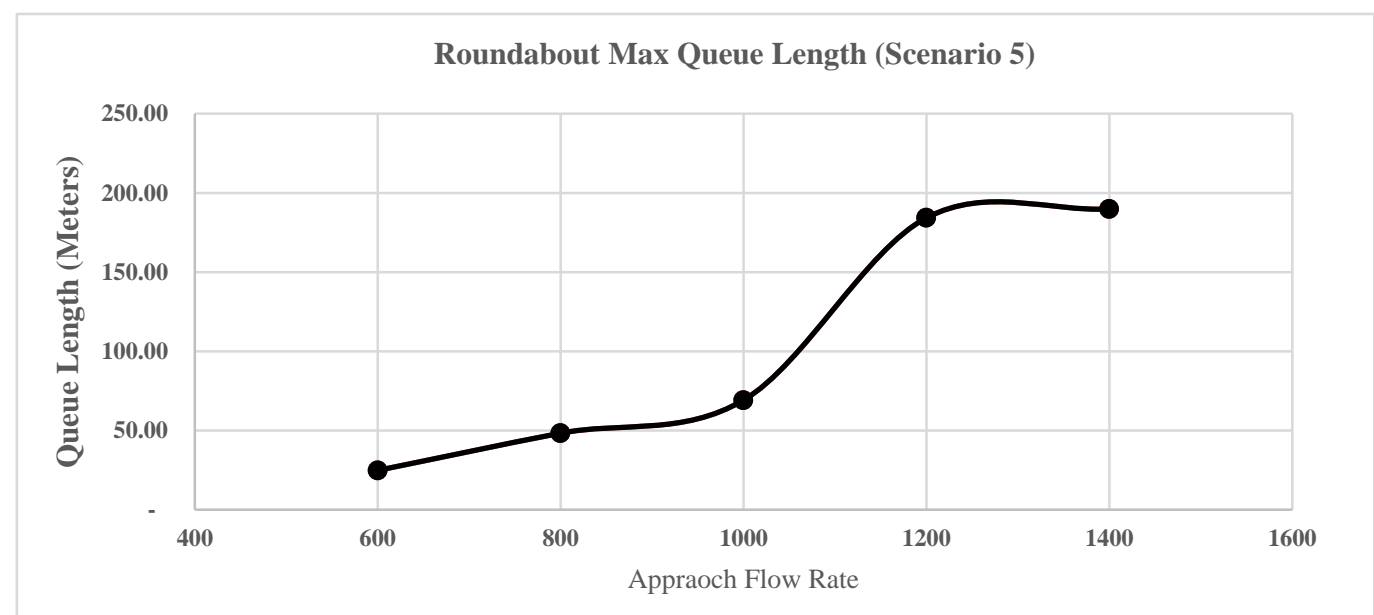

Figure 4.32: Maximum Queue Length for Scenario (5) 
The figures reveal that:

- In scenarios 1, 3 and 4, the queue lengths grow almost exponentially when compared to flow rates, but there are clear differences in how rapidly queues develop between scenarios. In scenarios 2 and 5 the growth is faster than in the other scenarios, but it levels off at approximately 1,200 vph flow rate.

- All scenarios reach queue lengths of approximately 200 meters in the simulation.

Overall the VISSIM case study shows that changes in input parameters can cause significant differences in the output values and roundabout performance. In my analysis, for throughput, all scenarios performed fairly well up to 1,200 veh/hr/approach flow rate, although the growth rate of queues/delays, etc. vary between scenarios. Since actual input values needed for the simulation were not available, the results should not be used as the basis of capacity analysis for any specific location (including Abdul Haq), but they are rather provided as illustration on how changes in configurations and input parameters impact the performance. 


\section{Conclusions and Recommendation for Future Work}

Circular intersections, in the form of traffic circles and rotaries, were built around the world in the first half of the twentieth century. However, with the rise in traffic flow, regular traffic congestion and accidents forced authorities to look for alternative solutions and in many cases, signalized intersections became the preferred alternative. In the 1960s, the UK introduced concept of modern roundabouts and a new set of priority rules for the circulating traffic. Since the inception of modern roundabouts, they have enhanced both operational and safety aspects at these locations, proving that circular intersections can still exist in urban transportation networks.

Kabul City, Afghanistan, has had more than 30 traditional traffic circles and rotaries, ranging from as large as over 100 meters (330 feet) in inscribed diameter to as small as 30 meters (100 feet). Regular traffic congestion has long been a problem. Recently, more than ten of them have been updated, but instead of considering modern roundabouts, the solution has been signalized intersection. The primary objective of this research was to understand the situation with Kabul's current traffic circles and rotaries and initiate an inquiry whether modern roundabouts could be a suitable, or even preferred alternative for updating at least some of them. Past literatures have shown that large traffic circles or rotaries can be converted to modern roundabouts by improving their geometries and eventually enhancing both operation and safety.

The first step of research used geometric data of current traffic circles and rotaries. In the second step, this data was used in the preliminary analysis for a total of 21 traffic circles that still exist in Kabul City was used to develop a suitability score, based on size, shape and distance to the nearest intersections. Third step conducted a survey with Kabul engineers to further characterize the current traffic circles/rotaries and obtain their opinions on the suitability of modern roundabout as an improvement option. 13 engineers responded to the survey and one participated in a follow up interview. The final step included operational analysis of Abdul Haq traffic circle with PTV VISSIM simulation software. A concept design of a double lane modern roundabout with bypass right turning lane (according to NCHRP guidelines) was developed for the analysis. Since there was no actual operational data available for a detailed operational analysis, a sensitivity analysis was performed for a total of 25 simulations with five distinct turning movements and five flow rates.

Preliminary analysis provided clear evidence on the differences in geometric suitability of various traffic circles. While there was no science behind the method, it concentrated on geometric aspects that have proven to be important for effective roundabouts. The survey findings indicated poor traffic rules and aggressive driver's behavior as some of the reasons for current problems at traffic circles/roundabouts. The survey results showed an openness by Kabul engineers to consider modern roundabout as an option, although they also highlight the need to a more detailed data collection and analysis. In addition, the results also showed mixed opinions on whether the conversion to signalized intersections has significantly improved their performance, making consideration of 
modern roundabout alternative even more attractive. Finally, VISSIM analysis showed that there were some differences in performance between the scenarios. In most scenarios the performance deteriorated rapidly after certain threshold was reached. It also showed that modern roundabout with bypass lane performed better in terms of average queue length and delay when compared modern roundabout without bypass lane. In addition, results showed modern roundabout is more preferred when there is high proportion of left turns.

Overall, this study has provided a foundation to build upon when considering the suitability of modern roundabouts as a traffic circle/rotary replacement in Kabul, Afghanistan. There are still more than 20 of them left that need to be updated. The preliminary analysis showed that several of them possess characteristics that suggest their suitability for a modern roundabout conversion.

Based on the proven track record of modern roundabouts across the world and the results of this study, there is evidence that they should be considered as one alternative in Kabul. However, some of the limitations and shortcomings of my work should be recognized and addressed, including:

- One of the main data sources to existing traffic circles and rotaries were aerial images of Kabul. Since Kabul City does not have proper lane markings for approaches leading to traffic circles or rotaries, it was hard to properly find the number of lanes approaching per leg. The same is true inside the traffic circles where the lack of lane markings made it difficult to distinguish the number of lanes available.

- I did not have access to actual traffic input data for detailed operational analysis. Data such as peak hour traffic flow rate, turning movement percentages, and critical gap headway are critical variables that need to be collected or confirmed before accurate operational analysis and simulations can be conducted.

- Some of the traffic circles/rotaries located are near to other main intersections can create queue spillback. In our simulation case study, I presumed the Abdul Haq traffic circle as an isolated intersection but the effect of other intersections may result in different operational outcomes.

The future work should focus on following elements to further clarify the suitability of converting traffic circles/rotaries to modern roundabouts:

\section{Data Collection:}

- Peak hour flow rate, turning movement percentages, dimensions of large vehicles, possible number of circulatory and approach lanes of existing traffic circles/rotaries are fundamental data that needs to be collected prior any analysis procedure.

- The need for better understanding of driver's behavior and gap acceptance in Kabul, for example drivers responses to priority rules at the entrance of existing 
traffic circles. Such values are needed to determine critical gap or minimum gap that Kabul users accept, one important factor in analysis. The values determined through local efforts in Kabul can also be compared with ones used in similar regions, if those are available.

- In addition to adding yields signs, it is important to investigate the tools and methods to make road users aware from the importance of the priority rights in circular intersection. Recorded videos and questionnaires can be part of research tools.

Comparative Studies:

- The decision making process needs to include the value a modern roundabout adds in terms of safety and performance. Since Kabul has recent experience in converting traffic circles/rotaries to signalized intersections, implementing a single modern roundabout and then comparing with signalized intersection(s) would offer interesting case study. Both the estimated cost of life and crashes, as well as impacts on traffic performance could be compared for both modern roundabout and signalized intersection.

- Another comparative study could compare implemented modern roundabout elsewhere in the region (if available) and the benefits associated..

Modern roundabout amongst Kabul transportation policies and plans:

- Whether a modern roundabout can fit transportation system of Kabul City under the current policies and future plans of Kabul Municipality is also an area that needs investigation. How the city changes in terms of road network and how that shapes the traffic conditions in future will have impact on the applicability of modern roundabouts. Some areas might become better candidates in the future plans while others might lose their suitability.

- Since the suitability of modern roundabouts depends on traffic volumes, the number of cars in traffic is critical for their performance. Hence, Kabul's public transportation system is relevant for roundabout applications. If the system is enabled to reduce drivers on the road, modern roundabouts are also more likely to succeed. 


\section{Reference List}

[1] Transportation Research Board, Roundabouts: An Informational Guide - Second Edition, The National Academies Press, Washington, DC, 2010.

[2] A. Habibzai, S. Habibzai, C. Sun, A Overview of Transportation in Kabul City, Afghanistan, (2020).

[3] Britannica, Kabul Map. https://www.britannica.com/place/Kabul.

[4] A. Pratelli, P. Sechi, R.R. Souleyrette, Upgrading traffic circles to modern

roundabouts to improve safety and efficiency - Case studies from Italy, PROMET-Traffic \& Transportation,2018.

[5] G. Jacquemart, Modern roundabout practice in the United States, National Academy Press, Washington, D.C, 1998.

[6] Washington County Minnisota, Traffic Circle vs Rotary.

https://www.co.washington.mn.us/, Access Date: Mar 13, 2021.

[7] Transportation Board Research, HCM 2010 : Highway Capacity Manual, 2010.

[8] R.M. Kimber, The Traffic Capacity of Roundabouts, 1980.

[9] M.S. DeAmico, Roundabout Capacity And Comparative Software Analysis, 2012.

[10] K. Shaaban, H. Hamad, Critical Gap Comparison between One-, Two-, and Three-Lane Roundabouts in Qatar, Sustainability, 2020.

[11] S. Rao, Y. Krishna, P. Atmakuri, P. Bhuyan, Calibration of Performance of Roundabouts Based on Gap Acceptance Parameters Using Simulation for Indian Scenario, 2016.

[12] H.M.N. Al-Madani, Dynamic vehicular delay comparison between a policecontrolled roundabout and a traffic signal, Transportation Research Part A: Policy and Practice, 2003.

[13] M.A. LeBas, A Comparative Analysis of Roundabouts and Traffic Signals through a Corridor, Louisiana State University, 2015.

[14] Fedral HighwayAdministration, Signalized Intersections: Informational Guide, 2004. https://www.fhwa.dot.gov/publications/research/safety/04091/07.cfm\#chp74, Accessed: Dec, 02, 2020.

[15] J.G. Bared, W. Prosser, C.T. Esse, State-of-the-Art Design of Roundabouts, Transportation Research Record, 1997.

[16] M. Valdez, R.L. Cheu, C. Duran, Operations of Modern Roundabout with Unbalanced Approach Volumes, Transportation Research Record, 2011.

[17] WSDOT, Design procedures and geometric criteria, 2019.

[18] R.E.M. Timothy J. Gates, Converting Old Traffic Circles To Modern

Roundabouts: Michigan State University Case Study.

[19] Transportation Research Board, Driveway and Street Intersection Spacing, 1996. 


\section{Appendix A: Survey Questions:}

This questionnaire (11 questions) information inquiry is part of Mohammad Anas Taeb's Master of Science research study "An overview of potential conversion of Kabul traffic circles/rotaries to modern roundabout".

The term "Modern Roundabout" refers to circulatory intersection designed to work with priority to circulating traffic, traveling at a slower speed $(25 \mathrm{mph}-30 \mathrm{mph})$, relatively smaller in size than older traffic circles/rotaries that exist today in Kabul City. Modern roundabouts have been used extensively across the world and they have proven to improve safety and traffic flow, reduce delays. The goal of the study is to investigate whether conversion to modern roundabouts would be a potential alternative for improving the operations of some traffic circles in Kabul.

Due to the lack of specific data commonly used in modern roundabout analysis (such as traffic flow data), I am compiling data from multiple sources to obtain as complete a picture as possible of current circumstances. This questionnaire is to collect expert opinions and will help me to understand:

a. The current status of the traffic circles/rotaries.

b. The driver's behavior at these traffic circles/rotaries.

c. Your view on modern roundabout as an improvement option for these traffic circles/rotaries.

d. The preference between modern roundabouts and other alternatives.

This questionnaire is limited to Kabul engineers who have a background in

"Transportation Engineering".

Your responses are confidential.

A summary of all results will be presented in the report, but individual results will not.

Estimated time the questionnaire can take (15 20 minutes).

I would like to thank you in advance for providing your expertise in support of this study.

1) What are the current traffic rules in "Kabul traffic circles/rotaries"?

Check all that apply:

Entering traffic should yield to circulating traffic.

Circulating traffic should yield to entering traffic.

Traffic Signals control and decide the movement.

Traffic Officer controls and decides the movement. 
No rules are applied.

2) As per your understanding, please rank the causes of congestion problems at traffic circles/rotaries in Kabul.

Rank 1-7 in order of importance (1 is the highest).

\begin{tabular}{|l|l|}
\hline Causes & Rank \\
\hline a- Lack of signs and pavement markings. & \\
\hline b- Lack of strict traffic rules. & \\
\hline $\begin{array}{l}\text { c- Unawareness or ignorance of traffic } \\
\text { rules. }\end{array}$ & \\
\hline d- Aggressive driving behaviors. & \\
\hline e- Lack of proper geometric design. & \\
\hline f- Demand beyond capacity. & \\
\hline $\begin{array}{l}\text { g- Lack of proper planning from the } \\
\text { transportation authorities. }\end{array}$ & \\
\hline
\end{tabular}

3) Aggressive driving can mean, lacking respect to the traffic rules and forcing their way in traffic circles/rotaries. How often is aggressive driving seen in traffic circles? Select one of the followings:

- All the time.

○ Most of the time.

○ About half of the time.

○ Once in a while.

○ Never.

4) Certain rules are typical when modern roundabouts, such as entering traffic yielding to circulating traffic, choosing entry lane based on destination (changing lane inside the modern roundabout is discouraged). Efficient operation of modern roundabout relies on drivers respecting and abiding by these rules. Would you expect Kabul drivers to follow the rules set for a modern roundabout?

Select one of the followings: 
○ Strongly agree

○ Agree

○ Neither Agree, nor disagree

○ Disagree

○ Strongly Disagree

Provide any comments here to question (4).

5) Based on your engineering judgment and the current traffic situation in Kabul City, would you consider the conversion from existing traffic circles/rotaries to modern roundabouts acceptable solution at any location?

Select one of the followings:

○ Yes

- No

- Maybe

Provide any comments here to question (5).

6) Which of the following aspects do you consider as the greatest hindrance for the application of modern roundabout in the Kabul environment?

Please select one based on its importance. 


\begin{tabular}{|l|l|l|l|l|l|}
\hline & $\begin{array}{l}\text { Not } \\
\text { important }\end{array}$ & $\begin{array}{l}\text { Slightly } \\
\text { important }\end{array}$ & $\begin{array}{l}\text { Moderately } \\
\text { important }\end{array}$ & important & Very \\
space. & & & & & \\
\hline important \\
\hline $\begin{array}{l}\text { b- Excessive } \\
\text { traffic flow. }\end{array}$ & & & & & \\
\hline $\begin{array}{l}\text { c- Unbalanced } \\
\text { traffic flow. }\end{array}$ & & & & & \\
\hline $\begin{array}{l}\text { d- Driver's } \\
\text { behavior. }\end{array}$ & & & & & \\
\hline $\begin{array}{l}\text { e- Large } \\
\text { vehicles. }\end{array}$ & & & & & \\
\hline $\begin{array}{l}\text { f- Construction } \\
\text { cost. }\end{array}$ & & & & & \\
\hline $\begin{array}{l}\text { g- Local } \\
\text { perception }\end{array}$ & & & & & \\
\hline
\end{tabular}


7) Which of the following perceived benefits would be the most important when considering the application of modern roundabouts in Kabul *

Please select one based on its importance

\begin{tabular}{|l|l|l|l|l|l|}
\hline & $\begin{array}{l}\text { Sot } \\
\text { importa } \\
\text { nt }\end{array}$ & $\begin{array}{l}\text { Slightly } \\
\text { important }\end{array}$ & $\begin{array}{l}\text { Moderately } \\
\text { important }\end{array}$ & important & Very \\
\hline a- Safety reasons. & & & & & \\
\hline $\begin{array}{l}\text { b- Environmental } \\
\text { friendliness. }\end{array}$ & & & & & \\
\hline $\begin{array}{l}\text { c- Aesthetics. } \\
\text { d- Elimination of } \\
\text { traffic signals and } \\
\text { maintenance. }\end{array}$ & & & & & \\
\hline $\begin{array}{l}\text { e- Reduce the } \\
\text { need for traffic } \\
\text { officers. }\end{array}$ & & & & & \\
\hline $\begin{array}{l}\text { f- Construction } \\
\text { Cost. }\end{array}$ & & & & & \\
\hline $\begin{array}{l}\text { g- Dealing with } \\
\text { more than four } \\
\text { legs. }\end{array}$ & & & & & \\
\hline $\begin{array}{l}\text { h- Dealing with } \\
\text { intersections. } \\
\text { access to business }\end{array}$ & & & & & \\
\hline $\begin{array}{l}\text { improving } \\
\text { andence. }\end{array}$ & & & & & \\
\hline
\end{tabular}


8) Recently a series of traffic circles were changed to actuated signal intersections in Kabul, such as Baraki square, Parwan Seh Square, Charahi Shaeed, Traffic Square, and others. To what extent are you satisfied with the improvement?

Select one of the followings:

○ Very satisfied

○ Somewhat satisfied

○ Neither satisfied nor dissatisfied

- Somewhat dissatisfied.

○ Very dissatisfied

○ Not aware.

Provide any comments to question (8) here

9) How has the application of actuated signals in traffic circles impacted the following operational parameters? $*$

Select one of the impacts:

\begin{tabular}{|l|l|l|l|l|l|}
\hline & $\begin{array}{l}\text { Significantly } \\
\text { Increased }\end{array}$ & Increased & Same & Decreased & $\begin{array}{l}\text { Significantly } \\
\text { decreased }\end{array}$ \\
\hline Delay & & & & & \\
\hline Queue & & & & & \\
\hline $\begin{array}{l}\text { Accident } \\
\text { Records }\end{array}$ & & & & & \\
\hline
\end{tabular}


Provide any comments to question (9) here

10) In order to find solution to problems in current Kabul traffic circles and rotaries, how would you rank the following improvements?

Rank 1-3 in the order of importance (1 is the highest).

\begin{tabular}{|l|l|l|l|}
\hline & 1 & 2 & 3 \\
\hline $\begin{array}{l}\text { a- Convert them to } \\
\text { signalized }\end{array}$ & & & \\
intersections. & & & \\
\hline $\begin{array}{l}\text { b- Convert them to } \\
\text { modern roundabouts. }\end{array}$ & & & \\
\hline $\begin{array}{l}\text { c- Either signalized } \\
\text { intersection or modern } \\
\text { roundabout based on } \\
\text { location. }\end{array}$ & & & \\
\hline
\end{tabular}

Please write any additional improvement to the Kabul traffic circle and rotaries in question (10). 
11) Traffic volumes are some of the most important parameters for the success of modern roundabouts (studies have shown a modern roundabout can work within an acceptable "Level of Service", if the entering flow is not more than 1,000 vehicles per hour per approach). Since I have had limited access to volume data, I have derived parameters from aerial maps (size, location, number of legs, etc.) to make preliminary selections for traffic circles most likely for modern roundabout conversion. These are listed below. To what extent do you agree with my preliminary assessment on their suitability for modern roundabout conversion?

Please, select one response for each.

\begin{tabular}{|l|l|l|l|l|l|}
\hline & $\begin{array}{l}\text { Strongly } \\
\text { agree }\end{array}$ & Agree & $\begin{array}{l}\text { Neither } \\
\text { Agree, nor } \\
\text { disagree }\end{array}$ & Disagree & $\begin{array}{l}\text { Strongly } \\
\text { disagree }\end{array}$ \\
\hline $\begin{array}{l}\text { Abdul Haq } \\
\text { Circle }\end{array}$ & & & & & \\
\hline $\begin{array}{l}\text { Shahid } \\
\text { Mazari } \\
\text { Chowk }\end{array}$ & & & & & \\
\hline $\begin{array}{l}\text { Medan } \\
\text { Arghandi }\end{array}$ & & & & & \\
\hline $\begin{array}{l}\text { Masood } \\
\text { Circle }\end{array}$ & & & & & \\
\hline
\end{tabular}




\section{Appendix B: Concept Roundabout Design Radiuses}

Fig. B.1 shows design radiuses $\left(\mathrm{R}_{1}, \mathrm{R}_{2}, \mathrm{R}_{3}, \mathrm{R}_{4}\right.$, and $\left.\mathrm{R}_{5}\right)$ of concept modern roundabout for each leg. Fig B.2 identifies different radiuses used for the roundabout curve design.

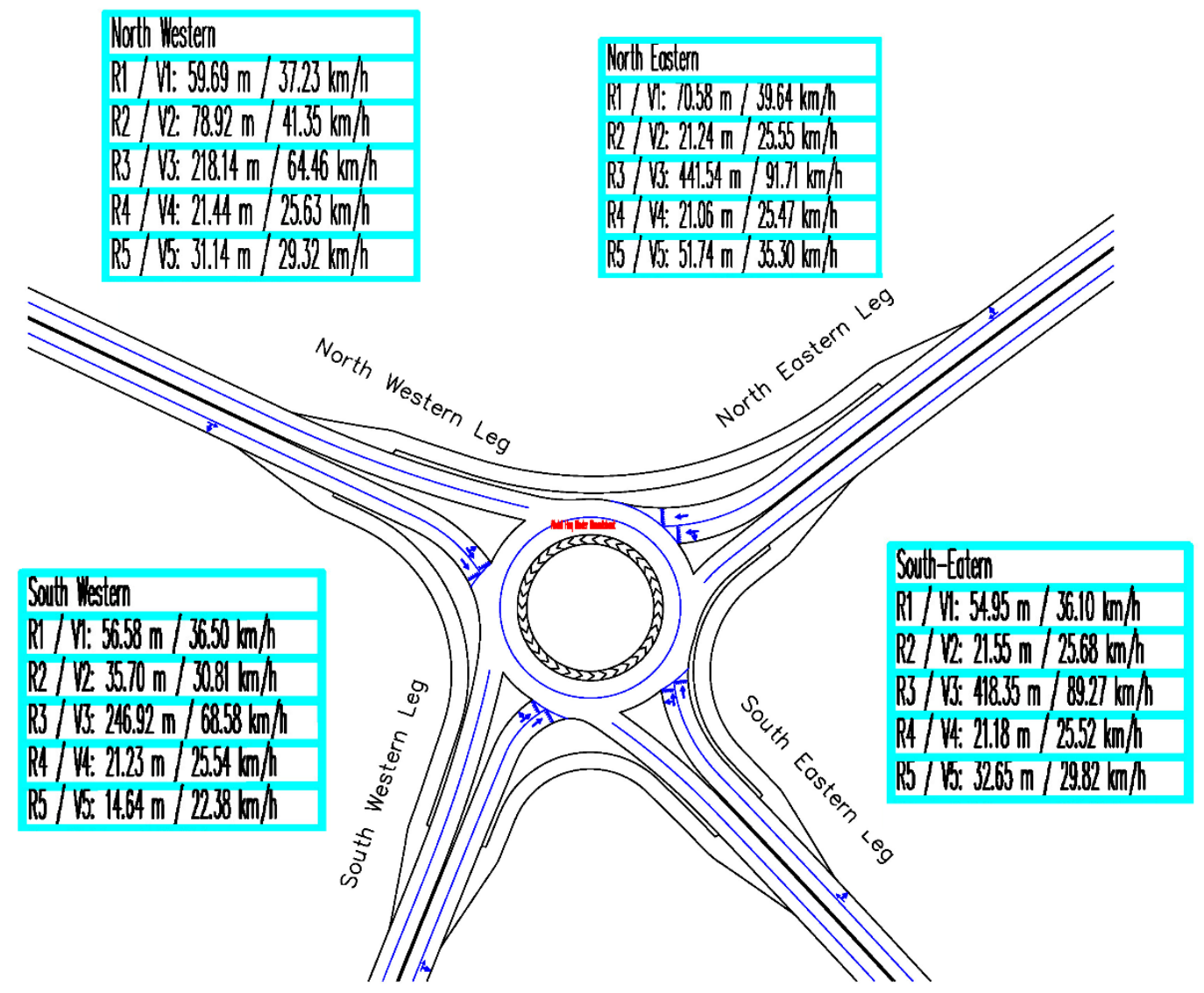

Fig. B. 1. Concept modern roundabout radiuses.

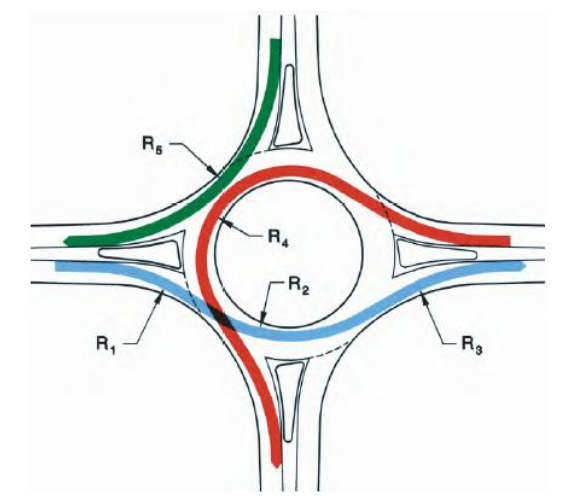

Fig. B. 2. Reference to radiuses in a Modern Roundabout. 


\section{Appendix C: VISSIM Input Data}

The following sections summarize all input data used to develop the roundabout scenario for the VISSIM analysis to assist with a potential replication of the analysis.

Figure C.1 shows modelled concept design of modern roundabout in PTV VISSIM.

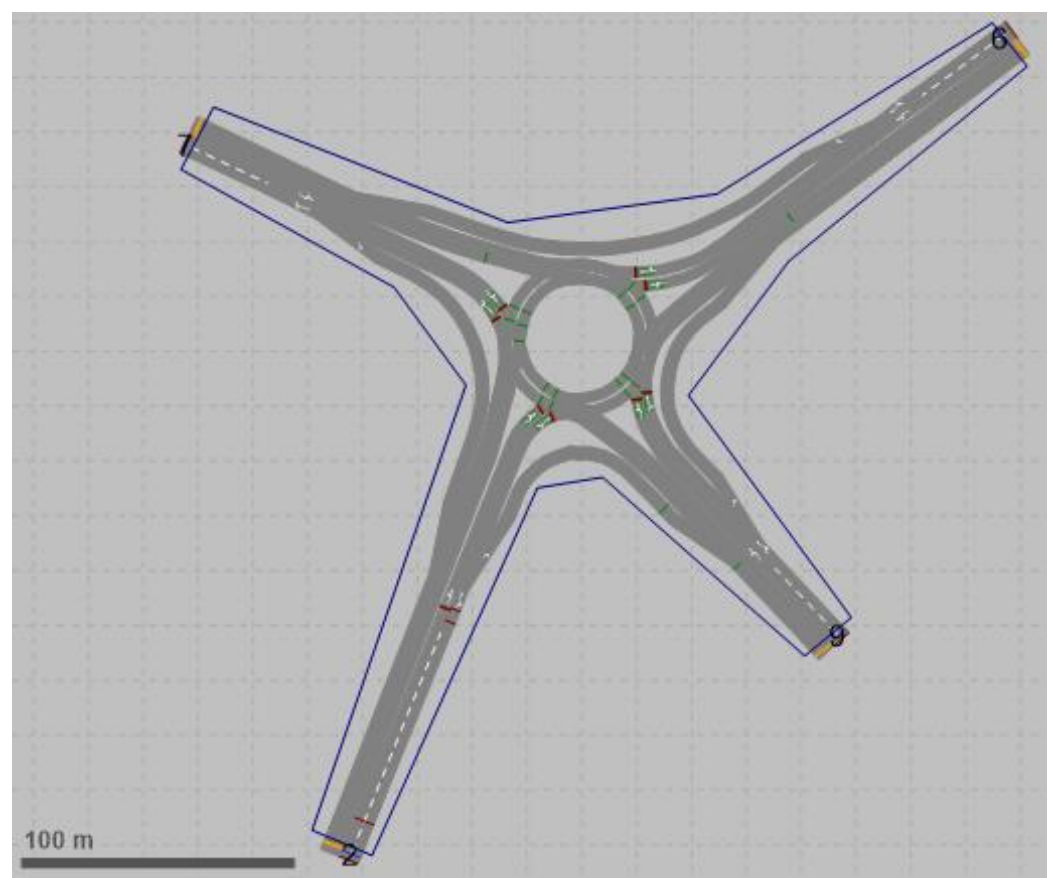

Fig. C. 1. Abdul-Haq Modern Roundabout Model in VISSIM

Fig. C. 2 shows all the straight links used in modelling the concept design with number of lanes and length of the links. Fig. C. 3 shows the curved links in the roundabout.

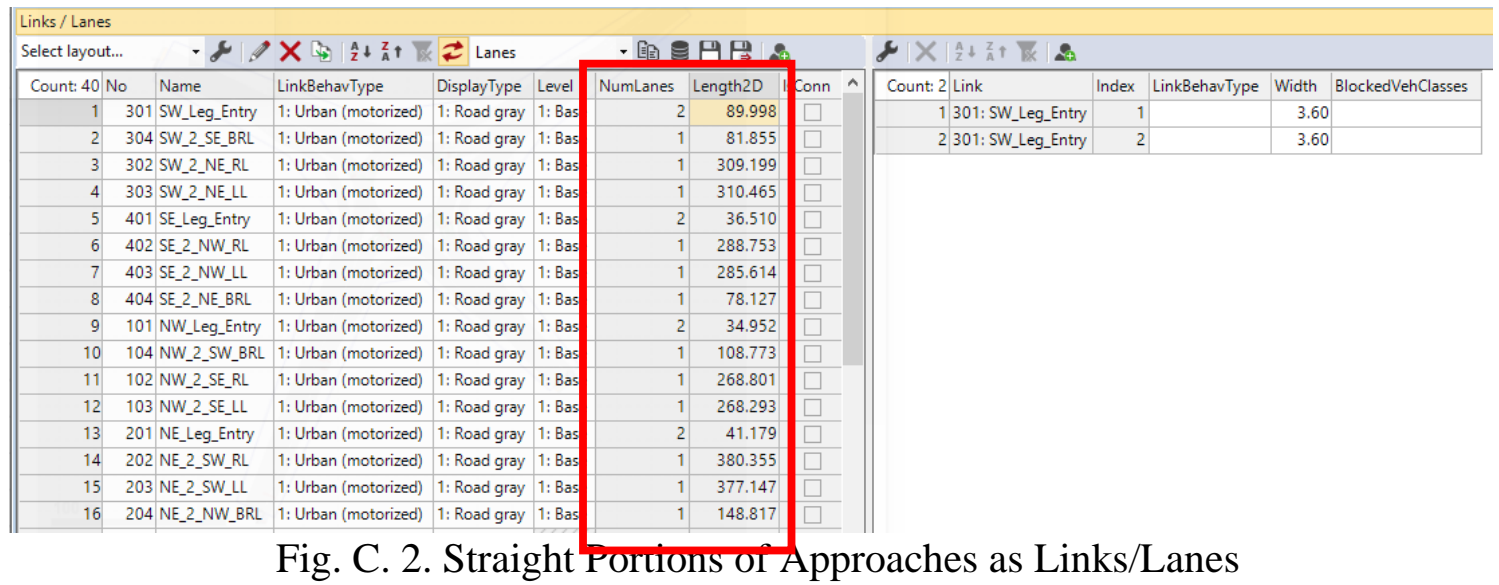




\begin{tabular}{|c|c|c|c|c|c|}
\hline 1710000 & 1: Urban (motorized) & 1: Road gray & 1 & 30.237 & v \\
\hline 1810001 & 1: Urban (motorized) & 1: Road gray & 1 & 26.948 & v \\
\hline 1910002 & 1: Urban (motorized) & 1: Road gray & 1 & 29.175 & $\nabla$ \\
\hline 2010003 & 1: Urban (motorized) & 1: Road gray & 1 & 30.414 & $\nabla$ \\
\hline 2110004 & 1: Urban (motorized) & 1: Road gray & 1 & 27.548 & v \\
\hline 2210005 & 1: Urban (motorized) & 1: Road gray & 1 & 26.705 & 四 \\
\hline 2310006 & 1: Urban (motorized) & 1: Road gray & 1 & 27.577 & v \\
\hline 2410007 & 1: Urban (motorized) & 1: Road gray & 1 & 6.255 & $\nabla$ \\
\hline 2510008 & 1: Urban (motorized) & 1: Road gray & 1 & 7.360 & v \\
\hline 2610009 & 1: Urban (motorized) & 1: Road gray & 1 & 9.685 & 囯 \\
\hline 2710010 & 1: Urban (motorized) & 1: Road gray & 1 & 7.813 & $\nabla$ \\
\hline 2810011 & 1: Urban (motorized) & 1: Road gray & 1 & 8.802 & v \\
\hline 2910012 & 1: Urban (motorized) & 1: Road gray & 1 & 10.509 & 四 \\
\hline 3010013 & 1: Urban (motorized) & 1: Road gray & 1 & 9.940 & $\nabla$ \\
\hline 3110014 & 1: Urban (motorized) & 1: Road gray & 1 & 6.209 & v \\
\hline 3210015 & 1: Urban (motorized) & 1: Road gray & 1 & 27.848 & v \\
\hline 3310016 & 1: Urban (motorized) & 1: Road gray & 1 & 4.319 & v \\
\hline 3410017 & 1: Urban (motorized) & 1: Road gray & 1 & 4.347 & v \\
\hline 3510018 & 1: Urban (motorized) & 1: Road gray & 1 & 4.330 & v \\
\hline 3610019 & 1: Urban (motorized) & 1: Road gray & 1 & 4.283 & v \\
\hline 3710020 & 1: Urban (motorized) & 1: Road gray & 1 & 5.874 & v \\
\hline 3810021 & 1: Urban (motorized) & 1: Road gray & 1 & 5.925 & 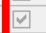 \\
\hline 3910022 & 1: Urban (motorized) & 1: Road gray & 1 & 4.039 & $\nabla$ \\
\hline 4010023 & 1: Urban (motorized) & 1: Road gray & 1 & 3.593 & $\sqrt{\square}$ \\
\hline
\end{tabular}

Fig. C. 3. Turning Portions of Approaches in Roundabout as Links/Lanes

Fig. C. 4 shows the reduced speed area tool used at the entry of each leg. The vehicles in the model are forced to reduce speed to $40 \mathrm{~km} / \mathrm{h}$ for "Cars" category and $30 \mathrm{~km} / \mathrm{h}$ for "Heavy Goods Vehicle".

\begin{tabular}{|c|c|c|c|c|c|c|c|c|c|c|c|c|}
\hline \multicolumn{13}{|c|}{ Reduced Speed Areas / Speed Elements By Vehicle Class } \\
\hline \multicolumn{3}{|c|}{ Select layout... } & \multirow{2}{*}{\multicolumn{2}{|c|}{\begin{tabular}{l|l}
$-\mathcal{C}$ & $\times$ \\
Lane & Pos
\end{tabular}}} & \multicolumn{2}{|c|}{${ }_{z}^{A}+{ }_{A}^{z}+E_{K} \rightleftarrows$} & \multicolumn{2}{|c|}{ 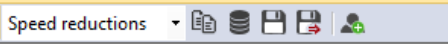 } & \multicolumn{4}{|l|}{$\mathcal{L} \mid \frac{A}{z}+\frac{z}{A}+V_{k}$} \\
\hline \multicolumn{2}{|c|}{ Count: 8 No } & \multirow{2}{*}{ Name } & & & \multirow{2}{*}{\begin{tabular}{|r|} 
Length \\
6.204 \\
\end{tabular}} & TimeFrom & \multirow{2}{*}{$\begin{array}{l}\text { DesSpeedDistr(10) } \\
40: 40 \mathrm{~km} / \mathrm{h}\end{array}$} & DesSpeedDistr(20) & \multirow{2}{*}{\begin{tabular}{c|c|} 
Count: 16 & RedSpeedArea \\
11
\end{tabular}} & VehClas: & Tesopecutistr & \multirow{2}{*}{2.00} \\
\hline 1 & 1 & & $303-1$ & Pos 78.211 & & 0 & & $30: 30 \mathrm{~km} / \mathrm{h}$ & & 10: Car & $40: 40 \mathrm{~km} / \mathrm{h}$ & \\
\hline 2 & 2 & & $302-1$ & 78.975 & 5.967 & 0 & $9999940: 40 \mathrm{~km} / \mathrm{h}$ & $30: 30 \mathrm{~km} / \mathrm{h}$ & 21 & 20: HGV & $30: 30 \mathrm{~km} / \mathrm{h}$ & 2.00 \\
\hline 3 & 3 & & $403-1$ & 69.638 & 5.967 & 0 & $9999940: 40 \mathrm{~km} / \mathrm{h}$ & $30: 30 \mathrm{~km} / \mathrm{h}$ & 32 & 10: Car & $40: 40 \mathrm{~km} / \mathrm{h}$ & 2.00 \\
\hline 4 & 4 & & $402-1$ & 69.135 & 5.967 & 0 & $9999940: 40 \mathrm{~km} / \mathrm{h}$ & $30: 30 \mathrm{~km} / \mathrm{h}$ & 42 & 20: HGV & $30: 30 \mathrm{~km} / \mathrm{h}$ & 2.00 \\
\hline 5 & 5 & & $202-1$ & 111.999 & 5.967 & 0 & $9999940: 40 \mathrm{~km} / \mathrm{h}$ & $30: 30 \mathrm{~km} / \mathrm{h}$ & 53 & 10: Car & $40: 40 \mathrm{~km} / \mathrm{h}$ & 2.00 \\
\hline 6 & 6 & & $203-1$ & 111.353 & 5.967 & 0 & $9999940: 40 \mathrm{~km} / \mathrm{h}$ & $30: 30 \mathrm{~km} / \mathrm{h}$ & 63 & 20: HGV & $30: 30 \mathrm{~km} / \mathrm{h}$ & 2.00 \\
\hline 7 & 7 & & $102-1$ & 87.542 & 5.625 & 0 & $9999940: 40 \mathrm{~km} / \mathrm{h}$ & $30: 30 \mathrm{~km} / \mathrm{h}$ & 74 & 10: Car & $40: 40 \mathrm{~km} / \mathrm{h}$ & 2.00 \\
\hline \multirow[t]{9}{*}{8} & 8 & & $103-1$ & 86.336 & 5.967 & 0 & $9999940: 40 \mathrm{~km} / \mathrm{h}$ & $30: 30 \mathrm{~km} / \mathrm{h}$ & 84 & 20: HGV & $30: 30 \mathrm{~km} / \mathrm{h}$ & 2.00 \\
\hline & & & & & & & & & 95 & 10: Car & $40: 40 \mathrm{~km} / \mathrm{h}$ & 2.00 \\
\hline & & & & & & & & & 105 & 20: HGV & $30: 30 \mathrm{~km} / \mathrm{h}$ & 2.00 \\
\hline & & & & & & & & & 116 & 10: Car & $40: 40 \mathrm{~km} / \mathrm{h}$ & 2.00 \\
\hline & & & & & & & & & 126 & 20: HGV & $30: 30 \mathrm{~km} / \mathrm{h}$ & 2.00 \\
\hline & & & & & & & & & 137 & 10: Car & $40: 40 \mathrm{~km} / \mathrm{h}$ & 2.00 \\
\hline & & & & & & & & & 147 & 20: HGV & $30: 30 \mathrm{~km} / \mathrm{h}$ & 2.00 \\
\hline & & & & & & & & & 158 & 10: Car & $40: 40 \mathrm{~km} / \mathrm{h}$ & 2.00 \\
\hline & & & & & & & & & 168 & 20: HGV & $30: 30 \mathrm{~km} / \mathrm{h}$ & 2.00 \\
\hline
\end{tabular}

Fig. C. 4. Reduced Speed Area at Roundabout Entry 
Fig. C.5 shows the priority rules input added at the entry point of roundabout. The table on the left shows all the priority rules added for each entering lane while the table on the right is used to add the minimum gap time (headway) for vehicles while accepting the entering gap.

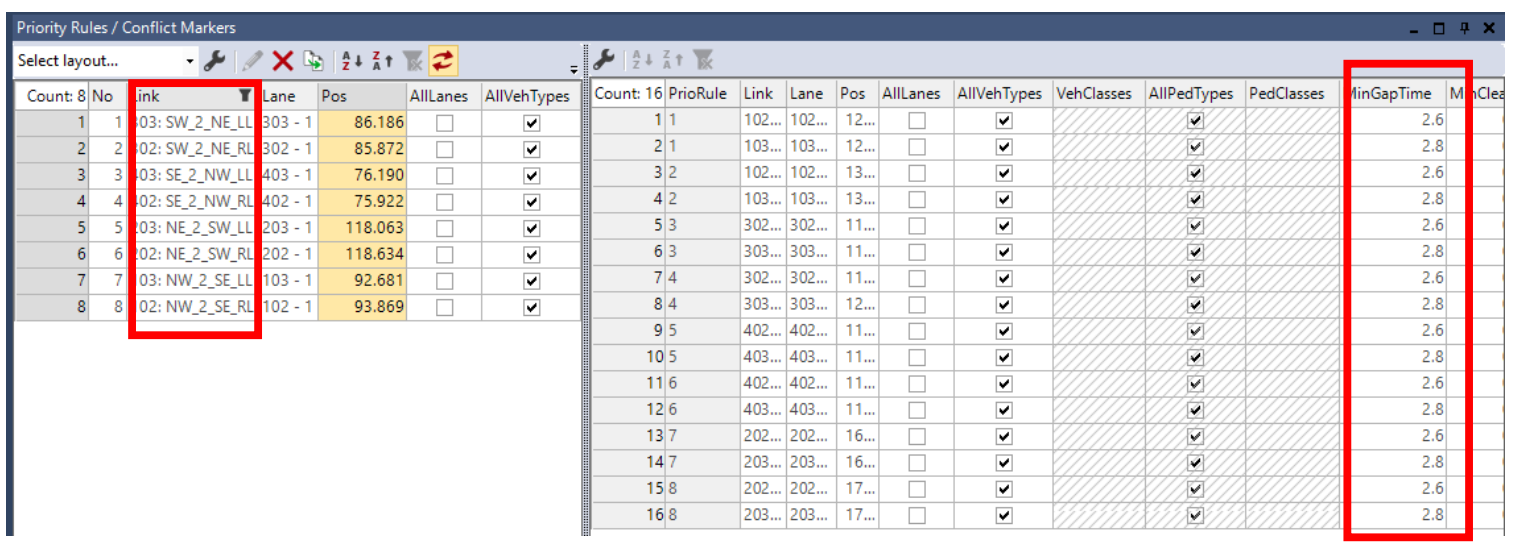

Fig. C. 5. Priority Rules at Roundabout Entry.

Fig. C.6 shows the relative turning movement input provided for each leg based on the scenarios designed.

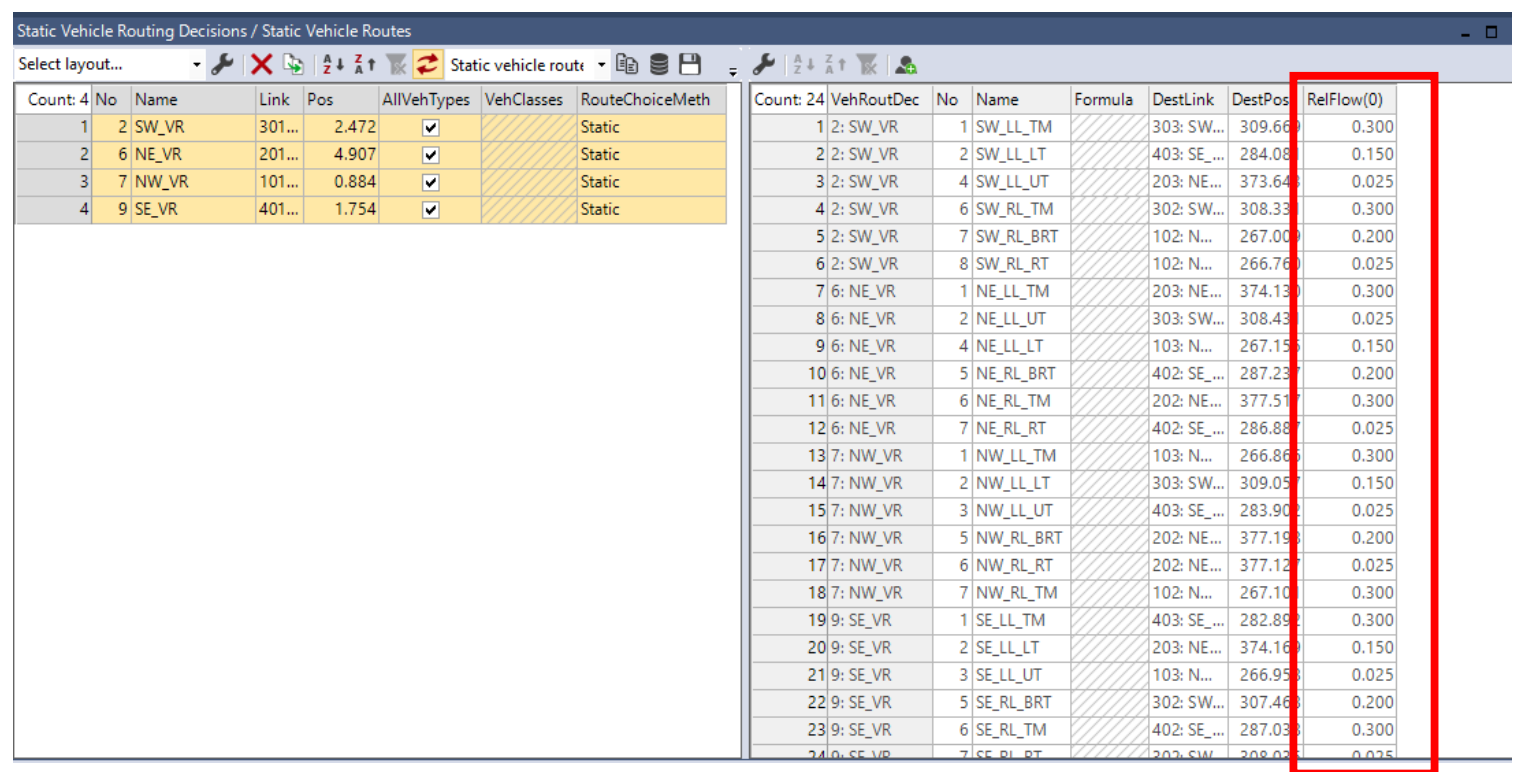

Fig. C. 6. Vehicle Routing Decisions (Turning Movements with Relative Flow) 
Fig. C.7. shows the tool used to define the "from" and "to" section for each lane which is used to measure the travel time in the section including stops and delays.

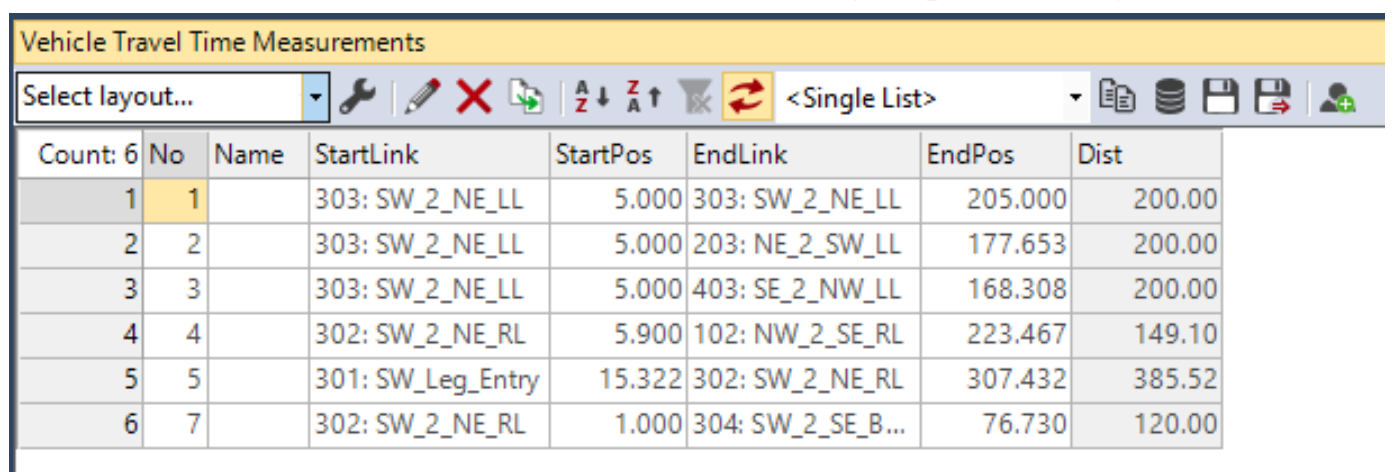

Fig. C. 7. Vehicle Travel Time Measurements.

Fig. C.8. shows points on each lane used for recording traffic volume.

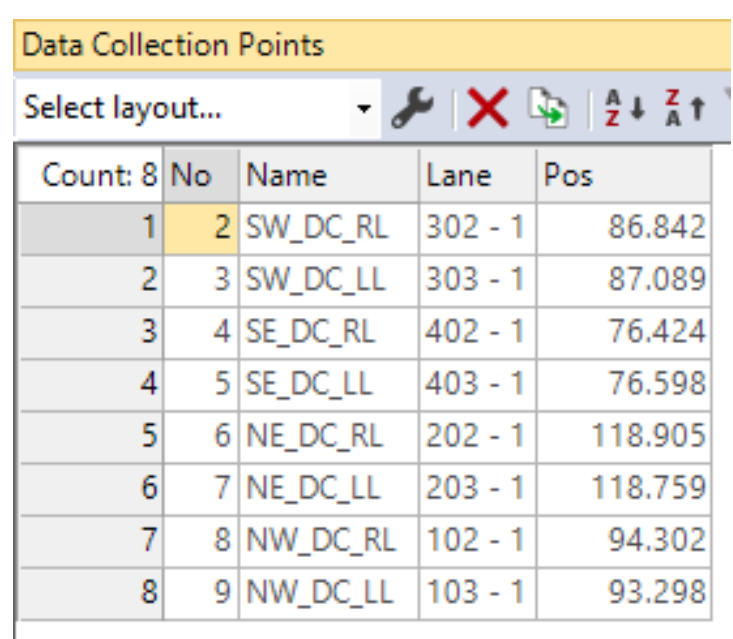

Fig. C. 8. Data Collection Points. 
Fig. C.9. used to define what specific data is collected for analysis.

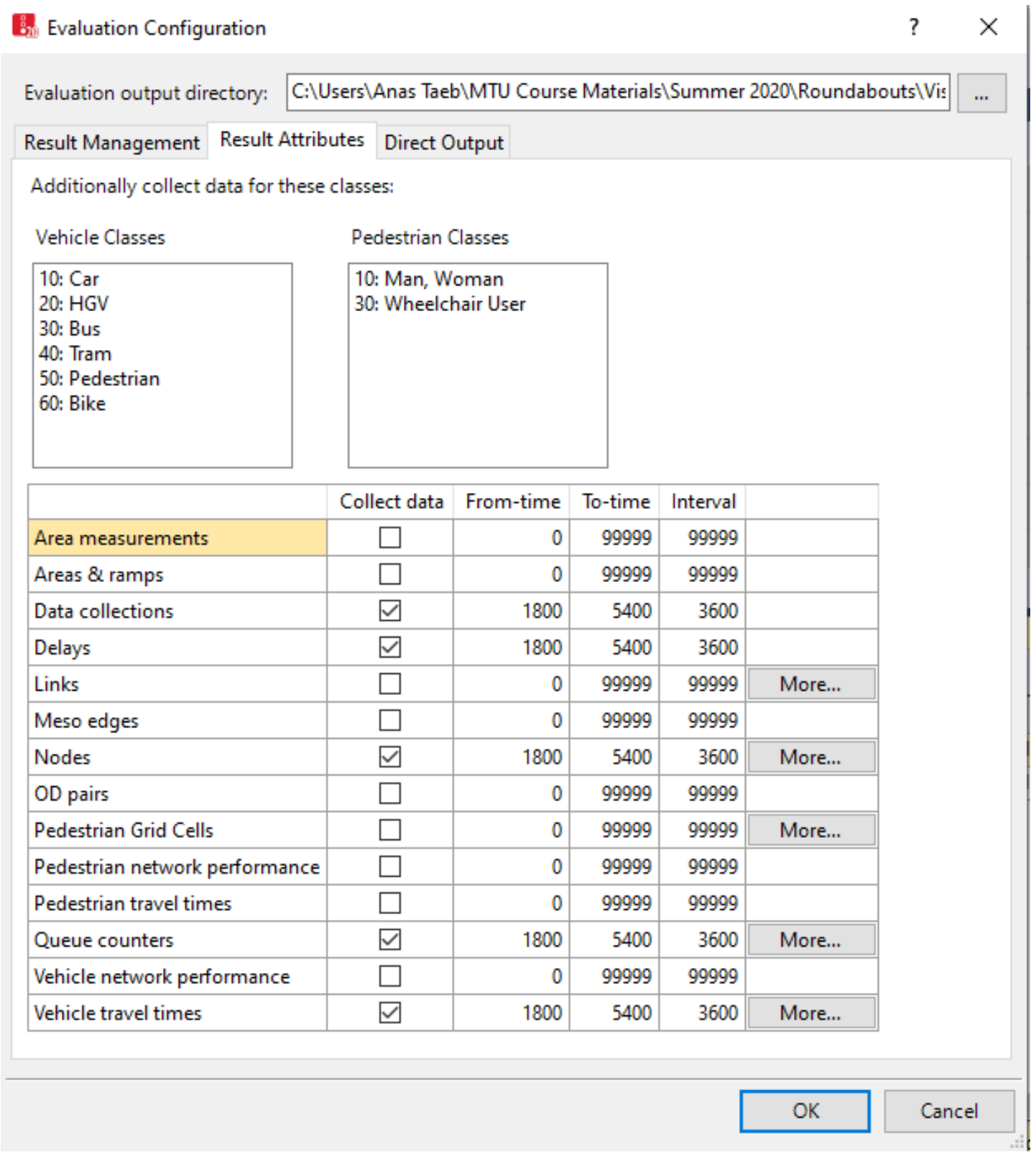

Fig. C. 9. Evaluation Configuration. 
Figure C.10 shows settings used to define various simulation inputs.

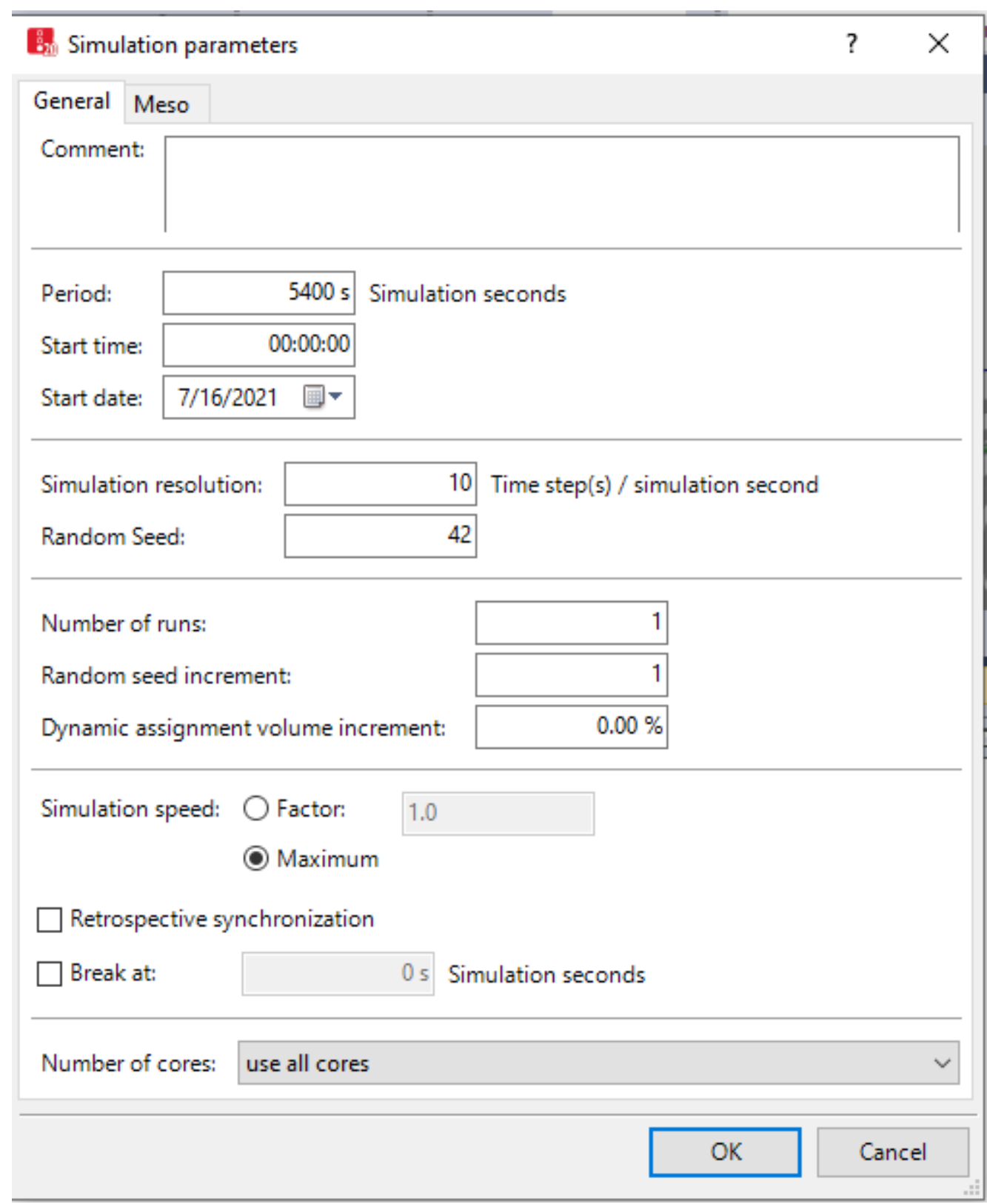

Fig. C. 10. Simulation Parameters 